NBER WORKING PAPER SERIES

\title{
INTERMEDIARY ASSET PRICING: NEW EVIDENCE FROM MANY ASSET CLASSES
}

\author{
Zhiguo He \\ Bryan Kelly \\ Asaf Manela \\ Working Paper 21920 \\ http://www.nber.org/papers/w21920 \\ NATIONAL BUREAU OF ECONOMIC RESEARCH \\ 1050 Massachusetts Avenue \\ Cambridge, MA 02138 \\ January 2016
}

We thank Markus Brunnermeier, Ian Dew-Becker, Valentin Haddad, Arvind Krishnamurthy, Alan Moreira, Tyler Muir, Lasse Pedersen, Alexi Savov, Rob Vishny, seminar participants at Stanford University, Penn State University, University of Iowa, Emory University, London School of Economics, London Business School, University of Houston, University of Washington, University of Oklahoma, Washington University, Gerzensee Summer School 2015, CITE 2015, NBER AP 2015, and Chicago Booth Asset Pricing Conference 2015 for helpful comments. The views expressed herein are those of the authors and do not necessarily reflect the views of the National Bureau of Economic Research.

NBER working papers are circulated for discussion and comment purposes. They have not been peerreviewed or been subject to the review by the NBER Board of Directors that accompanies official NBER publications.

(C) 2016 by Zhiguo He, Bryan Kelly, and Asaf Manela. All rights reserved. Short sections of text, not to exceed two paragraphs, may be quoted without explicit permission provided that full credit, including (C) notice, is given to the source. 
Intermediary Asset Pricing: New Evidence from Many Asset Classes

Zhiguo He, Bryan Kelly, and Asaf Manela

NBER Working Paper No. 21920

January 2016

JEL No. G01,G12,G21,G24

\begin{abstract}
$\underline{\text { ABSTRACT }}$
We find that shocks to the equity capital ratio of financial intermediaries-Primary Dealer counterparties of the New York Federal Reserve-possess significant explanatory power for crosssectional variation in expected returns. This is true not only for commonly studied equity and government bond market portfolios, but also for other more sophisticated asset classes such as corporate and sovereign bonds, derivatives, commodities, and currencies. Our intermediary capital risk factor is strongly pro-cyclical, implying counter-cyclical intermediary leverage. The price of risk for intermediary capital shocks is consistently positive and of similar magnitude when estimated separately for individual asset classes, suggesting that financial intermediaries are marginal investors in many markets and hence key to understanding asset prices.
\end{abstract}

\author{
Zhiguo He \\ University of Chicago \\ Booth School of Business \\ 5807 S. Woodlawn Avenue \\ Chicago, IL 60637 \\ and NBER \\ zhiguo.he@chicagobooth.edu \\ Bryan Kelly \\ University of Chicago \\ Booth School of Business \\ 5807 S. Woodlawn Avenue \\ Chicago, IL 60637 \\ and NBER \\ bryan.kelly@chicagobooth.edu
}

Asaf Manela

Washington University in St. Louis,

Olin Business School,

Campus Box 1133

One Brookings Drive

St. Louis, MO 63130

amanela@wustl.edu 


\section{Introduction}

Intermediary asset pricing theories offer a new perspective for understanding risk premia. These theories are predicated on the fact that financial intermediaries are in the advantageous position of trading almost all asset classes, anytime and everywhere. For instance, Siriwardane (2015) shows that in 2011 about 50\% of total net Credit Derivative Swaps (CDS) protection in U.S. was sold by the top five dealers. ${ }^{1}$ In the corporate bond market, more than $95 \%$ of bonds are traded in over-the-counter markets, in which dealers are necessarily involved. ${ }^{2}$ It is likely that intermediaries are marginal investors in many asset markets, and that their marginal value of wealth is a plausible pricing kernel for a broad cross-section of securities.

This view stands in contrast to standard consumption-based models in which the focal pricing kernel is that of the household (e.g., Campbell and Cochrane (1999); Bansal and Yaron (2004)). Households' comparative lack of expertise in trading assets, especially sophisticated ones like derivatives or commodities, casts doubt on the viability of household marginal utility as a unified model for jointly pricing the wide array of traded assets in the economy. ${ }^{3}$ Our hypothesis, inspired by intermediary asset pricing theory, is that the classic risk-return asset pricing trade-off is more likely to hold once we replace the first-order condition of unsophisticated households with that of sophisticated intermediaries.

The central challenges facing this hypothesis are (i) how to identify a set of financial intermediaries that are marginal investors in many markets, and (ii) how to measure their marginal utility of wealth in order to construct the pricing kernel. For the first choice, we focus on primary dealers who serve as counterparties of the Federal Reserve Bank of New York ("NY Fed" henceforth) in its implementation of monetary policy. Primary dealers are large and sophisticated financial institutions that operate in virtually the entire universe of capital markets, and include the likes of Goldman Sachs, JP Morgan, and Deutsche Bank. ${ }^{4}$

Our second choice is guided by the recent intermediary asset pricing models of He and $\mathrm{Kr}-$

\footnotetext{
${ }^{1}$ The set of all dealers are responsible for $80 \%$ of the net CDS sales in 2011. On the buy side, all dealers comprise $55 \%$ of net CDS purchases, and the top five dealers account for $25 \%$ of CDS purchases.

${ }^{2}$ These trades are reported in the Trade Reporting and Compliance Engine (TRACE) database. According to Edwards et al. (2007), fewer than $5 \%$ of bonds are listed on the NYSE, and trades occuring via NYSE's Automated Bond System (ABS) are almost all from small retail investors. In contrast, only $2 \%$ of corporate bonds trades in TRACE are from retail investors.

${ }^{3}$ Vissing-Jorgensen (2002) and Calvet et al. (2007) document limited stock market participation by households.

${ }^{4}$ Primary dealers as of 2014 are listed in Table 1, and the list of all primary dealers since 1960 is in Table A.1.
} 
ishnamurthy $(2012,2013)$ and Brunnermeier and Sannikov (2014). In these models, which follow the tradition of Bernanke and Gertler (1989) and Holmstrom and Tirole (1997), the intermediary sector's net worth (or, equivalently, its equity capital ratio) is the key determinant of its marginal value of wealth. When the intermediary experiences a negative shock to its equity capital, say due to an unexpected drop in the securitized mortgage market, its risk bearing capacity is impaired and its utility from an extra dollar of equity capital rises.

Prompted by these theories, in Section 2 we propose a model for the intermediary pricing kernel that is composed of two-factors: the excess return on aggregate wealth, and the shock to intermediaries' (equity) capital ratio. The return on aggregate wealth captures the usual TFP-style persistent technology shock that drives general economic growth. Innovations to the intermediary capital ratio capture financial shocks that affect the soundness of the financial intermediary sector, arising for example from shocks to agency/contracting frictions, changes in regulation, or large abnormal gains/losses in parts of an intermediary's portfolio. We show how this pricing kernel arises in the theoretical framework of He and Krishnamurthy (2012).

We construct the aggregate capital ratio for the intermediary sector by matching the New York Fed's primary dealer list with CRSP/Compustat and Datastream data on their publicly traded holding companies (see Section 3). We define the intermediary capital ratio, denoted $\eta_{t}$, as the aggregate value of market equity divided by aggregate market equity plus aggregate book debt of primary dealers active in quarter $t$

$$
\eta_{t}=\frac{\sum_{i} \text { Market Equity }_{i, t}}{\sum_{i}\left(\text { Market Equity }_{i, t}+{\text { Book } \left.\text { Debt }_{i, t}\right)}\right.} .
$$

Our main empirical result is that assets' exposure to intermediary capital ratio shocks (innovations in $\eta_{t}$ ) possess a strong and consistent ability to explain cross-sectional differences in average returns for assets in seven different markets, including equities, US government and corporate bonds, foreign sovereign bonds, options, credit default swaps (CDS), commodities, and foreign exchange $(\mathrm{FX})$.

We perform cross-sectional asset pricing tests both independently within each asset class, as well as jointly using all asset classes. By comparing the risk price on intermediary capital shocks estimated from different sets of test assets, we can evaluate the model assumptions that (i) inter- 
mediaries are marginal pricers in many markets and (ii) their equity capital ratio is a sensible proxy for their marginal value of wealth. In particular, if we find large disparities in intermediary capital risk prices across markets, it suggests that (i) and/or (ii) are violated.

To the contrary, we estimate significantly positive prices of risk on the intermediary capital factor in all asset classes, and find that all estimates have similar magnitudes, consistent with the view that primary dealers are marginal investors in all of these markets. Furthermore, we show in placebo tests that equity capital ratios of other sectors do not exhibit this property. When we replace primary dealers by non-primary dealers (who tend to be smaller, standalone broker-dealers with little activity in derivatives markets) or non-financial firms, we find large discrepancies in risk prices estimated from different asset classes that are largely insignificant and often have conflicting signs.

Our estimates for the price of risk on intermediary capital shocks carry two important economic implications. First, positivity of the estimated risk price means that assets that pay more in states of the world with low intermediary capital ratio (that is, assets with low betas on $\eta_{t}$ shocks) also have lower expected returns in equilibrium. This implies that low capital-risk-beta assets are viewed as valuable hedges by marginal investors or, in other words, that primary dealers have high marginal value of wealth when their capital ratio is low. This conclusion accords with ample empirical evidence that institutional investors become distressed and place higher marginal value on a dollar when their capital is impaired. ${ }^{5}$ Our risk price estimates also suggest that intermediary (primary dealer) equity capital ratios are pro-cyclical, or equivalently, that intermediary leverage is counter-cyclical.

The second economic implication arises from the similarity in magnitudes of capital ratio risk prices estimated from different asset classes. Our pricing kernel is a single aggregate capital ratio (as opposed to heterogeneous ratios among intermediaries), and is based on the assumption that one set of intermediaries is marginal in all classes. ${ }^{6}$ This assumption also predicts that the estimated

\footnotetext{
${ }^{5}$ Examples include Froot and O'Connell (1999), Gabaix et al. (2007), Mitchell et al. (2007), Mitchell and Pulvino (2009), and Siriwardane (2015), among others.

${ }^{6}$ Our tests are also potentially informative about the assumption of homogeneity among intermediaries, which is implicit in essentially all intermediary asset pricing models. If intermediaries with heterogeneous pricing kernels specialize in specific asset classes, the risk prices identified in different markets may differ. We view this as a plausible explanation for the small discrepancy of risk prices that we estimate from different markets, but our empirical approach is not designed to test this hypothesis. Our tests cannot differentiate between the same intermediaries being marginal in all asset classes, versus different intermediaries marginal in each asset class but all having highly correlated capital ratios.
} 
price of capital ratio risk should be the same in all asset classes. Our cross-asset empirical results are not far from this theoretical prediction. The risk price estimated jointly from all asset classes is $9 \%$ per quarter. When we instead estimate the risk price independently from each asset class, we find that five of the seven estimates are between $7 \%$ and $11 \%$. For options and FX portfolios, the estimated risk prices are $22 \%$ and $19 \%$, respectively. While we reject the null of $0 \%$ in all seven markets, ${ }^{7}$ we cannot reject the null of $9 \%$ in any individual market. This fact is surprising and quite striking. One might expect that trading in different asset classes involves substantially different knowledge, expertise, and terminology; and yet all of these markets produce estimated prices of intermediary capital risk that are statistically indistinguishable.

An important precursor to our paper is Adrian et al. (2014a) (henceforth AEM), which is the first paper to unite the intermediary-based paradigm with mainstream empirical asset pricing. Our identification of a positive price for exposure to primary dealer capital ratio shocks contrasts with AEM, who estimate a positive price for broker-dealer leverage shocks. These two results are contradictory because leverage, defined as assets over equity, is just the reciprocal of the equity capital ratio. That is, AEM find pro-cyclical broker-dealer leverage while our paper suggests that the leverage of primary dealers is counter-cyclical.

One key piece of evidence supports our choice of proxy for the intermediary pricing kernel compared to AEM. The results of AEM are based on test portfolios comprised of stocks and government bonds. We confirm their main findings that the AEM leverage factor is especially powerful for describing the cross section of stock and bond returns. But when we perform our test pooling all seven asset classes and replace our variable with the AEM factor, the implied price of AEM leverage risk becomes insignificant. When estimated independently by asset class, the AEM risk price changes sign for options, CDS, and FX markets, and for CDS the opposite-sign estimate is statistically significant.

In Section 4, we explore potential explanations for conflicting results in our analysis versus AEM. Our papers differ in the definition of financial intermediaries and in data sources. AEM focus on the definition of the security broker-dealer sector and associated book leverage ratios provided in the Federal Reserve's Flow of Funds. Our definition instead uses New York Fed primary dealers and

\footnotetext{
${ }^{7}$ For foreign sovereign bonds, we find a GMM t-statistic of 1.66 on the intermediary capital factor, which is significant at the $10 \%$ level. In all other markets, the estimate is significant at the $5 \%$ level or better.
} 
data on their holding companies from CRSP/Compustat and Datastream to construct the market equity capital ratio.

We find little evidence that the accounting treatment of book versus market leverage drives these differences. ${ }^{8}$ Rather, we argue that the discrepancy in our findings is most likely due to compositional differences in our data. Flow of Funds data only contains information about standalone US broker-dealers and broker-dealer subsidiaries of conglomerates. Our equity capital ratio instead relies on data at the holding company level. The distinction between these two approaches rests on the role of internal capital markets within financial holding companies. Consider, for example, our treatment of JP Morgan Securities LLC, which is one of the largest broker-dealers in the world and a wholly-owned subsidiary of JP Morgan Chase \& Co. Flow of Funds data would only reflect the financial health of the subsidiary. If the subsidiary suffers a large trading loss relative to the size of the subsidiary, it will be reflected as broker-dealer financial distress in the Flow of Funds. However, if other businesses of the JP Morgan holding company are thriving, financial distress in the broker-dealer subsidiary may be largely mitigated thanks to its access to internal capital markets. On the other hand, a sufficiently bad shock in one of the holding company's non-dealer business (for example in its large mortgage lending activities) can potentially drive the holding company into distress. If losses are severe enough to impair internal capital flow, it will reduce risk bearing capacity in the broker-dealer arm even though the shock originated elsewhere and the dealer's balance-sheet does not reflect ill health.

In short, if internal capital markets are important sources of funds for broker-dealer subsidiaries, then financial soundness of the holding company may be a superior proxy for the intermediary sector pricing kernel. While it is generally difficult to measure capital flows within financial conglomerates, we provide anecdotal evidence from the bankruptcies of Drexel Burnham Lambert in 1990 and Lehman Brothers in 2008. In these two cases, postmortem analysis by bank regulators revealed large capital transfers between broker-dealer holding companies, in support of the idea that holding company leverage is the economically important one.

Section 5 provides additional results and a battery of robustness tests. In single factor models without the market factor, our intermediary capital ratio continues to demonstrate large explana-

\footnotetext{
${ }^{8}$ We discuss this possibility in Section 4. Because book assets of broker-dealers are marked-to-market, the wedge between their book and market values is quite small. We reinforce this view empirically by showing that book leverage and market leverage in our primary dealer sample have a strong positive correlation.
} 
tory power for differences in average returns within sophisticated asset classes. We show that our results are qualitatively similar in the pre-crisis sample period 1970Q1-2006Q4, in the more recent 1990Q1-2012Q4 sample period, and when we conduct our tests at the monthly rather than quarterly frequency. Lastly, we report time series evidence that the intermediary capital ratio predicts future returns in five of the seven asset classes we study.

\section{Related Literature}

Until recently, the role of financial institutions in determining equilibrium asset prices has been under-appreciated by the finance literature (early contributions include Shleifer and Vishny, 1992, 1997; Allen, 2001). Our paper belongs to a burgeoning literature on intermediary asset pricing, which highlights the pricing kernel of financial intermediaries, rather than that of households, in explaining the pricing behavior of sophisticated financial assets (He and Krishnamurthy, 2012, 2013; Brunnermeier and Sannikov, 2014)). The list of theory contributions includes Allen and Gale (1994), Basak and Cuoco (1998), Gromb and Vayanos (2002), Xiong (2001), Kyle and Xiong (2001), Vayanos (2004), Pavlova and Rigobon (2007), Brunnermeier and Pedersen (2009), Duffie (2010), Adrian and Shin (2010), Garleanu and Pederson (2011), Adrian and Boyarchenko (2012), Basak and Pavlova (2013), Gabaix and Maggiori (2015), among others. Kondor and Vayanos (2015) study equilibrium asset pricing with multiple assets when the arbitrage capital is scarce, which is more in line with our cross-sectional asset pricing tests.

AEM is the first paper to provide systematic empirical support for intermediary asset pricing theory in equity and bond markets, using classic cross-sectional pricing tests. Adrian et al. (2014b) extends the AEM evidence by demonstrating that broker-dealer leverage has significant time-series forecasting power for returns on stocks and bonds. Haddad and Sraer (2015) argue that banks are central in understanding interest rate risk and document that banks' exposure to fluctuations in interest rates forecasts excess Treasury bond returns.

Equity and bond markets see greater direct participation by households. Participation of households in less sophisticated markets in no way precludes financial intermediaries from also being marginal, so that the intermediary kernel may also price assets in these markets as well. ${ }^{9}$ In more

\footnotetext{
${ }^{9}$ Conceptually, if households are marginal investors in equity and bond markets and households' pricing kernel is accurately measured, it should also succeed in pricing the cross section of equities and bonds, regardless of the presence of intermediaries as additional marginal traders in the market. The daunting task facing the household view
} 
specialized asset classes, on the other hand, trading is dominated by intermediaries. Past work has shown direct evidence linking the behavior of intermediary capital to asset prices. Early work by Froot and O'Connell (1999) studies the effects of slow-moving intermediary capital in the catastrophe insurance market. Gabaix et al. (2007) study the mortgage-backed securities market, and present evidence that the marginal investor pricing these assets is a specialized intermediary rather than a CAPM-type representative household. Bates (2003); Garleanu et al. (2009) present similar evidence for index options. Mitchell et al. (2007) provide a range of pricing distortions in certain asset markets - including convertible bond arbitrage and merger arbitrage - when arbitrageurs that specialize in these assets suffer significant losses in capital. Mitchell and Pulvino (2009) offer further evidence on the divergent behavior of the bond-CDS basis during the 2008 financial crisis. Siriwardane (2015) demonstrates the effect of intermediary capital losses on CDS spreads. In exchange rate literature, Adrian et al. (2009), Adrian et al. (2011), and Hong and Yogo (2012) show that financier's positions are useful in predicting expected currency returns, a fact that is consistent with the broad view proposed by our paper. Perhaps the most important contribution of our paper is to formally and simultaneously test the intermediary model in a wide range of asset classes where we expect intermediaries to matter most and households to matter least.

\section{Intermediary capital risk in a two-factor asset pricing model}

We propose a two-factor model in which the intermediary's equity capital ratio enters the pricing kernel alongside aggregate wealth. Section 2.1 provides an argument for why this specification captures the intermediary's marginal value of wealth and thus why it prices all asset classes in which the intermediary participates as a marginal investor. There are various economic mechanisms for why and how the intermediary's capital ratio affects its marginal value of wealth, and Section 2.2 lays out one such theory based on He and Krishnamurthy (2012).

\subsection{Intermediary capital ratio and pricing kernel}

Traditional consumption-based asset pricing models (Campbell and Cochrane, 1999; Bansal and Yaron, 2004) are cast in a complete market where the marginal investor is a consumer household.

is constructing a pricing kernel from relatively poor quality household data. 
These models implicitly view intermediation as a pure pass through, and asset markets are studied as direct interactions among households. By contrast, intermediary asset pricing models emphasize the unique role that sophisticated intermediaries play in many risky financial assets. These models short circuit the aggregation arguments that lead to representative household models by limiting the participation of households in certain markets and introducing frictions in the ability of "specialist/expert" intermediaries to raise financing from the household sector. As a result, households are not marginal in at least some markets, and household marginal utility of consumption fails to price assets in those markets. For these same markets, intermediaries take over the role of marginal trader, raising the possibility that their marginal value of wealth is better suited as an empirical pricing kernel.

We propose the following intermediary pricing kernel, in which the equity capital ratio of the intermediary sector determines its marginal value of wealth. We define the intermediary's (equity) capital ratio as the equity fraction of total assets in the aggregate balance sheet of the intermediary sector:

$$
\eta_{t} \equiv \frac{\text { Equity }_{t}}{\text { Asset }_{t}}
$$

Denote aggregate wealth in the economy by $W_{t}$. We define the intermediary's marginal value of wealth at time $t$ as

$$
\Lambda_{t} \propto e^{-\rho t} \cdot\left(\eta_{t} W_{t}\right)^{-\gamma}
$$

where $\rho>0$ and $\gamma>0$ are positive constants, which we later show correspond to the intermediary's time-discount rate and relative risk-aversion, respectively.

The empirical study in this paper relies on the qualitative implications of (2), but not on the specific functional form. The exact functional form in (2), which arises from existing theories under appropriate assumptions, is intuitive. First, the aggregate wealth term $W_{t}$ captures the asset pricing role of persistent productivity shocks that affect the overall fundamentals of the economy. It is the standard economic growth term consumption-based theories and has the same interpretation here - all else equal, $W_{t}$ is negatively related to the economic agent's marginal value of wealth.

The second and more novel aspect of intermediary asset pricing models is the role of $\eta_{t}$. Specification (2) implies that the intermediary's marginal value of wealth rises when the intermediary's capital ratio $\eta_{t}$ falls. It captures the intuition that an intermediary's risk bearing capacity is in- 
hibited when its equity capital is low. Risk aversion drives up the intermediary's marginal value of wealth in low equity states. This theoretical mechanism operates in the micro foundation of Section 2.2 as long as a significant portion of the compensation received by managers/traders is stock-based. Importantly, there are other potential mechanisms that lead intermediaries to value a dollar more when their (equity) capital is impaired. For institutions that face regulatory capital requirements, risk-tolerance shrinks as losses eat into their capital base, leading them to potentially forgo otherwise profitable investment opportunities. An extra dollar of capital is especially valuable to the institution in these states. ${ }^{10}$

To summarize, the marginal value of wealth specification in (2) has a two-factor structure that embeds the broad economic growth shocks of traditional models via $W_{t}$, along with shocks that govern soundness of the financial intermediary sector via $\eta_{t}$. This second factor captures agency/contracting frictions in the intermediation business, regulator considerations, or shocks to non-dealer portions of the intermediary's portfolio (e.g., the mortgage market collapse in 2007-09) that affect the intermediary's broader risk bearing capacity. ${ }^{11}$ This two-factor view is consistent with Muir (2014) who shows that the asset pricing behavior is markedly different during "fundamental" disaster episodes (such as wars) and "financial disasters" (such as banking panics).

Given (2), we use the asset pricing Euler equation to derive the two-factor asset pricing model that is the basis of our cross-sectional tests. For any asset $i$ with instantaneous return $d R_{t}^{i}$, the first-order condition of the intermediary who acts as the marginal investor implies

$$
\mathbb{E}_{t}\left(d R_{t}^{i}\right)-r_{t}^{f} d t=-\mathbb{E}_{t}\left(d R_{t}^{i} \cdot \frac{d \Lambda_{t}}{\Lambda_{t}}\right)
$$

where throughout $\mathbb{E}_{t}(\cdot)$ stands for conditional expectations and $r_{t}^{f}$ is the risk-free rate. This further

\footnotetext{
${ }^{10}$ Many of the largest primary dealers in our sample are constrained by Basel capital requirements (Kisin and Manela, 2013), and potentially also by the SEC's net capital rule. Capital constraints are particularly costly during liquidity crises (Kashyap et al., 2008; Hanson et al., 2011; Koijen and Yogo, forthcoming; Kisin and Manela, 2013).

${ }^{11}$ For example, He and Krishnamurthy (2012) (page 757, Section 4.4.5) consider a setting in which the second shock affects the severity of agency problems when intermediaries contract with households. In equilibrium, a negative shock to agency frictions lowers the households' equity capital contribution, which drives the evolution of leverage and hence the pricing kernel in (2).
} 
implies

$$
\begin{aligned}
\mathbb{E}_{t}\left(d R_{t}^{i}\right)-r_{t}^{f} d t & =\gamma \mathbb{E}_{t}\left[d R_{t}^{i} \cdot \frac{d W_{t}}{W_{t}}\right]+\gamma \mathbb{E}_{t}\left[d R_{t}^{i} \cdot \frac{d \eta_{t}}{\eta_{t}}\right] \\
& =\beta_{W, t}^{i} d t \cdot \lambda_{W}+\beta_{\eta, t}^{i} d t \cdot \lambda_{\eta} .
\end{aligned}
$$

The term $\lambda_{W} \equiv \gamma \sigma_{W, t}^{2}>0$ is the price of risk on aggregate wealth shocks (or "market risk") and $\lambda_{\eta} \equiv \gamma \sigma_{\eta, t}^{2}>0$ is the price of intermediary capital risk, where we use the standard notation for variance and beta:

$$
\begin{aligned}
\sigma_{W, t}^{2} d t & =\operatorname{Var}_{t}\left[\frac{d W_{t}}{W_{t}}\right], \beta_{W, t}^{i}=\frac{\mathbb{E}_{t}\left[d R_{t}^{i} \cdot\left(d W_{t} / W_{t}\right)\right]}{\operatorname{Var}_{t}\left[d W_{t} / W_{t}\right]} \\
\sigma_{\eta, t}^{2} d t & =\operatorname{Var}_{t}\left[\frac{d \eta_{t}}{\eta_{t}}\right], \beta_{\eta, t}^{i}=\frac{\mathbb{E}_{t}\left[d R_{t}^{i} \cdot\left(d \eta_{t} / \eta_{t}\right)\right]}{\operatorname{Var}_{t}\left[d \eta_{t} / \eta_{t}\right]}
\end{aligned}
$$

Equation (3) is the two-factor pricing model that guides our cross-sectional pricing tests, and in particular predicts that the price of both market risk and intermediary capital risk are positive. The intuition behind the prediction is that a positive shock to either $W_{t}$ or $\eta_{t}$ drives down the marginal value of wealth $\Lambda_{t}$; hence, the higher an asset's covariance with either factor, the higher the expected equilibrium return that the asset must promise to compensate its investor, all else equal.

\subsection{An intermediary asset pricing model}

We now provide a theoretical framework where the exact intermediary pricing kernel in (2) arises in general equilibrium. Consider a two-agent economy populated by households and financial intermediaries. Suppose that the intermediary (or, the specialist/expert who runs the intermediary in the language of He and Krishnamurthy (2013); Brunnermeier and Sannikov (2014)) has power utility over its consumption stream

$$
\mathbb{E}\left[\int_{0}^{\infty} e^{-\rho t} u\left(c_{t}\right) d t\right]=\mathbb{E}\left[\int_{0}^{\infty} e^{-\rho t} \frac{c_{t}^{1-\gamma}}{1-\gamma} d t\right]
$$

with $\rho$ being the discount rate and $\gamma$ being the constant relative risk aversion.

Since intermediaries (rather than households) are always marginal investors in risky assets, their 
marginal utility of wealth, which equals the marginal utility of consumption, prices all assets in equilibrium. ${ }^{12}$ To a first-order approximation, the intermediary's consumption $c_{t}$ is proportional to its wealth $W_{t}^{I}$. That is, $c_{t}=\beta W_{t}^{I}$, where $\beta$ is a positive constant. For log utility this simple consumption rule is exact with $\beta=\rho$. Hence the intermediary's discounted marginal utility of consumption is

$$
\Lambda_{t}=e^{-\rho t} u^{\prime}\left(\beta W_{t}^{I}\right)=e^{-\rho t}\left(\beta W_{t}^{I}\right)^{-\gamma}
$$

It is the intermediary's wealth $W_{t}^{I}$ (or the bankers' net worth, in connection to the macro finance literature) that enters directly into the pricing kernel.

Let aggregate wealth, $W_{t}$, include the wealth of both the household and intermediary sectors, and define $\eta_{t}$ as the intermediary sector's share of aggregate wealth in the economy:

$$
W_{t}^{I}=\eta_{t} W_{t}
$$

That is, the intermediary's wealth share is directly linked to the its level of capital, and captures the soundness of the intermediary sector in this economy.

This brings us back to our definition of the intermediary capital ratio in Section $2.1, \eta_{t}=$ $\frac{\text { Equity }_{t}}{\text { Assets }_{t}}$. Under stylized assumptions, the intermediary's capital ratio exactly coincides with its wealth share. For instance, He and Krishnamurthy $(2012,2013)$ assume that risky assets are held directly only by the intermediary sector. ${ }^{13}$ Then, in general equilibrium, equity measures the intermediary's net worth and assets on the intermediary balance sheet measure aggregate wealth, thus the capital ratio indeed measures the wealth share of the intermediary sector. ${ }^{14}$ Therefore, plugging (5) into (4) arrives at the pricing kernel in Equation (2).

We emphasize, though, that our reduced form cross-sectional asset pricing tests only rely on qualitative properties of the pricing kernel, and hence this stringent assumption about asset holdings can be easily relaxed. For the pricing kernel specification (2) to price assets, we require that the

\footnotetext{
${ }^{12}$ We need not to specify the utility function of households as the intermediary's optimality condition yields the pricing relations that we take to data.

${ }^{13}$ Although the assumption in He and Krishnamurthy (2012, 2013) appears rather stark, it is consistent with He et al. (2010) who document that mortgage-related toxic assets are always on the balance sheet of financial intermediaries (mainly commercial banks) at the height of the crisis, 2008Q4 to 2009 Q1.

${ }^{14}$ In He and Krishnamurthy (2012, 2013), households can also access risky assets indirectly through the intermediary sector with certain agency frictions, which could bind (the "constrained" region) or not (the "unconstrained" region). This mapping between $\eta_{t}$ and the capital ratio is exact in the constrained region.
} 
intermediary's capital ratio is positively correlated with its wealth share $\eta_{t}$. This key property holds in Brunnermeier and Sannikov (2014), which allows households to manage risky assets at some exogenous holding cost. ${ }^{15}$

\section{Cross-Sectional Analysis}

We present our main empirical results in this section. After explaining the data construction, we perform formal cross-sectional asset pricing tests for a variety of asset classes.

\subsection{Data}

\subsubsection{Primary dealers' market equity capital ratio}

Our definition of the intermediary sector is the set of primary dealers. These form a select group of financial intermediaries that serve as trading counterparties to the Federal Reserve Bank of New York in its implementation of monetary policy. We obtain the historical list of primary dealers from the NY Fed's website, and hand-match dealers to data on their publicly-traded holding companies from either CRSP/Compustat (for US dealers) or Datastream (for foreign dealers). We list current primary dealer designees in Table 1 and provide the full historical list in Table A.1. ${ }^{16}$

The primary dealer sector is a natural candidate for the representative financial intermediary. These institutions are large and active intermediaries who are likely to be marginal in almost all financial markets. Table 2 shows that this relatively small group of firms represents essentially all of the broker-dealer sector by size, a substantial share of the broader banking sector, and is even large relative to the entire publicly traded sector. ${ }^{17}$ Below, we use "primary dealer" and "intermediary" interchangeably whenever there is no ambiguity in the context.

\footnotetext{
${ }^{15}$ In Brunnermeier and Sannikov (2014), a series of negative shocks impairs the capital of intermediaries leading them to reduce their borrowing and shed assets and by selling them to households. Nevertheless, debt reduction lags behind the pace of equity impairment, and the endogenous capital ratio of the intermediary sector falls following negative shocks. As a result, the intermediaries' wealth share $\eta_{t}$ moves together with their capital ratio.

${ }^{16}$ Cheng et al. (2015) also focus on primary dealers in their study of executive compensation in financial firms.

${ }^{17}$ For comparison, we focus on US-only firms in Table 2, and define the total broker-dealer sector as the set of US primary dealers plus any firms with a broker-dealer SIC code (6211 or 6221). Note that had we instead relied on the SIC code definition of broker-dealers, we would miss important dealers that are subsidiaries of holding companies that not classified as broker-dealers, for instance JP Morgan.
} 
Each quarter $t$, we construct the (aggregate) primary dealer capital ratio as

$$
\eta_{t}=\frac{\sum_{i} \text { Market Equity }_{i, t}}{\sum_{i}\left(\text { Market Equity }_{i, t}+{\text { Book } \left.\text { Debt }_{i, t}\right)}^{\text {Market }}\right.}
$$

where firm $i$ is a NY Fed primary dealer designee during quarter $t$. We use book value of debt to proxy for the unobserved market value of debt, as customary in corporate finance. Our data inputs for the capital ratio come from the quarterly CRSP/Compustat file for US firms. Book value of debt is equal to total assets less common equity, using the most recent data available for each firm at the end of a calendar quarter. The market value of equity is share price times shares outstanding on the last trading day of the quarter. We follow the same calculation with Datastream data for public holding companies of foreign primary dealers.

We plot the intermediary capital ratio, which runs from 1970 to 2012, in Figure 1 (with shaded areas indicating NBER recessions). Intermediary capital falls during recessions and reaches its nadir in the 2008 financial crisis. The capital ratio also exhibits a sudden drop and rebound around the 1998 LTCM collapse, representing shocks that only affect certain asset markets (e.g., options) but not the entire stock market.

We construct the capital ratio growth rate, denotes $\eta_{t}^{\Delta}$, as follows. We estimate a shock to the capital ratio in levels, $u_{t}$, as an innovation in the auto-regression $\eta_{t}=\rho_{0}+\rho \eta_{t-1}+u_{t},{ }^{18}$ and convert this to a growth rate by dividing by the lagged capital ratio

$$
\eta_{t}^{\Delta}=u_{t} / \eta_{t-1}
$$

This serves as the risk factor that is the key input into our cross section tests.

Figure 1 plots $\eta_{t}$ and $\eta_{t}^{\Delta}$, and Table 3 shows their correlations with an array of aggregate macro variables. Specifically, we compare to the S\&P 500 earnings-to-price ratio from Shiller, the unemployment rate, GDP growth, the Chicago Fed National Financial Conditions Index (for which a high level corresponds to weak financial conditions), and realized volatility of the CRSP value-weighted stock index. Correlations with $\eta_{t}^{\Delta}$ are based on log changes in each macro variable. All correlations reflect pro-cyclicality of the capital ratio (or counter-cyclicality of leverage) in that

\footnotetext{
${ }^{18}$ In this time-series regression with quarterly frequency, the estimated $\operatorname{AR}(1)$ coeffcient is 0.94 .
} 
low intermediary capital growth coincides with adverse economic shocks, measured as increases in the earnings-to-price ratio, increases in high unemployment rate, decreases in GDP growth, a deterioration in financial conditions (based on the Chicago Fed index), or increases in realized volatility.

\subsubsection{Asset portfolios}

A key feature distinguishing our paper from existing literature is our use of test portfolios that span a wide range of asset classes. To avoid potential arbitrariness in our choice of test portfolios, especially for asset classes that are less standard than the Fama-French equity data, we rely on readily available asset portfolios provided by authors of pre-existing studies wherever possible.

For equities, we use the Fama and French (1993) 25 size and value sorted portfolios (from Ken French's website). For US bond portfolios, we include government and corporate bond portfolios in the same class. ${ }^{19}$ We use ten maturity-sorted government bonds portfolios from CRSP's "Fama Bond Portfolios" file with maturities in six month intervals up to five years. For corporate bonds, we use ten portfolios sorted on yield spreads from Nozawa (2014). These portfolios are based on a comprehensive bond data set combining TRACE, the Lehman bond database, and others, starting in 1973.

For sovereign bonds we use six portfolios from Borri and Verdelhan (2012). These portfolios are based on a two-way sort on a bond's covariance with the US equity market return and the bond's Standard \& Poor's credit rating. Monthly portfolio returns begin in January 1995 and end in April 2011.

For options, we use 54 portfolios of S\&P 500 index options sorted on moneyness and maturity from Constantinides et al. (2013), split by contract type (27 call and 27 put portfolios), and starting in 1986. Portfolio returns are leverage-adjusted, meaning that each option portfolio is combined with the risk free rate to achieve a targeted market beta of one. According to Constantinides et al. (2013), "The major advantage of this construction is to lower the variance and skewness of the monthly portfolio returns and render the returns close to normal (about as close to normal as the index return), thereby making applicable the standard linear factor pricing methodology." To keep

\footnotetext{
${ }^{19}$ Our choice to combine US government and corporate bonds into a single asset class is driven by our desire to estimate prices of intermediary capital risk separately for each asset class. Treating US government bonds as its own asset class is not statistically sensible due to the very high correlation in the returns on these portfolios.
} 
the number of portfolios used in our tests similar across asset classes, we reduce the 54 portfolios to 18 portfolios by constructing equal-weighted averages of portfolios that have the same moneyness but different maturity (though our results are essentially unchanged if we use all 54 portfolios separately).

For foreign exchange, we combine two datasets of currency portfolios to arrive at a total of twelve portfolios. First is the set of six currency portfolios sorted on the interest rate differential from Lettau et al. (2014). Second is the set of six currency portfolios sorted on momentum from Menkhoff et al. (2012). We use the sample period intersection of these datasets, covering March 1976 to January $2010 .^{20}$

For commodities, we include 24 commodity futures returns studied in Koijen et al. (2013). The commodities series include six energy products, eight agricultural crops, three livestock, and seven metals. We use the sample during which all futures returns are non-missing (beginning in 2002).

CDS is the only asset class for which we do not have portfolio returns from preexisting studies. To fill this gap, we construct 20 portfolios sorted by spreads using individual name 5-year CDS. The data are from Markit and begin in 2001. We focus on 5-year CDS contracts for the well known reason that these are the most liquid contracts. Our definition of CDS returns follows Palhares (2013). In particular, let $C D S_{t}$ be the credit spread at day $t$. The one-day return on a short CDS strategy (in the case of no default) is

$$
C D S_{t}^{r e t}=\frac{C D S_{t-1}}{250}+\triangle C D S_{t} \times R D_{t-1}
$$

The first term on the right-hand-side is the carry component of the return due to the seller's receipt of insurance premium payments. The second term is the capital gain return, equal to the change in spread times the lagged risky duration of the contract (denoted $R D_{t-1}$ ). The risky duration capitalizes the future per-period CDS spread that a seller receives into a present value, which when

\footnotetext{
${ }^{20}$ We use combined data because the underlying data sources for the two sets of portfolios differ somewhat and the portfolio correlations are relatively low. Multiple regression of each Lettau et al. portfolio on to all six Menkhoff et al. portfolios yields $R^{2}$ s of $0.53,0.74,0.82,0.81,0.75$, and 0.56 . Since these portfolios are far from collinear, our tests benefit from improved power by doubling the number of portfolios. However, the qualitative results of our tests are identical if we restrict our currency analysis to only one of the two data sets.
} 
multiplied by the change in spread approximates the log capital gain of the short position. ${ }^{21}$

We also consider tests in which all portfolios are gathered into a single large cross-section. Because some asset classes (such as CDS and commodities) are only available toward the end of our sample, the tests of all portfolios use an unbalanced panel of portfolio returns.

Table 4 provides summary statistics by asset class. For each class, we report the average portfolio excess return and time series beta with respect to each risk factor. Importantly for our tests, we observe considerable risk dispersion within and across asset classes. For example, the Fama-French portfolios have an average time-series intermediary capital beta $\left(\beta_{\eta}\right)$ of 0.07 , with a standard deviation of 0.11 across the 25 portfolios. The last two columns show in the pool of all asset classes, the dispersion in $\beta_{\eta}$ is even higher, with a mean of 0.01 and standard deviation of 0.17 .

\subsection{Cross-sectional asset pricing tests}

We turn next to formal cross-sectional asset pricing tests. These assess whether differential exposure to intermediary capital shocks across assets can explain the variation in their expected returns. We investigate each asset class separately, and also conduct joint tests using the full universe of asset classes together.

\subsubsection{Estimated price of intermediary capital risk across asset classes}

Our investigation of these seven asset classes begins with cross-sectional asset pricing tests in each class separately. For each portfolio $i$ in asset class $k$, we estimate betas from time-series regressions of portfolio excess returns, $R_{t+1}^{i_{k}}-r_{t}^{f}$, on the intermediary capital risk factor, $\eta_{t+1}^{\Delta}$, and on the

${ }^{21}$ The risky duration for CDS of maturity $M$ years with quarterly premium payments is computed as

$$
R D_{t}=\frac{1}{4} \sum_{j=1}^{4 M} e^{-j \lambda / 4} e^{-j\left(r_{t}^{j / 4}\right) / 4}
$$

where $e^{-j \lambda / 4}$ is the quarterly survival probability, $r_{t}^{j / 4}$ is the risk-free rate for the quarter $j / 4$, and $e^{-j\left(r_{t}^{j / 4}\right) / 4}$ is the quarterly discount function. In the empirical implementation we assume that the term structure of survival probabilities is flat and extract $\lambda$ each day from the 5-year spread as $\lambda=4 \log (1+C D S / 4 L)$, where $C D S$ is the spread and $L$ is the loss given default (assumed to be 60\%). The risk-free term structure is constructed using swap rates for maturities 3 and 6 months and US Treasury yields for maturities from 1 year to 10 years (data from Gürkaynak et al., 2007). Risk-free rates are interpolated with a cubic function to find rates for each quarter. 
excess return of the market portfolio, $R_{t+1}^{W}-r_{t}^{f}:^{22}$

$$
R_{t+1}^{i_{k}}-r_{t}^{f}=a^{i_{k}}+\beta_{\eta}^{i_{k}} \eta_{t+1}^{\Delta}+\beta_{W}^{i_{k}}\left(R_{t+1}^{W}-r_{t}^{f}\right)+\epsilon_{t+1}^{i_{k}}
$$

We then run a cross-sectional regression across of average excess portfolio returns on the estimated betas within each asset class $k$ in order to estimate the asset class-specific risk prices $\lambda_{\eta}^{k}$ and $\lambda_{W}^{k}:{ }^{23}$

$$
\hat{\mathbb{E}}\left[R_{t+1}^{i_{k}}-r_{t}^{f}\right]=\gamma_{k}+\lambda_{\eta}^{k} \hat{\beta}_{\eta}^{i_{k}}+\lambda_{W}^{k} \hat{\beta}_{W}^{i_{k}}+\nu^{i_{k}}
$$

Our main focus is on the price of the intermediary capital risk, $\lambda_{\eta}^{k}$. Table 5 reports estimates for the 1970Q1-2012Q4 period. The first seven columns include results from independent estimation within each asset class. Below estimated risk prices we report Fama-MacBeth (1973) t-statistics (tFM) that correct for return cross-correlation as well as GMM t-statistics (t-GMM) that correct for cross-correlation and first-stage estimation error in betas (as advocated by Cochrane (2005)). The measures of model fit that we report are the cross-sectional $R^{2}$ for average portfolio returns, and the related mean absolute pricing error (MAPE) in percentage terms (that is, the mean absolute residual in the cross-sectional regression multiplied by 100).

Intermediary capital risk price estimates are positive in all asset classes, supporting the main empirical prediction of our proposed pricing kernel. Risk price estimates range from $7 \%$ for equities to $22 \%$ for options, and are statistically significant in all but one asset class at the $5 \%$ level, and in all classes at the 10\% (the GMM t-statistic based on six sovereign bond portfolios is 1.66). The model provides the closest fit for option portfolios $\left(R^{2}\right.$ of $\left.99 \%\right)$ and the weakest fit for commodities $\left(R^{2}\right.$ of $\left.44 \%\right)$.

The last column of Table 5 reports results when all 125 portfolios from seven asset classes are included simultaneously in the cross-sectional test. The estimated price of intermediary capital

\footnotetext{
${ }^{22}$ Notice that the model (3) is in the conditional form. Our empirical implementation uses an unconditional test. If test asset betas are constant over time, then the risk prices that we estimate are simply unconditional expectations of potentially state-dependent risk prices. If, however, the true betas are time-varying, then in general (7) and (8) are misspecified. The divergence between model and empirics is due to data limitations and for the sake of transparency. The conditional test requires an estimate of conditional betas, which is challenging due to the intermediary capital factor's reliance on quarterly accounting information (data limitations). This may be overcome with more sophisticated estimators and ad hoc specification of conditioning information, though we leave this for future research (sake of transparency).

${ }^{23}$ The cross section regressions in (8) include the constant $\gamma_{k}$. Section 5.7 reports estimation results that impose the model restriction $\gamma_{k}=0$, which produces nearly identical results.
} 
risk is $9 \%$ per quarter with a GMM t-statistic of 2.56 and $R^{2}$ of $45 \%$. This risk price estimate is economically large. For example, the cross-sectional standard deviation in intermediary capital growth betas for the all portfolios case is 0.17 (see Table 4). Thus, a one standard deviation difference in the capital risk beta of two assets corresponds to a difference of $0.17 \times 0.09 \times 4$, or 6.12 percentage points, in their annual risk premium. ${ }^{24}$

It is interesting to note that in our main bivariate specification, the estimated price of risk on the market portfolio is positive in all asset classes, though it is significant only in the FX test. The significance of intermediary capital risk after controlling for the market return indicates that our pricing kernel statistically improves on the CAPM for all sets of test assets. In Section 5.6, we show that capital risk remains a powerful determinant of asset price behavior after controlling for other standard risk factors.

\subsubsection{Are prices of risk similar across asset classes?}

The sign of the estimated price of risk for intermediary capital factor is consistently positive across all asset classes in Table 5. What can we learn from the magnitudes of the estimates?

Theoretically, if (2) is indeed an appropriate pricing kernel for all asset classes, then the price of risk from each asset class should be the same (up to sampling error). Risk prices are determined solely by the pricing kernel of marginal investors, and therefore must be invariant with respect to the attributes of the assets it is pricing. This is trivially evident from the Euler equation, which implies a functional form for risk prices that is independent of the specific asset in question:

$$
\mathbb{E}_{t}\left(d R_{t}^{i_{k}}\right)-r_{t}^{f} d t=\beta_{\eta, t}^{i_{k}} d t \cdot \underbrace{\gamma \sigma_{\eta, t}^{2}}_{\lambda_{\eta}}+\beta_{W, t}^{i_{k}} d t \cdot \underbrace{\gamma \sigma_{W, t}^{2}}_{\lambda_{W}}, \text { for all } i, k \text {. }
$$

The quantity of risk, or beta, is an attribute of the asset and can differ substantially across classes. Equation (9) makes the theoretical statement that any difference in risk premia across asset must come solely from differences in betas, holding risk prices fixed. If $\lambda$ is for some reason higher in a particular asset class, then the intermediary can earn a higher expected return (without increasing its risk) by shifting its portfolio toward this class. In turn, prices of risk would equalize, reinforcing

\footnotetext{
${ }^{24}$ Figure 3 plots average portfolio returns in all asset classes versus predicted values from the two-factor intermediary capital model. Appendix Table A.1 draws the same plot using separate parameter estimates within each asset class.
} 
the equilibrium consistency of risk prices across all assets.

The test in the last column of Table 5, i.e., the "all portfolios" column, indeed imposes that risk prices are equal across asset classes. Figure 2 compares intermediary risk prices from different asset classes, and also compares with the "all portfolios" estimate, to illustrate the impressive similarity in estimates across tests. Formally, our GMM test cannot reject the hypothesis that the estimated risk price is equal to $9 \%$ per quarter (the value found in the "all portfolios" case) for any of the individual asset classes, at the $5 \%$ significance level. This is not merely a statement that our standard errors are large and lack power — we indeed reject the null of a $0 \%$ risk price in all classes (at the 10\% significance level or better).

From a theory perspective, the prediction of equal risk prices relies on the following key assumptions. First, the proposed financial intermediary pricing kernel represents the intermediaries' marginal value of wealth. Second, financial intermediaries are actively making trading decisions in all asset markets. Also implicit in these assumptions is a degree of homogeneity in the pricing kernels of individual financial intermediaries. That all financial intermediaries are homogeneous is the most standard but perhaps the most tenuous assumption. Its failure could potentially explain the somewhat higher options and FX point estimates, if intermediaries that specialize in trading these instruments differ in some way from other intermediaries (see for example Gârleanu et al., forthcoming).

\subsubsection{Are primary dealers special?}

We next explore the role of our specific intermediary sector definition for the preceding results. We conduct placebo tests that replicate our cross section analysis, but replace the capital ratio of primary dealers with that of other "intermediary" definitions.

First, we consider defining intermediaries according to SIC codes of US broker-dealers - codes 6211 ("security brokers, dealers, and flotation companies") and 6221 (commodity contracts brokers and dealers) — but exclude firms that are designated NY Fed primary dealers. This definition, which we refer to as "non-primary" dealers, includes firms like Blackrock, Charles Schwab, and Waddell \& Reed. As shown in Table 2, non-primary dealers are small relative to primary dealers.

In Panel (a) of Table 6, we report cross section tests using non-primary dealer capital ratio as a factor. Only equities and CDS show a significantly positive price of capital ratio risk based 
on this intermediary definition; the estimated price of capital risk in other asset classes is either insignificant or has a negative sign.

Extending this idea further, we construct the equity capital ratio risk factor for the entire US non-bank sector, i.e., all public firms in CRSP/Compustat with SIC codes that do not begin with 6. The results, reported in Panel (b), demonstrate the overall inability of the non-bank capital ratio to price assets, with estimates switching sign across classes and a point estimate of nearly zero in the "all portfolios" test. Overall, Table 6 provides additional indirect evidence supporting our assumption that primary dealers are pricing-relevant financial intermediaries.

\subsubsection{Which is more important for pricing, equity or debt?}

Innovations in our measure of intermediary capital ratio are driven by either changes in market value of equity or changes in book debt. We investigate which of these is the more important driver of our asset pricing result.

We first show that our intermediary capital factor, which is the shock to $\ln \eta_{t}=\ln \frac{E_{t}}{E_{t}+D_{t}}$, can be decomposed into the growth rate of the primary dealer market equity, denoted by $d \ln E_{t}$, and the growth rate of their debt, denoted by $d \ln D_{t}$. More specifically, as we are only interested in diffusion terms (which implies that we can ignore Ito's correction terms which contribute to the drift), we have 25

$$
d \ln \eta_{t}=d \ln \frac{E_{t}}{E_{t}+D_{t}}=\left(1-\eta_{t}\right)\left(d \ln E_{t}-d \ln D_{t}\right)
$$

As a result, our innovations $d \ln \eta_{t}$ equal the equity growth rate shock $d \ln E_{t}$ minus the debt growth rate shock $d \ln D_{t}$, both scaled by $1-\eta_{t}$. Guided by (10), we test a three-factor version of our model that decomposes the capital risk factor into log innovations in primary dealer market equity and $\log$ innovations in their book value of debt. The decomposition in (10) also implies that the equity growth rate shock carries a positive price of risk, while price of the debt growth rate shock should be negative. ${ }^{26}$

\footnotetext{
${ }^{25}$ The derivation with intermediate steps is (recall $\eta_{t}=\frac{E_{t}}{E_{t}+D_{t}}$ and ignore drift terms with Ito corrections)

$$
d \ln \eta_{t}=d \ln E_{t}-d \ln \left(E_{t}+D_{t}\right)=d \ln E_{t}-\frac{E_{t} d \ln E_{t}+D_{t} d \ln D_{t}}{E_{t}+D_{t}}=\left(1-\eta_{t}\right)\left(d \ln E_{t}-d \ln D_{t}\right) .
$$

${ }^{26}$ The capital ratio decomposition gives rise to an $\eta_{t}$ term premultiplying the difference in equity growth and debt growth. This scales down the risk prices in this three-factor model relative to the benchmark model. But, because the time-series average of $\eta_{t}$ is 0.06 , this effect is quantitatively small, and risk price magnitudes can still be meaningfully
} 
Because the primary dealer list changes over time, we construct equity and debt growth measures that are insensitive to entry and exit. The equity growth rate from quarter $t$ to $t+1$ is defined as the log change in total market equity of all designated primary dealers as of time $t$. That is, if a designee enters the list in $t+1$, its equity is excluded from the $t+1$ growth rate calculation, and if it exits before $t+1$ then its market equity is still included in the growth rate (likewise for debt). ${ }^{27}$

The results are presented in Table 7. In all asset classes, the estimated price of risk on intermediary equity shocks remains positive and economically large (at least $5 \%$ per quarter in each asset class). For the "all portfolios" test, the price of intermediary equity risk is $9 \%$ per quarter. Overall, the pricing ability of intermediary equity is similar, but somewhat weaker, than that of the capital ratio variable. The estimated price on book debt innovations is negative in six out of seven asset classes, as we expect given our theory and the negative functional relation between debt shocks and capital ratio shocks. However, the magnitudes are often small and insignificant. For the all portfolios test, the intermediary debt risk price is $-2 \%$ per quarter and is insignificant.

In sum, these results suggest that while book debt innovations play some role in our main pricing results, it is the market equity component of the capital ratio that is most important for the effects that we document.

\section{Comparison with AEM: Empirics, Sample Composition, and Theory}

\subsection{Brief review of AEM}

AEM is an important precursor to our paper and is the first paper to bring the intermediary-based pricing paradigm into the conversation of "mainstream" empirical pricing models. These authors propose a one-factor intermediary pricing kernel. The factor is the innovation in broker-dealer book leverage derived from data in the Flow of Funds. In principle, the main intermediary leverage state variable in their empirical model is exactly the reciprocal of our capital ratio state variable. Though empirically, there are a number of important differences in our analyses that we discuss below.

\footnotetext{
compared to those in Table 7.

${ }^{27}$ We use this calculation to demonstrate that our findings are not driven by changes in the primary dealer list, though our results are unaffected if we allow entry and exit in our calculation.
} 
AEM conduct standard cross section pricing tests using the 25 Fama-French equity portfolios, 10 momentum equity portfolios, and six Treasury bond portfolios. The main result is the robust ability of broker-dealer leverage for pricing the cross section of stocks and Treasury bonds. They estimate a large and significant positive price of risk on leverage shocks. This has the interpretation that intermediary marginal value of wealth is higher when its leverage is lower, or equivalently implies that a high equity capital ratio indicates intermediary financial distress.

Due to the reciprocal relationship between capital ratio and leverage, AEM's finding is in direct contradiction with our finding of a robust positive price of risk price on the intermediary capital ratio. The AEM finding also contradicts the theoretical prediction of He and Krishnamurthy $(2012,2013)$ and Brunnermeier and Sannikov (2014) that a low capital ratio proxies for intermediary distress and hence a high marginal value of wealth.

The tension in the two sets of results is rather puzzling. Theoretically, we are attempting to measure the same quantity - financial distress of the intermediary sector - with the only conceptual difference being that their preferred measure is the inverse of our measure. Therefore, we would expect our price of risk estimates to always have the opposite sign, with otherwise similar magnitude and statistical significance. The facts are in stark contrast to this prediction. It stands to reason, therefore, that our empirical measures do not behave inversely to one another as predicted. Indeed, Figure 4a illustrates the inconsistency. Our capital ratio measure and AEM's leverage measure are significantly positively related in the time series, sharing a $42 \%$ correlation in levels. Figure $4 \mathrm{~b}$ compares innovations in the two series, which share a $14 \%$ correlation.

We devote this section to understanding the differences in our empirical facts, and to place these differences in context of various intermediary asset pricing theories.

\subsection{Empirical performance of AEM in many asset classes}

First, we extend our multiple asset class tests to better understand the empirical performance of AEM's intermediary pricing kernel. This portion of our analysis is exactly analogous to our earlier tests using the capital ratio. In particular, we consider a two-factor model that includes AEM leverage innovations and the return on the market portfolio. ${ }^{28}$

\footnotetext{
${ }^{28}$ We construct the AEM leverage factor for the 1970-2012 period as described in their paper. It is 0.99 correlated with the one provided by Tyler Muir at faculty.som.yale.edu/tylermuir/LEVERAGEFACTORDATA_001.txt, which ends in 2009 .
} 
Table 8 reports the estimated AEM leverage factor risk price and related model statistics for each asset class. For equities and US bonds, the AEM leverage factor carries a significantly positive price, which essentially replicates the key findings reported by AEM (with the exception that our "US bonds" definition also includes corporates). In these two classes, the performance of the AEM pricing kernel is superior to ours, as reflected in their higher cross-sectional $R^{2}$. AEM also emphasize that their leverage measure successfully explains differences in average returns among momentumsorted equity portfolios. Our measure, on the other hand, does not explain the momentum anomaly in equities.

The AEM model delivers very different results in other assets classes. The leverage risk price either becomes strongly negative (options, CDS, and FX) or remains positive but statistically insignificant (foreign sovereign bonds and commodities). In the "all portfolios" joint test, the estimated price of risk is positive but statistically insignificant. Furthermore, the estimated risk price of $13 \%$ is economically smaller. From Table 9, the standard deviation in AEM leverage betas across all portfolios is 0.05, implying differences in annual AEM leverage premia of $0.05 \times 0.13 \times 4$, or 2.6 percentage points, for a one standard deviation difference in beta (or forty percent of the risk premium effect that we find for our intermediary capital factor). Figure 5 illustrates the extent of inconsistency in AEM pricing performance across asset classes, which contrasts with the capital ratio model results in Figure 2.

We next consider a three-factor horse-race specification that includes our capital ratio factor and the AEM leverage factor together (along with the market return). Table 10 reports the estimation results for each asset class. In the equity market, the presence of AEM renders the capital ratio insignificant, reiterating the strong pricing power of AEM for the US equity market. In all other asset classes, the price of intermediary capital risk is at least $6 \%$ per quarter, and only loses statistical significance in the options market. The options market is an interesting case; in the horse-race specification, the lack of statistical significance for our measure appears due to the large and significant negative price of risk on the AEM factor.

Our emphasis on a variety of asset classes is the key empirical feature that distinguishes our paper from AEM. Most intermediary-based asset pricing models are founded on the limits-toarbitrage paradigm (Shleifer and Vishny, 1997), which implies that the pricing kernel of households might not be relevant if some asset classes are too complicated for households to trade in directly. 
Presumably, derivatives contracts or OTC markets are too sophisticated to be directly accessed by most household investors. By contrast, financial intermediaries play a central role in the market for derivatives and OTC assets. Our paper provides supporting evidence that this distinction is important for understanding the behavior of a wide variety of assets.

\subsection{Data source and measurement}

Our measure of financial distress differs from AEM in both the definition of a financial intermediary and the data sources employed. We define intermediaries as the set of primary dealers and rely on market equity and book debt data for their publicly traded holding companies. AEM define intermediaries as the set of broker-dealer firms (often bank holding company subsidiaries) that feed into the Flow of Funds broker-dealer accounts, and use the book equity and debt data reported in those accounts. ${ }^{29}$

The two key differences are (i) our use of market values for constructing capital ratios, versus AEM's reliance on accounting book values, and (ii) our use of data at the holding company level, versus the broker-dealer subsidiary level information in the Flow of Funds. We explore the role of these differences in this section.

\subsubsection{Market leverage vs. book leverage}

Our aim in constructing the capital ratio is to provide a current measure of financial distress that reflects the information available in prevailing market prices. Virtually all intermediary asset pricing theories would suggest using market values, which reflect forward looking information available in traded securities prices. While the market value of equity is readily available for publicly traded firms, market debt values are much more difficult to measure. Instead, we follow the standard approach in empirical corporate finance and use firms' most recently published book value of debt from accounting statements. The inverse of our market equity capital ratio is referred to as "market leverage."

Book leverage, on the other hand, relies on accounting statement data for both equity and debt. One would expect a positive correlation between market and book capital ratios due to the fact

\footnotetext{
${ }^{29}$ Flow of Funds broker-dealer data are from SEC tabulation of regulatory filings. It includes most broker-dealer firms that file the Financial and Operational Combined Uniform Single (FOCUS) report or the Finances and Operations of Government Securities Brokers and Dealers (FOGS) report with their regulator (e.g. FINRA).
} 
that broker-dealers and banks are required to frequently mark their books to market. When markto-market is implemented perfectly, book leverage coincides with its market counterpart. ${ }^{30}$ Because Flow of Funds data only includes book data for broker-dealers, Adrian et al. (2014a) rely on book leverage for their analysis, and appeal to mark-to-market accounting to support the timeliness and accuracy of their measure. ${ }^{31}$

An advantage of our data set is that we have access to both book and market equity values. We construct both book and market capital ratios for our sample of primary dealers, where the book capital ratio is defined similarly as in (6), but replacing the market equity with its corresponding book equity. We then investigate whether drastic differences in the two measures can potentially reconcile differences in our findings with AEM. For example, a negative correlation between book and market leverage in our sample could help explain the conflicting risk prices estimated in our study and that of AEM. ${ }^{32}$

We find, however, that the market capital ratio of primary dealers is in fact strongly positively associated with book capital ratio. Book and market capital ratios have a correlation of $50 \%$ in levels and $30 \%$ in innovations, indicating qualitatively similar behavior between them. This is illustrated in the time series plot of Figure 4b, and suggests that Compustat book leverage of primary dealers is in fact counter-cyclical. We present more direct evidence in appendix Table A.2, where we estimate the two-factor asset pricing model which replaces the market capital ratio factor with its corresponding book capital ratio. The estimated prices of intermediary book capital risk remain largely positive (though become much less significant) across different asset classes, consistent with idea that the market equity of financial institutions reflects more accurate and timely information than their (accounting) book equity.

Outside the sample of primary dealers, we find that book and market capital ratio measures are also highly correlated for the wider universe of publicly traded broker-dealers (all public US

\footnotetext{
${ }^{30}$ One caveat is that the market value of an financial intermediary not only reflects the market value of the financial assets on its balance sheet, but also includes the present value of its profits earned from future activities. Our view is that this future enterprise value also affects the intermediary's financial distress, and therefore will show up in its pricing kernel.

${ }^{31}$ In the accounting literature, there is some debate regarding accounting manipulations in the practice of mark-tomarket and indication that mark-to-market accounting is especially inaccurate during financial crises when capital requirements and credit channels tighten (Heaton et al., 2010; Milbradt, 2012). Ball et al. (2012) provide a skeptical assessment of mark-to-market accounting in a large sample of banks' trading securities.

${ }^{32}$ Previous literature such as Adrian et al. (2014b); Adrian and Shin (2014) show that market and book leverage can be negatively correlated for banks, and therefore note that empirical analyses can be sensitive to choice of market-based versus book-based measures.
} 
firms with SIC 6211 or 6221 , which includes some primary dealers). This group generally includes smaller broker-dealers that mainly focus on securities trading. Here we find a $75 \%$ correlation between market capital ratio and book capital ratio, again indicating reasonably accurate markingto-market.

The conclusion from this analysis is that the difference between market-based and book-based measures of financial distress is unlikely to be responsible for the tension between our facts and those of AEM.

\subsubsection{Holding company vs. broker-dealer subsidiary}

The more likely discrepancy between AEM and our paper is that we measure financial distress at the holding company level for primary dealers, while the Flow of Funds data used by AEM only aggregates balance sheet information at the broker-dealer subsidiary level. Most NY Fed primary dealers are the broker-dealer subsidiaries of a large financial institutions holding companies. Flow of Funds data come from quarterly FOCUS and FOGS reports filed with the Securities and Exchange Commission (SEC) by these broker-dealer arms in isolation from other parts of their larger institutions. The underlying Flow of Funds data is therefore not publicly available. However, as most primary dealers are owned by publicly traded companies, market and financial statement data for the holding company is widely available, and form the basis of our analysis. In short, our definition of an intermediary is broader than AEM in the sense that we treat the entire holding company as the observation of interest. ${ }^{33}$

The holding companies of primary dealers also often hold significant commercial banking businesses, ${ }^{34}$ making the distinction between holding company and broker-dealer arm potentially important. We find that the AEM implied capital ratio (i.e., the inverse of AEM leverage) is more closely in line with the capital ratio of non-primary dealers (defined in Section 3.2.3) than that of primary dealers. While the AEM implied capital ratio and that of our primary dealer sample are strongly negatively correlated at $-59 \%$, the correlation between the AEM capital ratio and nonprimary dealer capital ratio is 71 percentage points higher, at positive $12 \%$. As shown in Table

\footnotetext{
${ }^{33}$ At the same time, by focusing on primary dealers, we hone in on only the largest and most active intermediaries. By incorporating all broker-dealers that are subject to regulatory oversight, the Flow of Funds includes many small and standalone dealers.

${ }^{34}$ For instance, JP Morgan Securities LLC is the broker-dealer subsidiary of JP Morgan, and Citigroup Global Markets Inc. fulfills that role under the Citigroup umbrella.
} 
2 and discussed in Section 3.2.3, the small overall size of non-primary dealers suggests that the broker-dealer business is the dominant segment in these firms. The large difference between the correlations of AEM with primary versus non-primary dealers is consistent with the interpretation that AEM only captures the leverage of broker-dealer sector, while the holding companies of primary dealers include other intermediary businesses with potentially different leverage patterns.

A key distinction between these two approaches - holding company data versus subsidiary-level broker-dealer data - rests on the role of internal capital markets in the primary dealer's holding company. A well established view in corporate finance is that internal capital markets within a conglomerate are likely to diversify and transmit adverse financial shocks across divisions (e.g. Stein, 1997; Scharfstein and Stein, 2000). If internal capital markets are important sources of funds for broker-dealer subsidiaries, then the capital ratio of the intermediary's holding company is the economically relevant measure of financial distress. In the banking literature, Houston et al. (1997), Houston and James (1998) and de Haas and van Lelyveld (2010) show evidence to this effect. For instance, Houston et al. (1997) show that a bank subsidiary's loan growth more strongly correlates with the holding company's capital position than with the subsidiary's own capital position.

In addition to the loan business, two anecdotes support the view that internal capital markets play an important role in the financial health of broker-dealer subsidiaries. The first is the 2008 failure of Lehman Brothers. The bankruptcy examiner describes Lehman Brothers Holdings as a "central banker" for Lehman subsidiaries (Valukas, 2010, Vol. 5, p. 1944). Its broker-dealer units (the European in particular) required significant funding to unwind its prime brokerage services in the days immediately prior to the September 15, 2008 bankruptcy filing. The holding company attempted to avoid bankruptcy by using its liquid non-broker-dealer assets to guarantee the obligations of its broker-dealer subsidiaries to their clearing banks. This glimpse at the internal markets of a large financial institution at the peak of its financial distress indicates the fungibility of capital within broker-dealer holding companies. This point is further corroborated by the bankruptcy case of the Drexel Burnham Lambert Group in 1990, which led to the liquidation of its broker-dealer affiliate. In the three weeks before it filed for bankruptcy, approximately $\$ 220$ million was transferred to the holding company from its broker-dealer arm in the form of short-term loans. This instance of capital siphoning led the SEC to initiate group-wide risk assessments for all financial 
institutions with significant broker-dealer subsidiaries. ${ }^{35}$

Of course, if internal capital markets within the holding company malfunction, then the financial distress of the primary dealer might be more directly reflected by the broker-dealer arm's own capital structure. The importance of internal capital markets is ultimately an empirical question. Our evidence based on holding company financial ratios indirectly supports the view that internal markets are important to understanding the effect of intermediary distress on asset prices.

\subsection{Differences in theoretical motivation}

The interpretation of differences in our empirical results is complicated by the fact that different intermediary models predict different signs for the price of risk on intermediary capital shocks. In this subsection we discuss the theoretical distinction between two classes of intermediary asset pricing models, which we dub either "equity constraint" or "debt constraint" models.

The equity constraint framework originates with net worth-based based models such as Bernanke and Gertler (1989) and Holmstrom and Tirole (1997), and is exemplified by He and Krishnamurthy (2013, 2012) and Brunnermeier and Sannikov (2014). In these models, an adverse shock to the intermediary's equity capital reduces its risk bearing capacity. This leads to a fall in asset prices which directly increases the intermediary's leverage (holding debt fixed). At the same time, this rise in leverage is countervailed by the intermediary endogenously reducing its debt financing. In general equilibrium, the fall in equity values outweighs the debt reduction, and equilibrium leverage rises (this is especially true when there is no debt constraint, as in He and Krishnamurthy (2012, 2013); Brunnermeier and Sannikov (2014)). In other words, from the standpoint of the intermediary, leverage is counter-cyclical, rising in distress states where the intermediary values its wealth the most. This corresponds to a negative price of leverage risk, or a positive price of capital ratio risk.

Another group of models, exemplified by Brunnermeier and Pedersen (2009), and Adrian and Shin (2014), are set in a "debt constraint" framework. ${ }^{36}$ These models rule out equity financing by assumption; instead, they focus on a time-varying debt (or leverage) constraint that affects equilibrium pricing. The models are often static and feature a binding collateralized borrowing constraint,

\footnotetext{
${ }^{35}$ See testimony of Robert L.D. Colby before the U.S. House Subcommittee on Financial Institutions and Consumer Credit dated September 14, 2006, and Adoption of Amendments to SEC Rule 15c3-1 Regarding Withdrawals of Net Capital dated March 5, 1991.

${ }^{36}$ Other related papers are Geanakoplos and Fostel (2008), Adrian and Boyarchenko (2012) and Moreira and Savov (2013).
} 
either motivated by a value-at-risk constraint as in Adrian and Shin (2014) or an endogenous haircut as in Brunnermeier and Pedersen (2009). Bad times correspond to a tightening of the debt constraint reflected as lower allowable leverage, and this triggers deleveraging and fire-sales during which assets are sold to some second-best user at a lower equilibrium price. This directly implies that leverage is pro-cyclical in these models - debt falls in those states where debt constraints bind the most and intermediary marginal value of wealth is highest. This corresponds to a positive price for leverage risk, or a negative price of capital ratio risk.

This classification of theories, while in some ways over-simplified, ${ }^{37}$ is meant to clearly delineate how different financial constraints can give rise to different equilibrium leverage patterns. More importantly, we believe that given the spectrum of complexities in real world financial intermediation that these models may be attempting to describe, it should not be surprising that different intermediary models give opposing predictions. It is likely that intermediaries face both equity and debt constraints to varying degrees in different states of the world, leading to more nuanced and complex behavior than either class alone can generate.

A related possibility is that these two model classes describe different intermediary sub-sectors that interact in financial markets. He et al. (2010) and Ang et al. (2011) describe one example that supports this view. During a downturn when marginal value of wealth is likely to be high for all investors, hedge funds (who are perhaps closer to the type of intermediary described by debt constraint models) sell their assets to commercial banks (who may be better described by equity constraint models), and so leverage of these two sectors moves in opposite directions. In the appendix we present a simplified static equilibrium model that combines features of Brunnermeier and Pedersen (2009) and He and Krishnamurthy (2012) into an intermediary model with two sub-sectors. It illustrates how a debt-constrained "hedge fund" sector has procyclical leverage in equilibrium while leverage of the equity-constrained "bank" sector is countercyclical.

An interesting direction for future theory is to investigate different economic conditions under which debt or equity constraints are more likely to impact asset values, and to use this to guide

\footnotetext{
${ }^{37}$ For instance, Garleanu and Pederson (2011) build a dynamic stochastic general equilibrium model with margin constraints, which correspond to "debt constraint" in our language. However, the dynamic nature of that model implies that the margin/debt contrasint does not bind in the normal state of world, and binds only after a sequence of sufficiently negative shocks. This occasionally binding constraint is similar to He and Krishnamurthy (2013, 2012). In Garleanu and Pederson (2011), because the deleveraging force is relatively weak in "normal" times when the constraint does not bind, there is no simple monotonic relationship between leverage and state of the world.
} 
construction of a more sophisticated pricing kernel that nests both mechanisms in a state-dependent manner. And, ultimately, it is an empirical question whether our capital risk factor, the AEM leverage factor, or some combination is the most useful representation of the pricing kernel.

\section{Robustness}

This section presents an array of robustness tests that support our main findings.

\subsection{Pre-crisis and post-1990 subsamples}

Table 11 presents the performance of our intermediary capital risk factor and the AEM leverage factor during the 1970Q1-2006Q4 sample, which excludes the dramatic fluctuations associated with the financial crisis. This test is designed to address the concern that average returns in some asset classes are unduly influenced by the crisis subsample. We find that pre-crisis prices of capital ratio risk are substantially smaller in three asset classes, US bonds, sovereign bonds, and commodities. In the other four asset classes, the price of intermediary capital risk remains economically large. In the "all portfolios" case, the risk price estimate is $9 \%$ per quarter, identical to that in the full sample and highly significant.

We separately investigate the recent sample beginning in 1990 in Table 12. The capital risk price estimate remains economically large in five of the seven asset classes (the exceptions are equities and US bonds). The "all portfolios" estimate remains positive and significant, both economically and statistically.

\subsection{Monthly frequency}

Our main analysis focuses on the quarterly frequency, corresponding to the frequency of balance sheet data going into our capital ratio measure. Similarly, AEM construct their leverage factor based on the accounting Flow of Funds data and is only available at the quarterly frequency.

An advantage of using CRSP data is that we can update the capital ratio as new market equity data arrives each month. As a result, one can construct the monthly capital ratio for primary dealers by using the monthly market equity information from CRSP, together with the most recent quarterly book debt of their holding companies in Compustat. We repeat our cross section analysis 
at the monthly frequency.

Table 13 presents the results. The estimated price of intermediary capital risk remains positive for all asset classes. The magnitudes of estimates are now in monthly terms, and should therefore be multiplied by three in order to compare with our quarterly estimates in Table 5 . The monthly price of capital risk is noticeably weaker for equities and US bonds, but remains economically meaningful in the other five asset classes. In the "all portfolios" test, the risk price estimate is $4 \%$ per month and highly statistically significant.

Our use of the most recently reported quarterly debt ignores within-quarter variation in the debt taken by primary dealers. This approximation may hurt our model performance at the monthly frequency, if the time-series variation in book debt plays a role in driving the pricing power of our intermediary capital risk factor. From Table 7 in Section 3.2.4 we observe that book debt growth does possess some pricing power, which suggests a potential explanation for the weaker monthly performance of our intermediary capital risk factor.

\subsection{Time-series return predictability}

A common prediction of dynamic intermediary asset pricing models is that the risk premium is time-varying, implying predictability in asset returns based on lagged state variables that captures financial distress. We perform time-series predictive regressions in each asset class to evaluate this prediction.

Our framework requires additional structure to derive the time-varying risk premium, which is typically a nonlinear function of the state variable. In a simplified version of He and Krishnamurthy (2012) that focuses on the risk of intermediary capital ratio, the risk price can be described as

$$
\lambda_{\eta}=\gamma \operatorname{Var}_{t}\left[\frac{d \eta_{t}}{\eta_{t}}\right]=\gamma \sigma_{\eta, t}^{2} \propto\left(\frac{1}{\eta_{t}}\right)^{2}
$$

In words, the risk premium is linear in the squared reciprocal of the capital ratio of the intermediary sector.

Guided by (11), we regress the one-year holding period return on an equal weighted portfolio 
of assets within each class on the lagged inverse of the squared intermediary capital ratio:

$$
R_{t+1 \rightarrow t+4}^{k}-r_{t}^{f}=a_{k}+b_{k} \frac{1}{\eta_{t}^{2}}+u_{t+1 \rightarrow t+4}
$$

The model predicts a positive $b_{k}$ coefficient in Equation (11) because low intermediary capital ratio (high leverage) states are associated with low expected future returns. The model's prediction is generally supported by Table 14 , which reports a significantly positive $\hat{b}_{k}$ for five of the seven asset classes at the $10 \%$ significance level, and in four classes is significant at the $5 \%$ significance level.

The dependent variable in the last column of Table 14 is the weighted average of individual asset class portfolio returns, with weights inversely proportional to the unconditional standard deviation of a portfolio's return. This weighting scheme accounts for the fact that volatilities differ markedly across asset classes, so prediction results for an equal-weighted average would be driven by a subset of the highest volatility portfolios. We find a positive one-year-ahead predictive coefficient in the "all portfolios" test with a t-statistic of $2.89 .{ }^{38}$

For comparison, we also report predictive regression results for AEM, replaces $1 / \eta_{t}^{2}$ with their broker-dealer leverage ratio. The predictive coefficients are negative (as AEM would predict) in six out of seven classes, and are significant in four classes at the $10 \%$ level.

\subsection{Single factor models}

Our main analysis focuses on a two-factor structure for the pricing kernel. Although the economic rationale to include the market return is standard, the empirical price of risk associated with the market return is generally insignificant in Table 5 . Here we consider a one-factor specification that omits the market return.

Table 15 presents the estimation results. The only meaningful difference compared to our main results in Table 5 appears in the case of the 25 Fama-French portfolios, where the price of our intermediary capital risk is insignificant while the AEM result remains strong. This result is consistent with the horse-race outcomes in Table 10 where AEM leverage drives out our capital ratio factor in the equity market. But, for all other asset classes, the primary dealer capital ratio consistently carries a positive and significant risk price, while the AEM leverage risk price estimates

\footnotetext{
${ }^{38}$ Test statistics in Table 14 use Hodrick (1992) standard errors to adjust for the fact that annual returns are being forecast using overlapping quarterly observations.
} 
take opposite signs in CDS, Options, and FX markets. The take-away is basically the same as from the baseline two-factor model.

\subsection{Intermediary equity return}

As explained in equation (4) in Section 2.2, the representative intermediary's pricing kernel only depends on its own net worth $W_{t}^{I}$, a result that holds exactly for log preferences (e.g., He and Krishnamurthy (2012)). A similar derivation to equation (3) implies that the return on the intermediary's equity should be a sufficient statistic for the intermediary pricing kernel.

We test this single factor asset pricing model by constructing the value-weighted equity return for the primary dealer sector, ${ }^{39}$ and report the estimated price of the primary dealers' equity return in Table 16. We find a significantly positive price for all asset classes other than the Fama-French 25 portfolios at the $10 \%$ level. For the "all portfolio" test, the estimated price is positive and significant based on the Fama-MacBeth $t$-statistics but not the GMM $t$-statistics.

Recall that the single factor model with the factor being intermediary equity return holds only under log preferences. This is because the pricing kernel is the marginal investor's marginal utility of consumption, and the consumption of log investors is always a constant fraction of their wealth. But if the representative intermediary has recursive preferences, then future market prospects (say persistent TFP shocks) will in general enter the intermediary's pricing kernel, suggesting some reduce-form specification in line with (2). Indeed, when we include the market return as another factor in panel (b) of Table 15, we recover estimates that are closely in line with our baseline results from Table 5. In particular, the estimated price of intermediary equity return factor is positive and significant throughout. Overall, the results in this table suggest that primary dealers' equity return plays a similar role as the capital risk factor, offering further evidence in support of intermediary asset pricing models.

\subsection{Comparison with other factors}

A large literature investigates factors that explain the cross section of asset returns. These analyses focus on the pricing of US equities and have not been tested as pricing factors in many of the

\footnotetext{
${ }^{39}$ This value-weighted equity return is slightly different from the intermediary (market) equity growth rate constructed in Section 3.2.4. The latter "intermediary equity growth rate" includes new equity issuance, while the equity return does not.
} 
asset classes we study. In Table 17, we compare the pricing power of our intermediary capital ratio factor relative to the CAPM, the Fama and French $(1993,2015)$ three- and five-factor models, the momentum factor, and the Pástor and Stambaugh (2003) liquidity factor. The table reports the cross section $R^{2}$ and MAPE with and without the intermediary capital factor. Including the intermediary capital factor improves the cross-sectional $R^{2}$ in the "all portfolios" test by $15 \%$ and reduces the MAPE by $27 \%$ relative to the Fama-French five-factor model. In all cases, the estimated price of intermediary capital risk is essentially unchanged by inclusion of other commonly studied factors, and remains significant with a GMM $t$-statistic of at least $2.56 .^{40}$

\subsection{Cross-sectional tests without an intercept}

The empirical specification (8) allows the intercept $\gamma_{k}$, to vary across asset classes. The theory discussed in Section 3.2.2, however, predicts that $\gamma_{k}=0$ for all $k$ as in (9). This additional theoretical restriction might not be valid given potential model misspecification; however, it may matter for the empirical cross-asset pattern of estimated prices of intermediary capital risk $\lambda_{\eta}^{k}$.

In Table 18 we repeat our main cross-sectional regressions without an intercept. We find that constraining the intercept to zero has a minor impact on the prices of intermediary capital risk that we estimate and, if anything, their statistical significance improves.

\section{Conclusion}

We find that differences in assets' exposure to innovations in the capital ratio of primary dealers explain variation in expected excess returns on equities, US bonds, foreign sovereign bonds, options, CDS, commodities, and currencies. Our intermediary capital risk factor carries a positive price of risk and is strongly pro-cyclical, implying counter-cyclical intermediary leverage. Our findings lend new empirical support to the view that financial intermediaries are marginal investors in many asset classes, and in turn support the view that the financial soundness of these intermediaries is important for understanding wide ranging asset price behavior.

\footnotetext{
${ }^{40}$ Because our capital ratio factor is non-traded and theoretically motivated, statistically oriented models such as the Fama-French three and five-factor models are not natural benchmarks for comparison. In the words of Cochrane (2005), "it is probably not a good idea to evaluate economically interesting models with statistical horse races against models that use portfolio returns as factors.... Add any measurement error, and the economic model will underperform its own mimicking portfolio. And both models will always lose in sample against ad hoc factor models that find nearly ex post efficient portfolios." Nonetheless, some readers may find the comparison is informative.
} 


\section{References}

Adrian, Tobias, and Nina Boyarchenko, 2012, Intermediary leverage cycles and financial stability, Working paper, Staff Report, Federal Reserve Bank of New York.

Adrian, Tobias, Erkko Etula, and J Groen, 2011, Financial amplification of foreign exchange risk premia, European Economic Review 55, 354-370.

Adrian, Tobias, Erkko Etula, and Tyler Muir, 2014a, Financial intermediaries and the cross-section of asset returns, Journal of Finance LXIX, 2557-2596.

Adrian, Tobias, Erkko Etula, and Hyun Song Shin, 2009, Liquidity risk and the dynamics of arbitrage capital, Staff report 361, Federal Reserve Bank of New York.

Adrian, Tobias, Emanuel Moench, and Hyun Song Shin, 2014b, Dynamic leverage asset pricing, Working paper, Federal Reserve Bank of New York.

Adrian, Tobias, and Hyun Song Shin, 2010, Liquidity and leverage, Journal of Financial Intermediation 19, 418-437, Risk Transfer Mechanisms and Financial Stability.

Adrian, Tobias, and Hyun Song Shin, 2014, Procyclical leverage and value-at-risk, Review of Financial Studies 27, 373-403.

Allen, Franklin, 2001, Presidential address: Do financial institutions matter?, Journal of Finance $56,1165-1175$.

Allen, Franklin, and Douglas Gale, 1994, Limited market participation and volatility of asset prices, American Economic Review 933-955.

Ang, Andrew, Sergiy Gorovyy, and Gregory B. van Inwegen, 2011, Hedge fund leverage, Journal of Financial Economics 102, 102-126.

Ball, Ray, Sudarshan Jayaraman, and Lakshmanan Shivakumar, 2012, Mark-to-market accounting and information asymmetry in banks, Working paper, Chicago Booth.

Bansal, Ravi, and Amir Yaron, 2004, Risks for the long run: A potential resolution of asset pricing puzzles, Journal of Finance 59, 1481-1509.

Basak, Suleyman, and Domenico Cuoco, 1998, An equilibrium model with restricted stock market participation, Review of Financial Studies 11, 309-341.

Basak, Suleyman, and Anna Pavlova, 2013, Asset prices and institutional investors, American Economic Review 103, 1728-58.

Bates, David S., 2003, Empirical option pricing: a retrospection, Journal of Econometrics 116, 387-404, Frontiers of financial econometrics and financial engineering.

Bernanke, Ben, and Mark Gertler, 1989, Agency costs, net worth, and business fluctuations, American Economic Review 79, 14-31.

Borri, Nicola, and Adrien Verdelhan, 2012, Sovereign risk premia, Working paper.

Brunnermeier, Markus K, and Lasse Heje Pedersen, 2009, Market liquidity and funding liquidity, Review of Financial studies 22, 2201-2238. 
Brunnermeier, Markus K., and Yuliy Sannikov, 2014, A macroeconomic model with a financial sector, American Economic Review 104, 379-421.

Calvet, Laurent E., John Y. Campbell, and Paolo Sodini, 2007, Down or out: Assessing the welfare costs of household investment mistakes, Journal of Political Economy 115, 707-747.

Campbell, John Y., and John H. Cochrane, 1999, By force of habit: A consumption based explanation of aggregate stock market behavior, Journal of Political Economy 107, 205-251.

Cheng, Ing-haw, Harrison Hong, and Jose A. Scheinkman, 2015, Yesterday's heroes: Compensation and risk at financial firms, Journal of Finance 70, 839-879.

Cochrane, John H., 2005, Asset Pricing, revised edition (Princeton University Press).

Constantinides, George M., Jens Carsten Jackwerth, and Alexi Savov, 2013, The puzzle of index option returns, Review of Asset Pricing Studies 3, 229-257.

de Haas, R., and I. van Lelyveld, 2010, Internal capital markets and lending by multinational bank subsidiaries, Journal of Financial Intermediation 19, 1-25.

Duffie, Darrell, 2010, Asset price dynamics with slow-moving capital, Journal of Finance 65, 12371267.

Edwards, A., L. Harris, and M. Piwowar, 2007, Corporate bond market transaction costs and transparency, Journal of Finance 62, 1421-1451.

Fama, Eugene F., and Kenneth R. French, 1993, Common risk factors in the returns on stocks and bonds, Journal of Financial Economics 33, 3-56.

Fama, Eugene F, and Kenneth R French, 2015, A five-factor asset pricing model, Journal of Financial Economics 116, 1-22.

Froot, Kenneth A, and Paul GJ O'Connell, 1999, The pricing of us catastrophe reinsurance, in The Financing of Catastrophe Risk, 195-232 (University of Chicago Press).

Gabaix, Xavier, Arvind Krishnamurthy, and Olivier Vigneron, 2007, Limits of arbitrage: Theory and evidence from the mortgage-backed securities market, Journal of Finance 62, 557-595.

Gabaix, Xavier, and Matteo Maggiori, 2015, International liquidity and exchange rate dynamics, Quarterly Journal of Economics 130, 1369-1420.

Gârleanu, Nicolae, Stavros Panageas, and Jianfeng Yu, forthcoming, Financial entanglement: A theory of incomplete integration, leverage, crashes, and contagion, American Economic Review .

Garleanu, Nicolae, Lasse Heje Pedersen, and Allen M Poteshman, 2009, Demand-based option pricing, Review of Financial Studies 22, 4259-4299.

Garleanu, Nicolae, and Lasse Pederson, 2011, Margin-based asset pricing and deviations from the law of one price, Review of Financial Studies 24, 1980-2022.

Geanakoplos, John, and Ana Fostel, 2008, Leverage cycles and the anxious economy, American Economic Review 98, 1211-244.

Gromb, Denis, and Dimitri Vayanos, 2002, Equilibrium and welfare in markets with financially constrained arbitrageurs, Journal of Financial Economics 66, 361-407. 
Gürkaynak, Refet S, Brian Sack, and Jonathan H Wright, 2007, The US treasury yield curve: 1961 to the present, Journal of Monetary Economics 54, 2291-2304.

Haddad, Valentin, and David Sraer, 2015, The banking view of bond risk premia, Working paper, Princeton and UC Berkeley.

Hanson, Samuel, Anil K. Kashyap, and Jeremy C. Stein, 2011, A macroprudential approach to financial regulation, Journal of Economic Perspectives 25, 3-28.

He, Zhiguo, In Gu Khang, and Arvind Krishnamurthy, 2010, Balance sheet adjustment in the 2008 crisis, IMF Economic Review 1, 118-156.

He, Zhiguo, and Arvind Krishnamurthy, 2012, A model of capital and crises, The Review of Economic Studies 79, 735-777.

He, Zhiguo, and Arvind Krishnamurthy, 2013, Intermediary asset pricing, American Economic Review 103, 732-70.

Heaton, John C., Deborah Lucas, and Robert L. McDonald, 2010, Is mark-to-market accounting destabilizing? analysis and implications for policy, Journal of Monetary Economics 57, 64-75, Carnegie-Rochester Conference Series on Public Policy: Credit Market Turmoil: Implications for Policy April 17-18, 2009.

Hodrick, Robert J, 1992, Dividend yields and expected stock returns: Alternative procedures for inference and measurement, Review of Financial studies 5, 357-386.

Holmstrom, Bengt, and Jean Tirole, 1997, Financial intermediation, loanable funds, and the real sector, Quarterly Journal of Economics .

Hong, Harrison, and Motohiro Yogo, 2012, What does futures market interest tell us about the macroeconomy and asset prices?, Journal of Financial Economics 105, 473-490.

Houston, J., and C. James, 1998, Do bank internal capital markets promote lending?, Journal of Banking and Finance 22, 899-918.

Houston, J., C. James, and D. Marcus, 1997, Capital market frictions and the role of internal capital markets in banking, Journal of Financial Economics 46, 135-164.

Kashyap, Anil K., Raghuram G. Rajan, and Jeremy C. Stein, 2008, Rethinking capital regulation, Federal Reserve Bank of Kansas City Symposium on Maintaining Stability in a Changing Financial System 431-471.

Kisin, Roni, and Asaf Manela, 2013, The shadow cost of bank capital requirements, Working paper.

Koijen, Ralph SJ, Tobias J Moskowitz, Lasse Heje Pedersen, and Evert B Vrugt, 2013, Carry, Working paper, NBER.

Koijen, Ralph S.J., and Motohiro Yogo, forthcoming, The cost of financial frictions for life insurers, American Economic Review .

Kondor, Peter, and Dimitri Vayanos, 2015, Liquidity risk and the dynamics of arbitrage capital, Working paper, LSE. 
Kyle, Albert S, and Wei Xiong, 2001, Contagion as a wealth effect, Journal of Finance 56, 14011440 .

Lettau, Martin, Matteo Maggiori, and Michael Weber, 2014, Conditional risk premia in currency markets and other asset classes, Journal of Financial Economics 114, 197-225.

Menkhoff, Lukas, Lucio Sarno, Maik Schmeling, and Andreas Schrimpf, 2012, Carry trades and global foreign exchange volatility, Journal of Finance 67, 681-718.

Milbradt, Konstantin, 2012, Level 3 assets: Booking profits and concealing losses, Review of Financial Studies 25, 55-95.

Mitchell, Mark, Lasse Pederson, and Todd Pulvino, 2007, Slow moving capital, American Economic Review, Papers and Proceedings 97, 215-220.

Mitchell, Mark, and Todd Pulvino, 2009, Arbitrage crashes and the speed of capital, Working paper, AQR Capital Management.

Moreira, Alan, and Alexi Savov, 2013, The macroeconomics of shadow banking, Working paper, Yale.

Muir, Tyler, 2014, Financial crises and risk premia, Working paper, Yale.

Nozawa, Yoshio, 2014, What drives the cross-section of credit spreads?: A variance decomposition approach, Working paper, University of Chicago.

Palhares, Diogo, 2013, Cash-flow maturity and risk premia in CDS markets, Working paper, University of Chicago.

Pástor, L'uboš, and Robert F Stambaugh, 2003, Liquidity risk and expected stock returns, Journal of Political Economy 111, 642-685.

Pavlova, Anna, and Roberto Rigobon, 2007, Asset prices and exchange rates, Review of Financial Studies 20, 1139-1180.

Scharfstein, David S, and Jeremy C Stein, 2000, The dark side of internal capital markets: Divisional rent-seeking and inefficient investment, Journal of Finance 55, 2537-2564.

Shleifer, A., and R. W. Vishny, 1992, Liquidation values and debt capacity: A market equilibrium approach, Journal of Finance 47, 1343-1366.

Shleifer, Andrei, and Robert Vishny, 1997, The limits of arbitrage, Journal of Finance 52, 35-55.

Siriwardane, Emil, 2015, Concentrated capital losses and the pricing of corporate credit risk, Working paper, Harvard Business School.

Stein, Jeremy C, 1997, Internal capital markets and the competition for corporate resources, Journal of Finance 111-133.

Valukas, Anton R., 2010, Lehman brothers holdings inc. chapter 11 proceedings, Examiner report.

Vayanos, Dimitri, 2004, Flight to quality, flight to liquidity, and the pricing of risk, Working paper, NBER. 
Vissing-Jorgensen, Annette, 2002, Limited asset market participation and the elasticity of intertemporal substitution, Journal of Political Economy 110, 825-853.

Xiong, Wei, 2001, Convergence trading with wealth effects: an amplification mechanism in financial markets, Journal of Financial Economics 62, 247-292. 


\section{A Appendix}

The purpose of this appendix is to offer a general equilibrium framework to reconcile the empirical regularities documented in Adrian et al. (2014a) and our paper. For simplicity the model will be cast in a one-period setting, although given the "myopic" objective of agents (risk neutral and log preferences) the analysis will be valid in a dynamic setting. We do not solve for equilibrium asset prices. Instead, we focus on the implications of general equilibrium leverage patterns for heterogeneous financial sectors, taking as given some well-known equilibrium properties of statedependent asset pricing moments established in the literature. A version of this model was proposed in a conference discussion of our paper by Alexi Savov, to whom we are grateful for the suggestion.

The model combines the key features of He and Krishnamurthy (2012) and Brunnermeier and Pedersen (2009). There are three classes of agents. "Households" are assumed to only hold zero net supply riskless assets with an endogenous return of $r^{f}$, due to lack of sophistication or infinite risk-aversion. "Hedge funds" are risk-neutral but face a VaR constraint that binds in equilibrium, as in Adrian and Shin (2014). They are meant to represent the group of intermediaries (dealers and hedge funds) studied in Adrian et al. (2014a). "Banks" are risk-averse and have mean-variance preferences, with an absolute risk aversion of $\gamma$, following He and Krishnamurthy (2012), and correspond to the holding companies of primary dealers that our paper studies. Hedge funds and banks both actively trade in the risky asset market, which offers an endogenous return of $R$.

Of course, in practice holding companies are likely to include both proprietary trading and traditional banking businesses. ${ }^{41}$ And, in our framework, the financial health of the commercial banking sector matters for the equilibrium pricing of sophisticated financial assets if internal capital markets in holding companies are well-functioning.

Denote aggregate wealth by $W$. The wealth (net worth) of the hedge fund sector is denoted by $W^{H F} \equiv w^{H F} W^{\prime}$ and the wealth of bankers by $W^{B} \equiv w^{B} W$. The lower case symbols $w^{H F}$ and $w^{B}$ indicate the wealth fraction of each sector relative to the whole economy. Both dealers and banks can take on leverage, so that their asset positions $X^{j}$ may be greater than their net worth $W^{j}, j \in\{H F, B\}$. Denote the leverage choice as $\alpha^{j} \equiv \frac{X^{j}}{W^{j}}$ (assets over equity), and the resulting portfolio return by $R_{t+1}^{j}$. Then we have

$$
\frac{W_{t+1}^{j}}{W_{t}^{j}}=R_{t+1}^{j} \equiv r_{t+1}^{f}+\alpha_{i}\left(R_{t+1}-r_{t+1}^{f}\right), j \in\{H F, B\} .
$$

In our model, hedge funds solve

$$
\max _{\alpha_{H F}} \mathbb{E}_{t}\left[W_{t+1}^{H F}\right] \text { s.t. } \operatorname{Var}_{t}\left(R_{t+1}^{H F}\right)=\alpha_{H F}^{2} \sigma_{R, t}^{2} \leq \bar{\sigma}^{2},
$$

where $\sigma_{R, t}^{2} \equiv \operatorname{Var}_{t}\left(R_{t+1}\right)$ is the conditional volatility of the risky asset and $\bar{\sigma}^{2}$ is the maximum allowable risk in the hedge fund's position. Assuming that $\mathbb{E}_{t}\left(R_{t+1}-r_{t+1}^{f}\right)>0$ so that the risky asset offers a strictly positive risk premium in equilibrium, the solution to (A.2) is $\alpha_{H F}=\frac{\bar{\sigma}}{\sigma_{R, t}}$. On the other hand, given (A.1) bankers solve problem

$$
\max _{\alpha_{B}} \mathbb{E}_{t}\left[W_{t+1}^{B}\right]-\frac{\gamma}{2} \operatorname{Var}_{t}\left(W_{t+1}^{B}\right)
$$

whose solution is

$$
\alpha_{B}=\frac{1}{\gamma} \frac{\mathbb{E}_{t}\left(R_{t+1}-r_{t+1}^{f}\right)}{\sigma_{R, t}^{2}}
$$

Finally, we have the market clearing condition. Because only hedge funds and banks can hold risky assets, we have

$$
w^{B} \alpha_{B}+w^{H F} \alpha_{H F}=1
$$

We first explain how our model is able to generate leverage patterns found in the data. The solution for $\alpha_{H F}$ shows that hedge funds have lower leverage in bad states, when $\sigma_{R, t}$ tends to be high (He and Krishnamurthy (2012), Brunnermeier and Pedersen (2009)). That is, hedge funds have procyclical leverage. Also, because both hedge funds and banks take on leverage (and households save) in equilibrium, it is easy to show that their wealth shares $w_{B}$ and $w_{H F}$ go down following negative fundamental shocks. ${ }^{42}$ Combining the two results above, (A.3) implies that $\alpha_{B}=\frac{1-w^{D} \alpha_{D}}{w_{B}}$ increases in bad states, so banks have countercyclical leverage in equilibrium. Intuitively, this

\footnotetext{
${ }^{41}$ The latter is more likely to face equity-based constraints. Given deposit guarantees, the US commercial banking system is able to attract demand deposits even during severe crises like that in 2008.

${ }^{42}$ Take banks as an example. Leverage implies that $\frac{d W^{B}}{W^{B}}<\frac{d W}{W}$ following a negative shock. I.e., banks experience a worse equity return than the aggregate market. But $\frac{d W^{B}}{W^{B}}<\frac{d W}{W}$ is equivalent to $d w^{B}=d\left(\frac{W^{B}}{W}\right)<0$.
} 
correponds to the situation in which hedge funds sell their assets to commercial banks after negative shocks, and the leverages of these two sectors move in the opposite directions. This pattern is empirically supported by He et al. (2010) and Ang et al. (2011).

We briefly discuss how we map the pricing kernel in this simple model to the one used in our paper. In this simple model banks are always marginal in pricing any asset. Given their mean variance preferences, the "CAPM" type of result holds if one use the banks' equity return as the pricing kernel, similar to He and Krishnamurthy (2012). Naturally, the leverage of hedge funds can also be used to represent the pricing kernel, as in Adrian et al. (2014a), because hedge fund leverage $\alpha_{D}$ perfectly (negatively) correlates with bank equity. 


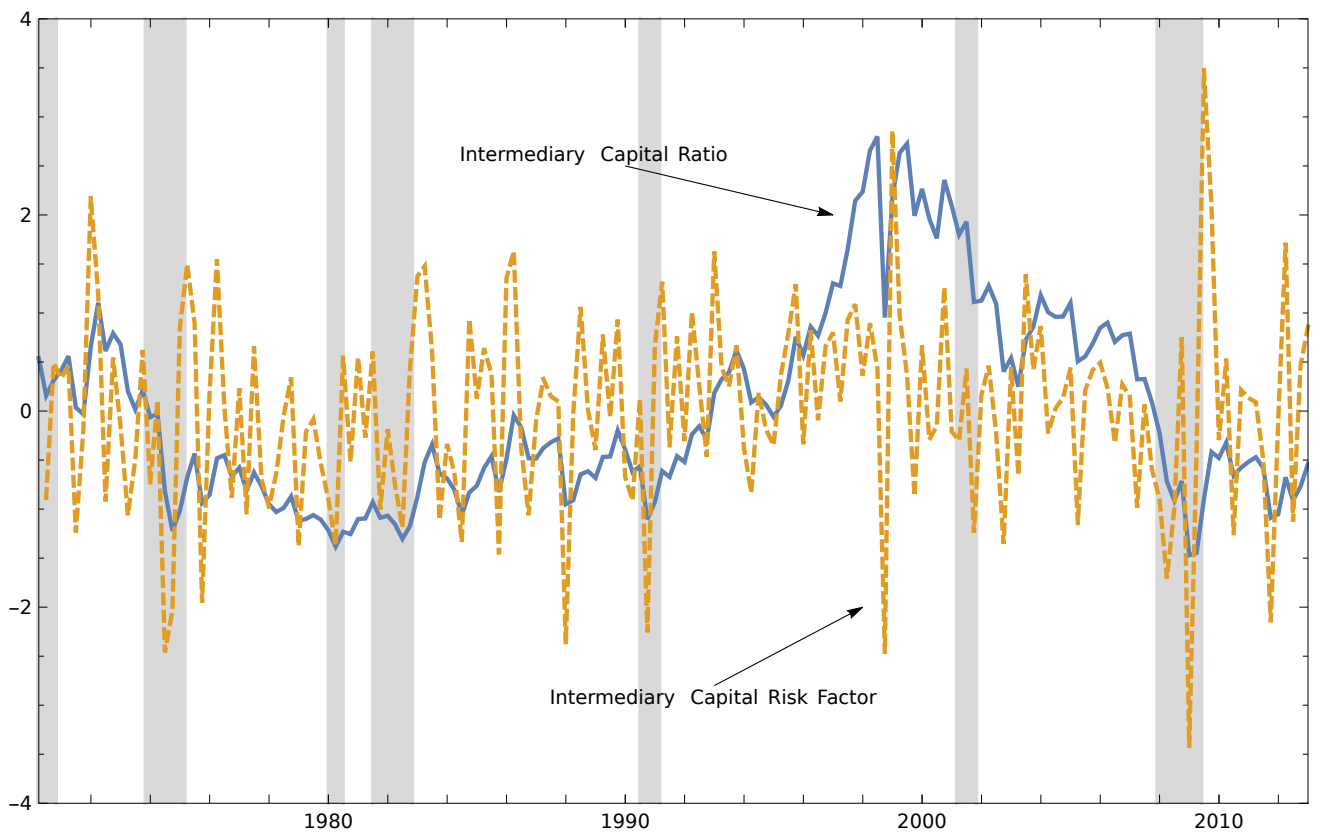

Figure 1: Intermediary Capital Ratio and Risk Factor

Intermediary capital risk factor (dashed line) is $\mathrm{AR}(1)$ innovations to the market-based capital ratio of primary dealers (solid line), scaled by the lagged capital ratio. Both time-series are standardized to zero mean and unit variance for illustration. The quarterly sample is 1970Q1-2012Q4. The intermediary capital ratio is the ratio of total market equity to total market assets (book debt plus market equity) of primary dealer holding companies. Shaded regions indicate NBER recessions. 


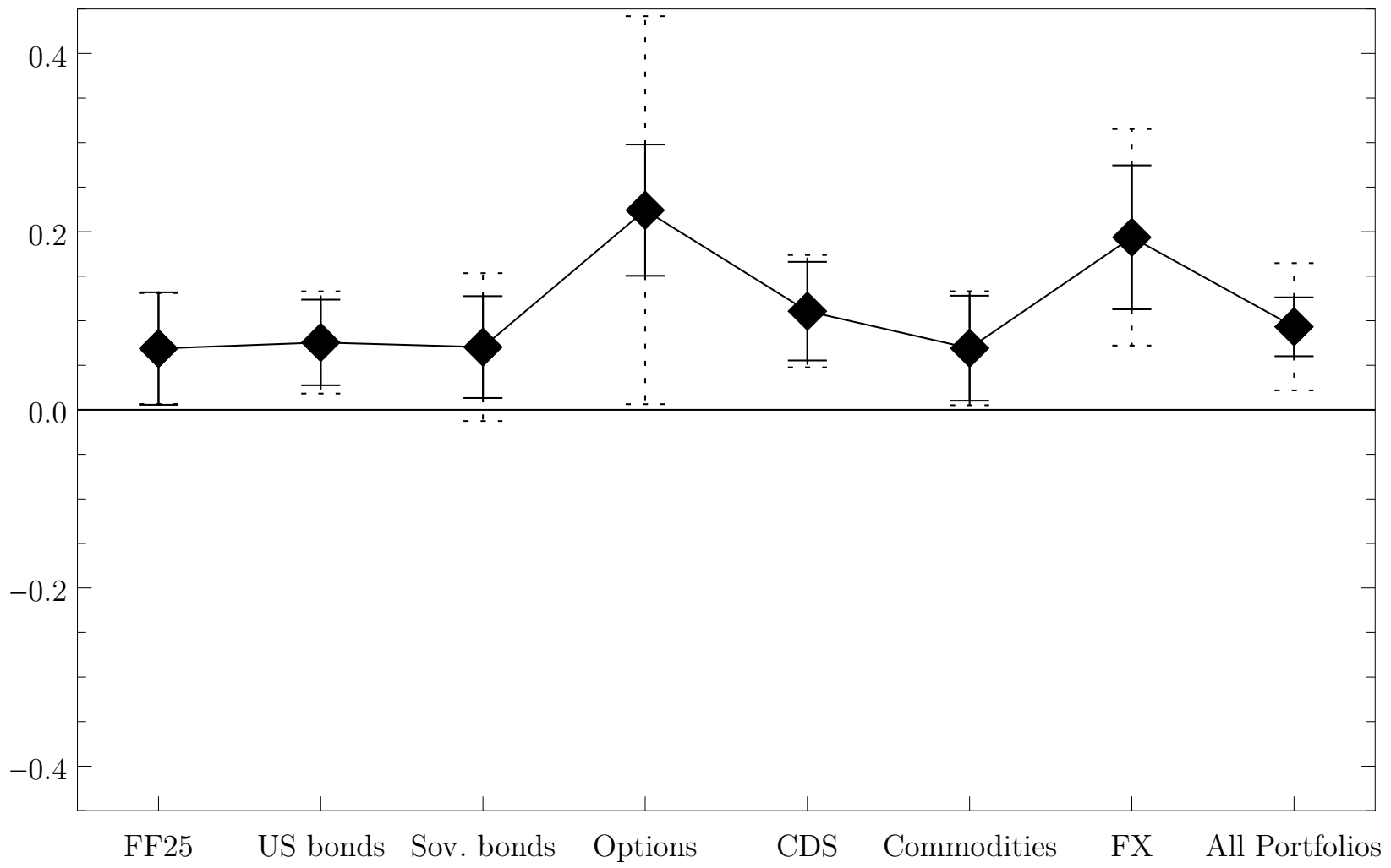

Figure 2: Intermediary Capital Risk Price $\lambda_{\eta}$ Estimates by Asset Class

Risk price estimates for shocks to the intermediary capital ratio, from a two-factor model that includes the excess return on the market. Risk prices are the mean slopes of period-by-period cross-sectional regressions of portfolio excess returns on risk exposures (betas). Betas are estimated in a first-stage time-series regression. The quarterly sample is 1970Q1-2012Q4. The intermediary capital ratio is the ratio of total market equity to total market assets (book debt plus market equity) of primary dealer holding companies. Shocks to capital ratio are defined as $\mathrm{AR}(1)$ innovations in the capital ratio, scaled by the lagged capital ratio. The AEM leverage factor, defined as the seasonally adjusted growth rate in broker-dealer book leverage level from Flow of Funds, is from its authors. Solid error bars are the $95 \%$ confidence interval around the point estimates, calculated using Fama-MacBeth standard errors that adjust for cross-asset correlation in the residuals. Dotted error bars use the more robust GMM standard errors that additionally correct for estimation error of the time-series betas. 


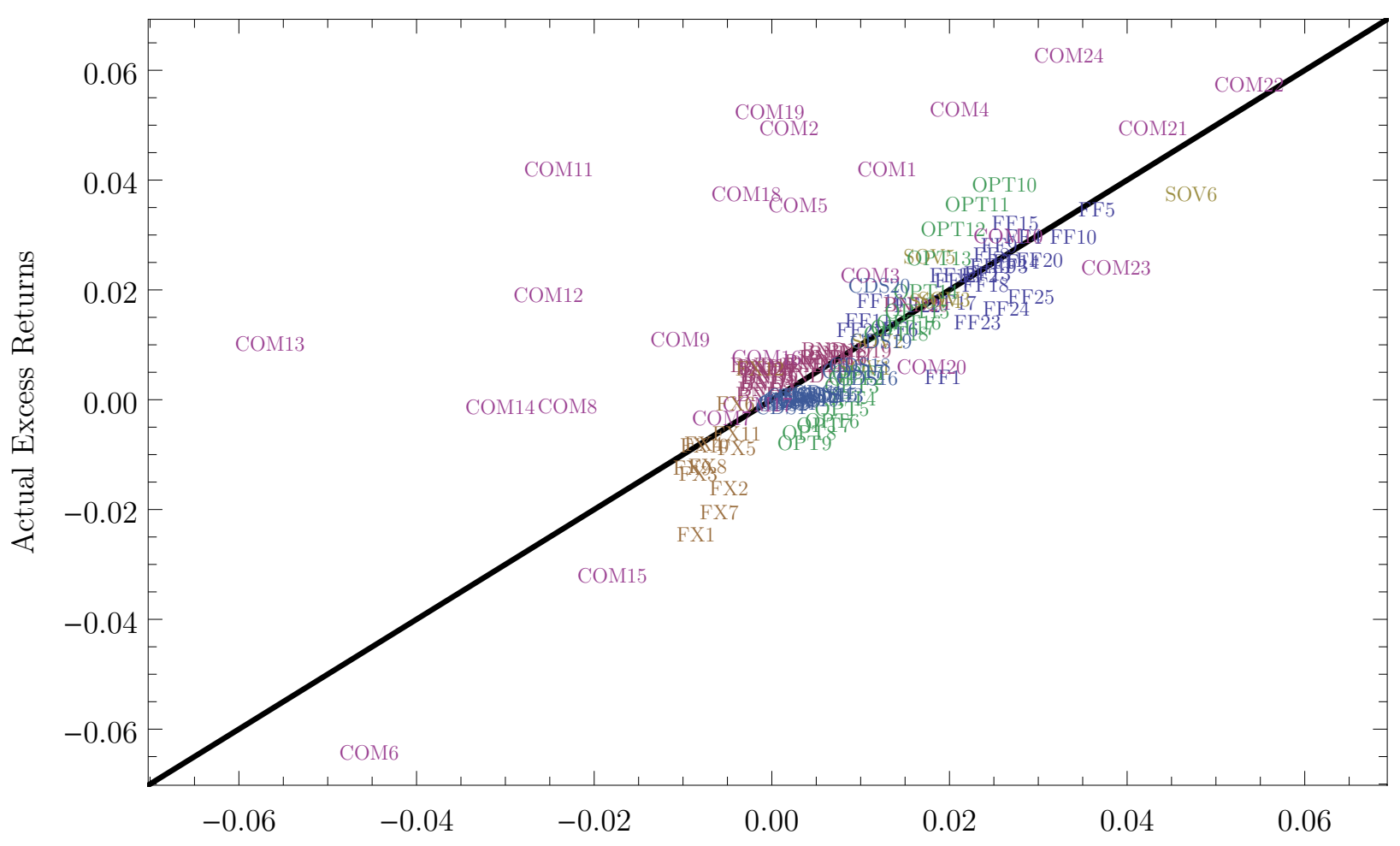

Predicted Excess Returns

Figure 3: Pricing Errors: All Portfolios

Actual average excess returns on all tested portfolios versus predicted expected returns using their risk exposures (betas) with respect to shocks to the intermediary capital ratio and the excess return on the market. Test portfolios are abbreviated based on their asset class: equities (FF), US bonds (BND), foreign sovereign bonds (SOV), options (OPT), CDS, commodities (COM), and foreign exchange (FX). Distance from the 45 degree line represents pricing errors (alphas). Betas are estimated in a first-stage time-series regression. The quarterly sample is 1970Q1-2012Q4. The intermediary capital ratio is the ratio of total market equity to total market assets (book debt plus market equity) of primary dealer holding companies. Shocks to capital ratio are defined as $\mathrm{AR}(1)$ innovations in the capital ratio, scaled by the lagged capital ratio. 


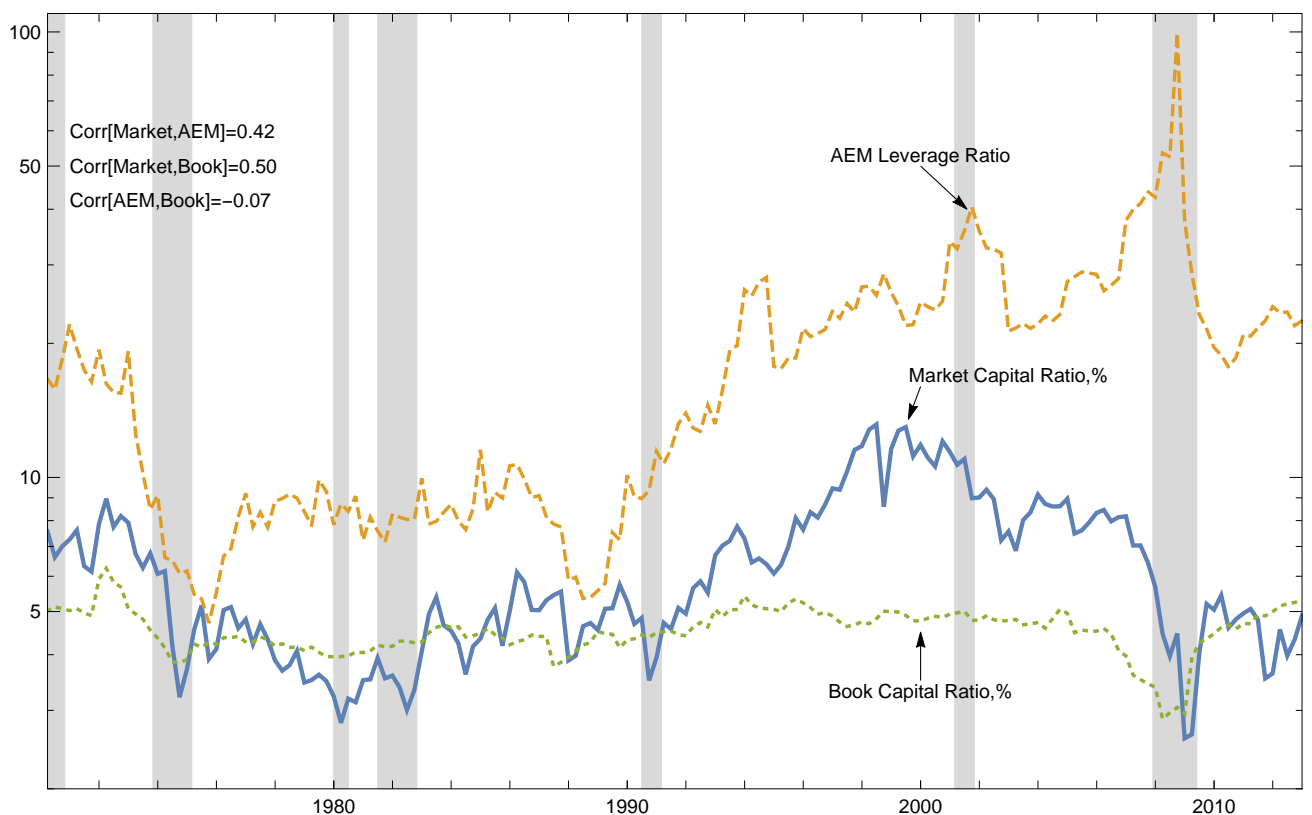

(a) Capital and Leverage Ratios (Levels)

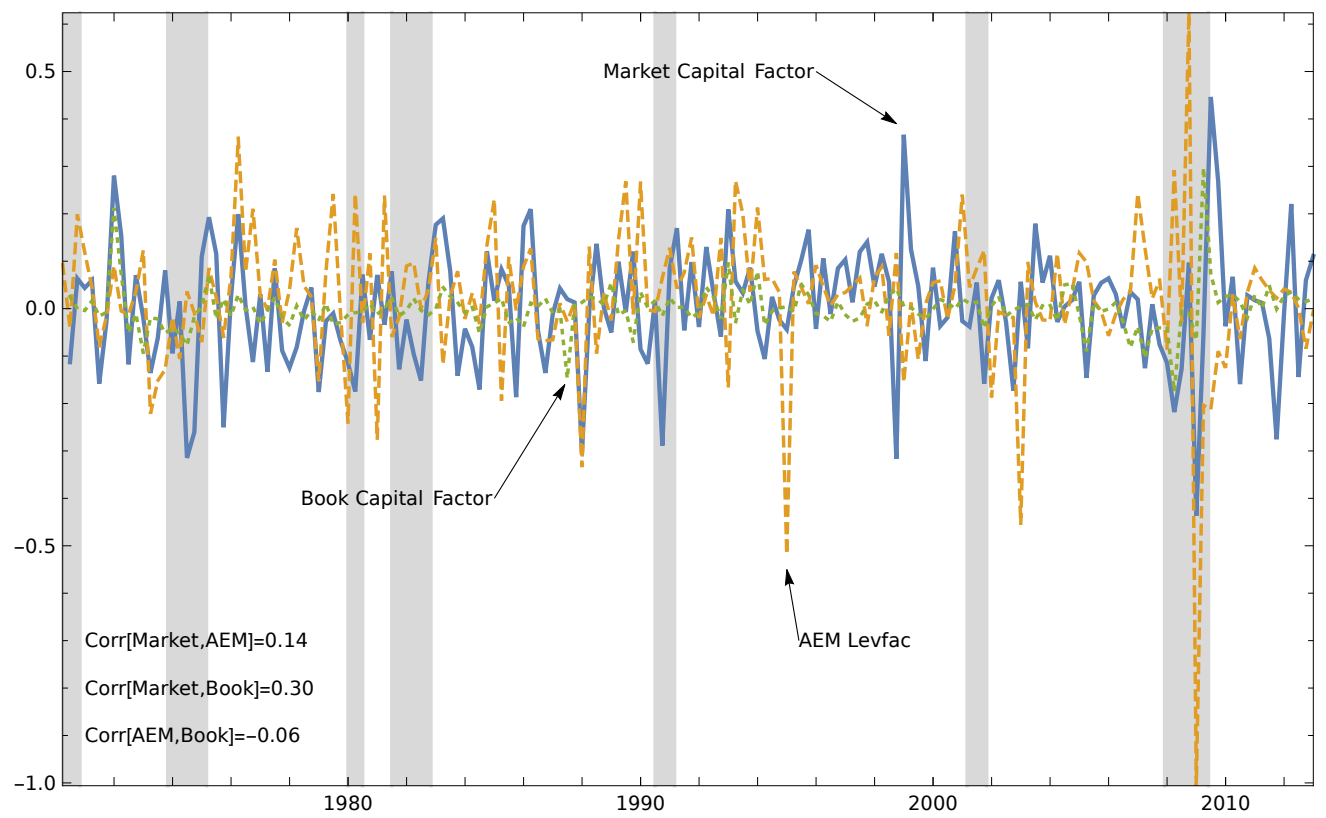

(b) Risk Factors (Innovations)

Figure 4: Intermediary Capital Measures Comparison

Sub-Figure (a) compares our main state variable of interest, the aggregate market-based capital ratio of NY Fed primary dealers with other measures of intermediary capital. Market capital ratio at $t$ is defined as $\frac{\sum_{i} \text { marketequity }}{\Sigma_{i}\left(\text { marketequity }_{i t}+\text { bookdebt }_{i t}\right)}$, where market equity is outstanding shares multiplying stock price, and book debt is total asset minus common equity $A T-C E Q$. Book capital ratio simply replaces marketequity with bookequity $y_{t}$ in this calculation. AEM leverage ratio is the leverage ratio of the broker-dealer sector used by Adrian et al. (2014a), constructed from Federal Reserve Z.1 security brokers and dealers series: Total Financial Assets (FL664090005) divided by Total Financial Assets (FL664090005) less Total Liabilities (FL664190005). In Sub-Figure (a), the capital ratios are in the scale of percentage points (i.e., 5 means 5\%). Sub-Figure (b) draws a similar comparison for the risk factors (innovations in the state variables). Our main asset pricing factor is $\mathrm{AR}(1)$ innovations to the market-based capital ratio of primary dealers, scaled by the lagged capital ratio. The quarterly sample is 1970Q1-2012Q4. The AEM leverage factor, defined as the seasonally adjusted growth rate in broker-dealer book leverage level from Flow of Funds, is from its authors. Shaded regions indicate NBER recessions. 


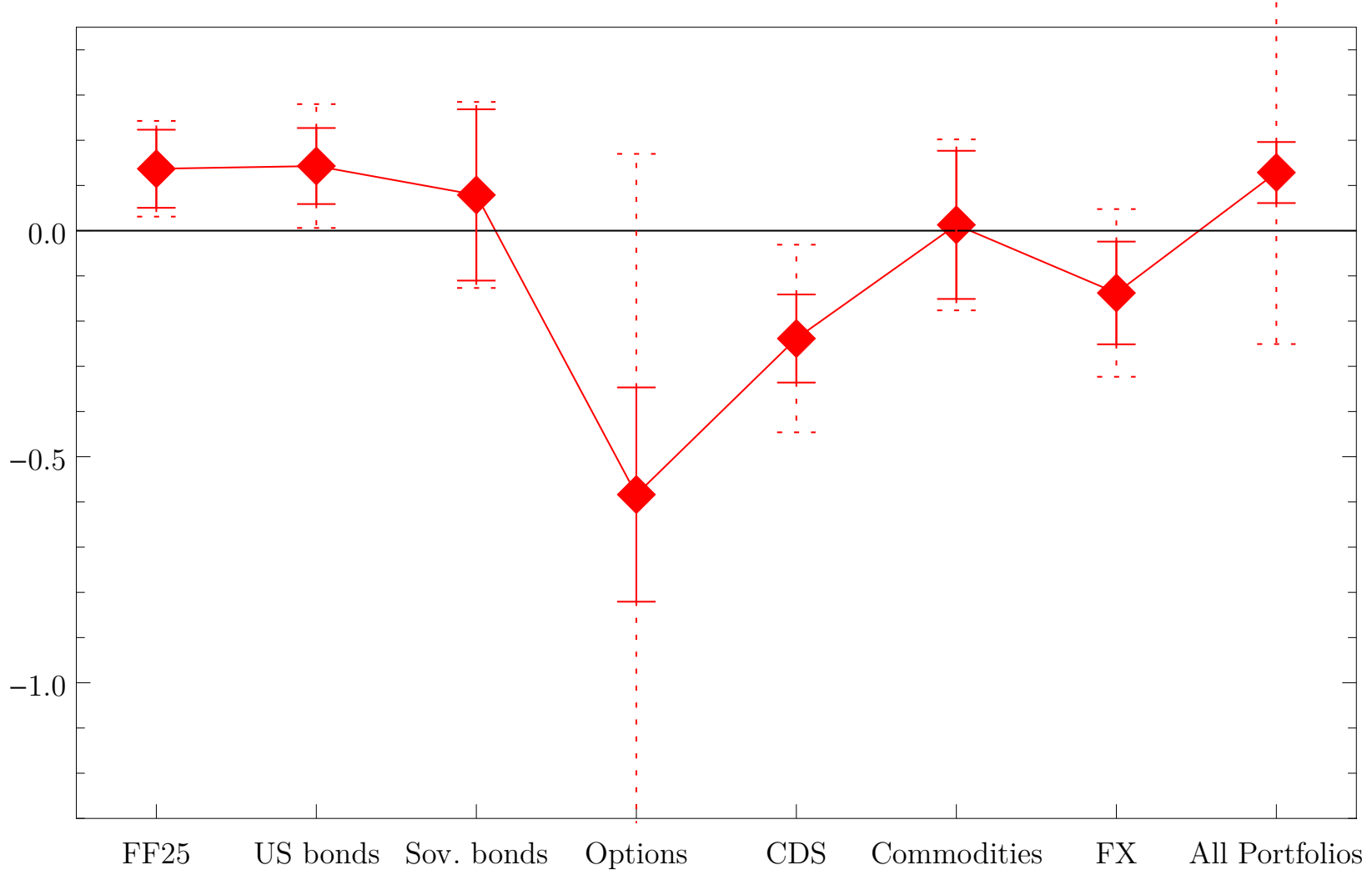

Figure 5: AEM Leverage Factor

Risk price estimates for shocks to the Adrian et al. (2014a) leverage factor (AEM), from a two-factor model that includes the excess return on the market. Risk prices are the mean slopes of period-by-period crosssectional regressions of portfolio excess returns on risk exposures (betas). Betas are estimated in a first-stage time-series regression. The quarterly sample is 1970Q1-2012Q4. The intermediary capital ratio is the ratio of total market equity to total market assets (book debt plus market equity) of primary dealer holding companies. Shocks to capital ratio are defined as AR(1) innovations in the capital ratio, scaled by the lagged capital ratio. The AEM leverage factor, defined as the seasonally adjusted growth rate in broker-dealer book leverage level from Flow of Funds, is from its authors. Solid error bars are the $95 \%$ confidence interval around the point estimates, calculated using Fama-MacBeth standard errors that adjust for cross-asset correlation in the residuals. Dotted error bars use the more robust GMM standard errors that additionally correct for estimation error of the time-series betas. 


\begin{tabular}{llr}
\hline Primary Dealer & Holding Company & Start Date \\
\hline Goldman, Sachs \& Co. & Goldman Sachs Group, Inc., The & $12 / 4 / 1974$ \\
Barclays Capital Inc. & Barclays PLC & $4 / 1 / 1998$ \\
HSBC Securities (USA) Inc. & HSBC Holdings PLC & $6 / 1 / 1999$ \\
BNP Paribas Securities Corp. & BNP Paribas & $9 / 15 / 2000$ \\
Deutsche Bank Securities Inc. & Deutsche Bank AG & $3 / 30 / 2002$ \\
Mizuho Securities USA Inc. & Mizuho Financial Group, Inc. & $4 / 1 / 2002$ \\
Citigroup Global Markets Inc. & Citigroup Inc. & $4 / 7 / 2003$ \\
UBS Securities LLC & UBS AG & $6 / 9 / 2003$ \\
Credit Suisse Securities (USA) LLC & Credit Suisse Group AG & $1 / 16 / 2006$ \\
Cantor Fitzgerald \& Co. & Cantor Fitzgerald \& Company & $8 / 1 / 2006$ \\
RBS Securities Inc. & Royal Bank Of Scotland Group PLC, The & $4 / 1 / 2009$ \\
Nomura Securities International,Inc & Nomura Holdings, Inc. & $7 / 27 / 2009$ \\
Daiwa Capital Markets America Inc. & Daiwa Securities Group Inc. (Japan) & $4 / 1 / 2010$ \\
J.P. Morgan Securities LLC & JPMorgan Chase \& Co. & $9 / 1 / 2010$ \\
Merrill Lynch, Pierce, Fenner \& Smith & Bank Of America Corporation & $11 / 1 / 2010$ \\
RBC Capital Markets, LLC & Royal Bank Holding Inc. & $11 / 1 / 2010$ \\
SG Americas Securities, LLC & Societe Generale & $2 / 2 / 2011$ \\
Morgan Stanley \& Co. LLC & Morgan Stanley & $5 / 31 / 2011$ \\
Bank Of Nova Scotia, NY Agency & Bank Of Nova Scotia, The & $10 / 4 / 2011$ \\
BMO Capital Markets Corp. & Bank Of Montreal & $10 / 4 / 2011$ \\
Jefferies LLC & Jefferies LLC & $3 / 1 / 2013$ \\
TD Securities (USA) LLC & Toronto-dominion Bank, The & $2 / 11 / 2014$ \\
\hline & &
\end{tabular}

Table 1: Primary Dealers as of February 11, 2014

Primary dealers, as designated by the New York Fed serve as its trading counterparties as it implements monetary policy. Primary dealers are obliged to: (i) participate consistently in open market operations to carry out US monetary policy; and (ii) provide the NY Fed's trading desk with market information and analysis. Primary dealers are also required to participate in all US government debt auctions and to make reasonable markets for the NY Fed. From 1960 to 2014 a total of 168 dealers were designated as primary ones, some of whom lost this designation previously. See http://www.newyorkfed.org/markets/primarydealers.html for current and historical lists of primary dealers. 


\begin{tabular}{|c|c|c|c|c|c|c|c|c|c|c|c|c|}
\hline & \multicolumn{3}{|c|}{ Total Assets } & \multicolumn{3}{|c|}{ Book Debt } & \multicolumn{3}{|c|}{ Book Equity } & \multicolumn{3}{|c|}{ Market Equity } \\
\hline & $\mathrm{BD}$ & Banks & Cmpust. & $\mathrm{BD}$ & Banks & Cmpust. & $\mathrm{BD}$ & Banks & Cmpust. & $\mathrm{BD}$ & Banks & Cmpust. \\
\hline 1960-2012 & 0.959 & 0.596 & 0.240 & 0.960 & 0.602 & 0.280 & 0.939 & 0.514 & 0.079 & 0.911 & 0.435 & 0.026 \\
\hline 1960-1990 & 0.997 & 0.635 & 0.266 & 0.998 & 0.639 & 0.305 & 0.988 & 0.568 & 0.095 & 0.961 & 0.447 & 0.015 \\
\hline 1990-2012 & 0.914 & 0.543 & 0.202 & 0.916 & 0.550 & 0.240 & 0.883 & 0.444 & 0.058 & 0.848 & 0.419 & 0.039 \\
\hline
\end{tabular}

\section{Table 2: Primary Dealers as Representative Financial Intermediaries}

Average sizes of prime dealers relative to all broker-dealers (BD), all banks (Banks), and all firms in Compustat (Cmptust). At the end of each month, we calculate the total assets (and book debt, book equity, and market equity) of prime dealers and divide them by the total for the comparison group. To make the samples comparable, we focus in this table only on US-based primary dealer holding companies that are in the CRSP-Compustat data. We report the time series average of this ratio in each sample period. 


\begin{tabular}{lrrr}
\hline & Market Capital & Book Capital & AEM Leverage \\
\cline { 2 - 4 } Market Capital & 1.00 & 0.50 & 0.42 \\
Book Capital & & 1.00 & -0.07 \\
AEM Leverage & & & 1.00 \\
\hline E/P & -0.83 & -0.38 & -0.64 \\
Unemployment & -0.63 & -0.10 & -0.33 \\
GDP & 0.18 & 0.32 & -0.23 \\
Financial Conditions & -0.48 & -0.53 & -0.19 \\
Market Volatility & -0.06 & -0.31 & 0.33 \\
\hline
\end{tabular}

(a) Correlations of Levels

\begin{tabular}{lccr}
\hline & Market Capital Factor & Book Capital Factor & AEM Leverage Factor \\
\cline { 2 - 4 } Market Capital Factor & 1.00 & 0.30 & 0.14 \\
Book Capital Factor & & 1.00 & -0.06 \\
AEM Leverage Factor & & & 1.00 \\
\hline E/P Growth & -0.75 & -0.10 & -0.18 \\
Unemployment Growth & -0.05 & 0.12 & -0.08 \\
GDP Growth & 0.20 & 0.09 & 0.04 \\
Financial Conditions Growth & -0.38 & -0.29 & -0.06 \\
Market Volatility Growth & -0.49 & -0.18 & -0.08 \\
\hline
\end{tabular}

(b) Correlations of Factors

Table 3: Pair-wise Correlations

Time-series pair-wise correlations over the 1970Q1-2012Q4 sample. Market Capital (ratio) is defined as the ratio of total market equity to total market assets (book debt plus market equity) of primary dealer holding companies, constructed using CRSP-Compustat and Datastream data. Market equity is outstanding shares multiplying stock price, and book debt is total asset minus common equity $A T-C E Q$. Market Capital Factor is our main asset pricing factor defined as $\mathrm{AR}(1)$ innovations to the market capital ratio, scaled by the lagged capital ratio. Book Capital and Book Capital Factor are similarly defined, but uses book equity instead of market equity. The AEM implied capital is the inverse of broker-dealer book leverage from Flow of Funds used in AEM, and the AEM leverage factor (LevFac) is from its authors which is defined as the seasonally adjusted growth rate in broker-dealer book leverage from Flow of Funds. Correlation for factors are with growth (log change) of the earnings-to-price ratio, Unemployment, GDP, the Chicago Fed National Financial Conditions Index (high level means poor financial conditions), or realized volatility of CRSP value-weighted stock index. 


\begin{tabular}{lcrrrrrrr}
\hline & FF25 & US bonds & Sov. bonds & Options & CDS & Commod. & FX & All Ptfs. \\
\hline $\operatorname{Mean}\left(\mu_{i}-r_{f}\right)$ & 0.02 & 0.01 & 0.02 & 0.01 & 0.00 & 0.02 & -0.01 & 0.01 \\
$\operatorname{Std}\left(\mu_{i}-r_{f}\right)$ & 0.01 & 0.00 & 0.01 & 0.01 & 0.01 & 0.03 & 0.01 & 0.02 \\
$\operatorname{Mean}\left(\beta_{i, \eta}\right)$ & 0.07 & 0.03 & 0.22 & -0.01 & 0.06 & -0.09 & -0.08 & 0.01 \\
$\operatorname{Std}\left(\beta_{i, \eta}\right)$ & 0.11 & 0.04 & 0.14 & 0.05 & 0.04 & 0.32 & 0.03 & 0.17 \\
$\operatorname{Mean}\left(\beta_{i, W}\right)$ & 1.02 & 0.06 & 0.09 & 0.83 & 0.04 & 0.60 & 0.15 & 0.48 \\
$\operatorname{Std}\left(\beta_{i, W}\right)$ & 0.30 & 0.07 & 0.12 & 0.11 & 0.03 & 0.34 & 0.04 & 0.45 \\
$\operatorname{Mean}\left(R^{2}\right)$ & 0.78 & 0.09 & 0.30 & 0.79 & 0.63 & 0.15 & 0.04 & 0.43 \\
Assets & 25 & 20 & 6 & 18 & 20 & 24 & 12 & 125 \\
Quarters & 172 & 148 & 65 & 103 & 47 & 42 & 135 & 172 \\
\hline
\end{tabular}

Table 4: Expected Returns and Risk Exposure by Asset Class

Average excess returns $\mu_{i}-r_{f}$, and risk exposures (betas) to shocks to the intermediary capital ratio, denoted by $\beta_{i, \eta}$, and to the excess return on the market $\left(\beta_{i, W}\right)$, across portfolios in each asset class. The quarterly sample is 1970Q1-2012Q4. The intermediary capital ratio is the ratio of total market equity to total market assets (book debt plus market equity) of primary dealer holding companies. Shocks to capital ratio are defined as AR(1) innovations in the capital ratio, scaled by the lagged capital ratio. The AEM leverage factor, defined as the seasonally adjusted growth rate in broker-dealer book leverage level from Flow of Funds, is from its authors. Betas are estimated in a first-stage time-series regression. 


\begin{tabular}{ccccccccc}
\hline & FF25 & US bonds & Sov. bonds & Options & CDS & Commod. & FX & All Ptfs. \\
\hline Capital & 0.07 & 0.08 & 0.07 & 0.22 & 0.11 & 0.07 & 0.19 & 0.09 \\
t-FM & $(2.14)$ & $(3.08)$ & $(2.41)$ & $(5.96)$ & $(3.92)$ & $(2.30)$ & $(4.70)$ & $(5.53)$ \\
t-GMM & $(2.16)$ & $(2.58)$ & $(1.66)$ & $(2.02)$ & $(3.44)$ & $(2.12)$ & $(3.12)$ & $(2.56)$ \\
Market & 0.01 & 0.01 & 0.01 & 0.03 & 0.01 & 0.03 & 0.10 & 0.02 \\
t-FM & $(0.81)$ & $(1.13)$ & $(0.49)$ & $(1.63)$ & $(0.64)$ & $(1.46)$ & $(3.38)$ & $(1.98)$ \\
t-GMM & $(0.78)$ & $(0.82)$ & $(0.32)$ & $(0.67)$ & $(0.41)$ & $(1.29)$ & $(2.17)$ & $(0.95)$ \\
Intercept & 0.00 & 0.00 & 0.00 & -0.01 & -0.00 & 0.01 & -0.01 & -0.00 \\
t-FM & $(0.37)$ & $(2.15)$ & $(0.56)$ & $(-0.87)$ & $(-5.69)$ & $(0.85)$ & $(-1.76)$ & $(-0.19)$ \\
t-GMM & $(0.36)$ & $(1.44)$ & $(0.33)$ & $(-0.31)$ & $(-2.77)$ & $(0.72)$ & $(-0.83)$ & $(-0.14)$ \\
$R^{2}$ & 0.53 & 0.84 & 0.81 & 0.99 & 0.67 & 0.44 & 0.53 & 0.45 \\
MAPE, \% & 0.34 & 0.13 & 0.32 & 0.14 & 0.18 & 1.84 & 0.44 & 0.85 \\
RRA & 4.21 & 4.63 & 4.32 & 13.73 & 6.79 & 4.24 & 11.86 & 5.71 \\
Assets & 25 & 20 & 6 & 18 & 20 & 24 & 12 & 125 \\
Quarters & 172 & 148 & 65 & 103 & 47 & 42 & 135 & 172 \\
\hline
\end{tabular}

Table 5: Cross-sectional Asset Pricing Tests by Asset Class

Risk price estimates for shocks to the intermediary capital ratio and the excess return on the market. The capital ratio is defined as the ratio of total market equity to total market assets (book debt plus market equity) of primary dealer holding companies. Risk prices are the mean slopes of period-by-period crosssectional regressions of portfolio excess returns on risk exposures (betas). Betas are estimated in a first-stage time-series regression. The quarterly sample is 1970Q1-2012Q4. Mean absolute pricing error (MAPE) is in percentage terms. Relative risk aversion (RRA) is the price of intermediary capital risk factor, scaled by its variance. Fama-MacBeth t-statistics (t-FM) adjust for cross-asset correlation in the residuals. The more robust GMM t-statistics (t-GMM) additionally correct for estimation error of the time-series betas. 


\begin{tabular}{ccccccccc}
\hline & FF25 & US bonds & Sov. bonds & Options & CDS & Commod. & FX & All Ptfs. \\
\hline Capital & 0.16 & 0.12 & 0.43 & -0.86 & 0.67 & -0.01 & -0.03 & 0.08 \\
t-FM & $(2.62)$ & $(0.91)$ & $(1.81)$ & $(-4.89)$ & $(5.22)$ & $(-0.05)$ & $(-0.17)$ & $(1.44)$ \\
t-GMM & $(2.45)$ & $(0.69)$ & $(1.24)$ & $(-2.33)$ & $(2.55)$ & $(-0.04)$ & $(-0.12)$ & $(0.52)$ \\
Market & -0.02 & 0.04 & 0.06 & -0.07 & 0.07 & 0.05 & 0.12 & 0.02 \\
t-FM & $(-1.92)$ & $(3.24)$ & $(2.61)$ & $(-2.45)$ & $(3.62)$ & $(2.18)$ & $(3.45)$ & $(2.03)$ \\
t-GMM & $(-1.66)$ & $(2.51)$ & $(1.74)$ & $(-1.20)$ & $(2.99)$ & $(1.81)$ & $(2.45)$ & $(0.93)$ \\
Intercept & 0.04 & 0.00 & 0.00 & 0.07 & -0.00 & -0.00 & -0.02 & 0.00 \\
t-FM & $(3.83)$ & $(1.75)$ & $(0.43)$ & $(3.26)$ & $(-5.87)$ & $(-0.20)$ & $(-4.75)$ & $(0.64)$ \\
t-GMM & $(3.36)$ & $(1.49)$ & $(0.22)$ & $(1.48)$ & $(-2.72)$ & $(-0.19)$ & $(-2.14)$ & $(0.76)$ \\
$R^{2}$ & 0.54 & 0.82 & 0.81 & 0.97 & 0.86 & 0.38 & 0.50 & 0.38 \\
MAPE, $\%$ & 0.36 & 0.14 & 0.32 & 0.23 & 0.15 & 1.92 & 0.45 & 1.08 \\
Assets & 25 & 20 & 6 & 18 & 20 & 24 & 12 & 125 \\
Quarters & 165 & 148 & 65 & 103 & 47 & 42 & 135 & 172 \\
\hline
\end{tabular}

(a) Non-Primary Broker-Dealers

\begin{tabular}{ccccccccc}
\hline & FF25 & US bonds & Sov. bonds & Options & CDS & Commod. & FX & All Ptfs. \\
\hline Capital & -0.01 & 0.03 & 0.02 & 0.04 & 0.00 & 0.02 & 0.07 & -0.00 \\
t-FM & $(-0.70)$ & $(3.76)$ & $(2.21)$ & $(3.99)$ & $(0.34)$ & $(2.13)$ & $(5.17)$ & $(-0.04)$ \\
t-GMM & $(-0.70)$ & $(2.90)$ & $(1.42)$ & $(2.01)$ & $(0.15)$ & $(1.83)$ & $(2.16)$ & $(-0.04)$ \\
Market & -0.01 & 0.03 & 0.02 & 0.09 & 0.09 & 0.05 & 0.14 & 0.02 \\
t-FM & $(-0.85)$ & $(2.51)$ & $(1.00)$ & $(5.15)$ & $(4.32)$ & $(2.16)$ & $(5.42)$ & $(2.19)$ \\
t-GMM & $(-0.83)$ & $(1.72)$ & $(0.88)$ & $(3.09)$ & $(1.78)$ & $(1.87)$ & $(2.78)$ & $(1.08)$ \\
Intercept & 0.03 & 0.00 & 0.02 & -0.06 & -0.00 & -0.00 & -0.02 & 0.00 \\
t-FM & $(3.18)$ & $(1.96)$ & $(1.59)$ & $(-5.09)$ & $(-4.13)$ & $(-0.02)$ & $(-4.64)$ & $(0.20)$ \\
t-GMM & $(3.09)$ & $(1.08)$ & $(1.57)$ & $(-2.99)$ & $(-1.38)$ & $(-0.02)$ & $(-1.55)$ & $(0.18)$ \\
$R^{2}$ & 0.08 & 0.85 & 0.74 & 0.91 & 0.90 & 0.38 & 0.51 & 0.36 \\
MAPE, $\%$ & 0.54 & 0.12 & 0.46 & 0.38 & 0.13 & 1.93 & 0.46 & 1.31 \\
RRA & -3.68 & 10.32 & 5.40 & 15.07 & 0.93 & 6.34 & 24.70 & -0.11 \\
Assets & 25 & 20 & 6 & 18 & 20 & 24 & 12 & 125 \\
Quarters & 172 & 148 & 65 & 103 & 47 & 42 & 135 & 172 \\
\hline
\end{tabular}

(b) Non-Banks

Table 6: Primary Dealers are Special: a Placebo Test

Risk price estimates for shocks to the capital ratios of complementary sets of financial intermediaries, and the excess return on the market. Panel (a) examines non-primary dealers defined as US firms in the brokerdealer SIC groups $(6211,6221)$ that are not in the NY Fed primary dealer list. Panel (b) examines non-banks defined as US firms with an SIC code that does not start with 6 . Risk prices are the mean slopes of period-byperiod cross-sectional regressions of portfolio excess returns on risk exposures (betas). Betas are estimated in a first-stage time-series regression. The quarterly sample is 1970Q1-2012Q4. The intermediary capital ratio is the ratio of total market equity to total market assets (book debt plus market equity) of primary dealer holding companies. Shocks to capital ratio are defined as AR(1) innovations in the capital ratio, scaled by the lagged capital ratio. The AEM leverage factor, defined as the seasonally adjusted growth rate in brokerdealer book leverage level from Flow of Funds, is from its authors. Mean absolute pricing error (MAPE) is in percentage terms. Relative risk aversion (RRA) is the price of intermediary capital risk factor, scaled by its variance. Fama-MacBeth t-statistics (t-FM) adjust for cross-asset correlation in the residuals. The more robust GMM t-statistics (t-GMM) additionally correct for estimation error of the time-series betas. 


\begin{tabular}{lcccccccc}
\hline & FF25 & US bonds & Sov. bonds & Options & CDS & Commod. & FX & All Ptfs. \\
\hline ME & 0.07 & 0.05 & 0.05 & 0.14 & 0.06 & 0.07 & 0.19 & 0.09 \\
t-FM & $(2.03)$ & $(2.18)$ & $(1.38)$ & $(3.74)$ & $(1.87)$ & $(2.24)$ & $(5.66)$ & $(5.04)$ \\
t-GMM & $(1.62)$ & $(1.34)$ & $(0.86)$ & $(1.54)$ & $(1.32)$ & $(2.06)$ & $(4.30)$ & $(2.29)$ \\
BD & -0.02 & 0.04 & -0.07 & -0.06 & -0.10 & -0.01 & -0.00 & -0.02 \\
t-FM & $(-2.02)$ & $(2.46)$ & $(-2.93)$ & $(-2.35)$ & $(-4.54)$ & $(-0.30)$ & $(-0.13)$ & $(-1.51)$ \\
t-GMM & $(-1.51)$ & $(1.53)$ & $(-2.24)$ & $(-0.93)$ & $(-2.12)$ & $(-0.28)$ & $(-0.08)$ & $(-0.48)$ \\
Market & 0.01 & 0.05 & 0.02 & 0.01 & -0.01 & 0.03 & 0.09 & 0.02 \\
t-FM & $(0.57)$ & $(3.78)$ & $(0.89)$ & $(0.50)$ & $(-0.28)$ & $(1.36)$ & $(3.44)$ & $(1.97)$ \\
t-GMM & $(0.46)$ & $(2.01)$ & $(0.48)$ & $(0.19)$ & $(-0.17)$ & $(1.22)$ & $(2.12)$ & $(0.85)$ \\
Intercept & 0.01 & 0.00 & -0.00 & -0.00 & -0.00 & 0.01 & -0.01 & -0.00 \\
t-FM & $(0.73)$ & $(1.67)$ & $(-0.24)$ & $(-0.05)$ & $(-5.78)$ & $(1.24)$ & $(-1.47)$ & $(-0.18)$ \\
t-GMM & $(0.56)$ & $(1.19)$ & $(-0.12)$ & $(-0.02)$ & $(-3.25)$ & $(1.15)$ & $(-0.76)$ & $(-0.17)$ \\
$R^{2}$ & 0.51 & 0.89 & 0.90 & 0.99 & 0.86 & 0.45 & 0.54 & 0.50 \\
MAPE, \% & 0.35 & 0.09 & 0.29 & 0.12 & 0.15 & 1.84 & 0.44 & 0.88 \\
RRA & 3.71 & 2.42 & 2.58 & 7.07 & 2.86 & 3.60 & 9.82 & 4.81 \\
Assets & 25 & 20 & 6 & 18 & 20 & 24 & 12 & 125 \\
Quarters & 172 & 148 & 65 & 103 & 47 & 42 & 135 & 172 \\
\hline
\end{tabular}

Table 7: Market Equity is More Important for Pricing than Book Debt

Risk price estimates for the market equity growth (ME) and book debt growth (BD) of the aggregate intermediary sector, and the excess return on the market. Both growth (log change) measures rely only on firms that are in the sample in both periods. Risk prices are the mean slopes of period-by-period crosssectional regressions of portfolio excess returns on risk exposures (betas). Betas are estimated in a first-stage time-series regression. The quarterly sample is 1970Q1-2012Q4. Mean absolute pricing error (MAPE) is in percentage terms. Relative risk aversion (RRA) is the price of intermediary capital risk factor, scaled by its variance. Fama-MacBeth t-statistics (t-FM) adjust for cross-asset correlation in the residuals. The more robust GMM t-statistics (t-GMM) additionally correct for estimation error of the time-series betas. 


\begin{tabular}{ccccccccc}
\hline & FF25 & US bonds & Sov. bonds & Options & CDS & Commod. & FX & All Ptfs. \\
\hline AEM & 0.14 & 0.14 & 0.08 & -0.58 & -0.24 & 0.01 & -0.14 & 0.13 \\
t-FM & $(3.11)$ & $(3.33)$ & $(0.82)$ & $(-4.83)$ & $(-4.80)$ & $(0.15)$ & $(-2.38)$ & $(3.73)$ \\
t-GMM & $(2.54)$ & $(2.05)$ & $(0.75)$ & $(-1.52)$ & $(-2.25)$ & $(0.13)$ & $(-1.46)$ & $(0.66)$ \\
Market & 0.01 & 0.04 & 0.03 & 0.02 & 0.05 & 0.05 & 0.09 & 0.02 \\
t-FM & $(0.66)$ & $(3.67)$ & $(1.54)$ & $(0.94)$ & $(2.52)$ & $(2.08)$ & $(4.08)$ & $(2.15)$ \\
t-GMM & $(0.57)$ & $(1.77)$ & $(1.00)$ & $(0.22)$ & $(2.24)$ & $(1.90)$ & $(2.62)$ & $(1.05)$ \\
Intercept & 0.01 & 0.00 & 0.01 & -0.02 & -0.00 & -0.00 & -0.02 & -0.00 \\
t-FM & $(0.69)$ & $(1.28)$ & $(1.64)$ & $(-1.58)$ & $(-2.48)$ & $(-0.05)$ & $(-4.38)$ & $(-0.16)$ \\
t-GMM & $(0.56)$ & $(0.64)$ & $(1.65)$ & $(-0.29)$ & $(-1.15)$ & $(-0.04)$ & $(-2.22)$ & $(-0.07)$ \\
$R^{2}$ & 0.70 & 0.87 & 0.73 & 0.98 & 0.93 & 0.38 & 0.59 & 0.38 \\
MAPE, $\%$ & 0.27 & 0.12 & 0.45 & 0.16 & 0.11 & 1.93 & 0.36 & 0.94 \\
RRA & 5.88 & 6.14 & 3.39 & -25.05 & -10.24 & 0.55 & -5.91 & 5.52 \\
Assets & 25 & 20 & 6 & 18 & 20 & 24 & 12 & 125 \\
Quarters & 172 & 148 & 65 & 103 & 47 & 42 & 135 & 172 \\
\hline
\end{tabular}

Table 8: Cross-sectional Asset Pricing Tests by Asset Class: AEM Leverage Factor Risk price estimates for the Adrian et al. (2014a) leverage factor (AEM) and the excess return on the market. Risk prices are the mean slopes of period-by-period cross-sectional regressions of portfolio excess returns on risk exposures (betas). Betas are estimated in a first-stage time-series regression. The quarterly sample is 1970Q1-2012Q4. The AEM leverage factor, defined as the seasonally adjusted growth rate in broker-dealer book leverage level from Flow of Funds, is from its authors. Mean absolute pricing error (MAPE) is in percentage terms. Relative risk aversion (RRA) is the price of intermediary capital risk factor, scaled by its variance. Fama-MacBeth t-statistics (t-FM) adjust for cross-asset correlation in the residuals. The more robust GMM t-statistics (t-GMM) additionally correct for estimation error of the time-series betas. 


\begin{tabular}{lrrrrrrrr}
\hline & FF25 & US bonds & Sov. bonds & Options & CDS & Commod. & FX & All Ptfs. \\
\hline Mean $\left(\mu_{i}-r_{f}\right)$ & 0.02 & 0.01 & 0.02 & 0.01 & 0.00 & 0.02 & -0.01 & 0.01 \\
$\operatorname{Std}\left(\mu_{i}-r_{f}\right)$ & 0.01 & 0.00 & 0.01 & 0.01 & 0.01 & 0.03 & 0.01 & 0.02 \\
$\operatorname{Mean}\left(\beta_{i, A E M}\right)$ & 0.03 & 0.01 & -0.01 & -0.03 & 0.00 & 0.05 & -0.02 & 0.01 \\
$\operatorname{Std}\left(\beta_{i, A E M}\right)$ & 0.05 & 0.01 & 0.04 & 0.02 & 0.01 & 0.08 & 0.02 & 0.05 \\
$\operatorname{Mean}\left(\beta_{i, W}\right)$ & 1.09 & 0.09 & 0.34 & 0.83 & 0.11 & 0.47 & 0.06 & 0.48 \\
$\operatorname{Std}\left(\beta_{i, W}\right)$ & 0.20 & 0.10 & 0.22 & 0.17 & 0.07 & 0.39 & 0.05 & 0.45 \\
$\operatorname{Mean}\left(R^{2}\right)$ & 0.78 & 0.09 & 0.23 & 0.79 & 0.52 & 0.13 & 0.02 & 0.41 \\
Assets & 25 & 20 & 6 & 18 & 20 & 24 & 12 & 125 \\
Quarters & 172 & 148 & 65 & 103 & 47 & 42 & 135 & 172 \\
\hline
\end{tabular}

Table 9: Expected Returns and Risk Exposure by Asset Class: AEM Leverage Factor Average excess returns $\mu_{i}-r_{f}$, and risk exposures (betas) to the Adrian et al. (2014a) leverage factor (AEM) and to the excess return on the market $\left(\beta_{i, W}\right)$, across portfolios in each asset class. The quarterly sample is 1970Q1-2012Q4. The intermediary capital ratio is the ratio of total market equity to total market assets (book debt plus market equity) of primary dealer holding companies. Shocks to capital ratio are defined as $\mathrm{AR}(1)$ innovations in the capital ratio, scaled by the lagged capital ratio. The AEM leverage factor, defined as the seasonally adjusted growth rate in broker-dealer book leverage level from Flow of Funds, is from its authors. Betas are estimated in a first-stage time-series regression. 


\begin{tabular}{ccccccccc}
\hline & FF25 & US bonds & Sov. bonds & Options & CDS & Commod. & FX & All Ptfs. \\
\hline Capital & -0.02 & 0.08 & 0.11 & 0.13 & 0.06 & 0.07 & 0.14 & 0.09 \\
t-FM & $(-0.48)$ & $(3.14)$ & $(3.13)$ & $(3.03)$ & $(2.17)$ & $(2.30)$ & $(4.54)$ & $(5.59)$ \\
t-GMM & $(-0.32)$ & $(3.32)$ & $(2.95)$ & $(1.00)$ & $(2.59)$ & $(2.13)$ & $(2.92)$ & $(2.60)$ \\
Market & 0.01 & 0.02 & 0.00 & 0.02 & 0.02 & 0.03 & 0.07 & 0.02 \\
t-FM & $(0.40)$ & $(1.99)$ & $(0.15)$ & $(1.00)$ & $(1.27)$ & $(1.34)$ & $(2.91)$ & $(1.85)$ \\
t-GMM & $(0.29)$ & $(0.73)$ & $(0.07)$ & $(0.44)$ & $(1.01)$ & $(1.32)$ & $(1.90)$ & $(0.92)$ \\
AEM & 0.18 & 0.13 & -0.12 & -0.26 & -0.21 & 0.03 & -0.12 & 0.01 \\
t-FM & $(3.91)$ & $(3.19)$ & $(-1.17)$ & $(-2.46)$ & $(-4.39)$ & $(0.35)$ & $(-2.15)$ & $(0.36)$ \\
t-GMM & $(2.23)$ & $(1.88)$ & $(-0.56)$ & $(-0.85)$ & $(-3.24)$ & $(0.29)$ & $(-1.38)$ & $(0.09)$ \\
Intercept & 0.01 & 0.00 & -0.01 & -0.01 & -0.00 & 0.01 & -0.01 & -0.00 \\
t-FM & $(0.92)$ & $(1.36)$ & $(-0.94)$ & $(-0.88)$ & $(-2.99)$ & $(0.85)$ & $(-2.10)$ & $(-0.03)$ \\
t-GMM & $(0.64)$ & $(0.63)$ & $(-0.78)$ & $(-0.36)$ & $(-1.94)$ & $(0.73)$ & $(-1.02)$ & $(-0.02)$ \\
$R^{2}$ & 0.71 & 0.88 & 0.85 & 0.99 & 0.94 & 0.44 & 0.62 & 0.48 \\
MAPE, $\%$ & 0.27 & 0.11 & 0.29 & 0.10 & 0.09 & 1.83 & 0.38 & 0.87 \\
RRA & -0.94 & 4.74 & 6.49 & 7.71 & 3.53 & 4.24 & 8.76 & 5.76 \\
Assets & 25 & 20 & 6 & 18 & 20 & 24 & 12 & 125 \\
Quarters & 172 & 148 & 65 & 103 & 47 & 42 & 135 & 172 \\
\hline
\end{tabular}

Table 10: Horse-races with the AEM Leverage Factor

Risk price estimates for shocks to the intermediary capital ratio (Capital), the Adrian et al. (2014a) leverage factor (AEM), and the excess return on the market. Risk prices are the mean slopes of period-by-period cross-sectional regressions of portfolio excess returns on risk exposures (betas). Betas are estimated in a first-stage time-series regression. The quarterly sample is 1970Q1-2012Q4. The intermediary capital ratio is the ratio of total market equity to total market assets (book debt plus market equity) of primary dealer holding companies. Shocks to capital ratio are defined as AR(1) innovations in the capital ratio, scaled by the lagged capital ratio. The AEM leverage factor, defined as the seasonally adjusted growth rate in brokerdealer book leverage level from Flow of Funds, is from its authors. Mean absolute pricing error (MAPE) is in percentage terms. Relative risk aversion (RRA) is the price of intermediary capital risk factor, scaled by its variance. Fama-MacBeth t-statistics (t-FM) adjust for cross-asset correlation in the residuals. The more robust GMM t-statistics (t-GMM) additionally correct for estimation error of the time-series betas. 


\begin{tabular}{|c|c|c|c|c|c|c|c|c|}
\hline & \multicolumn{2}{|c|}{ FF25 } & \multicolumn{2}{|c|}{ US bonds } & \multicolumn{2}{|c|}{ Sov. bonds } & \multicolumn{2}{|c|}{ Options } \\
\hline & HKM & AEM & HKM & AEM & HKM & AEM & HKM & AEM \\
\hline Capital & 0.12 & 0.14 & 0.02 & 0.02 & -0.00 & -0.03 & 0.20 & -0.34 \\
\hline t-FM & $(2.66)$ & $(3.20)$ & $(0.42)$ & $(0.38)$ & $(-0.05)$ & $(-0.72)$ & $(6.43)$ & $(-6.46)$ \\
\hline t-GMM & $(1.84)$ & $(2.22)$ & $(0.33)$ & $(0.31)$ & $(-0.05)$ & $(-0.56)$ & $(2.04)$ & $(-3.10)$ \\
\hline Market & 0.03 & 0.01 & 0.05 & 0.04 & 0.07 & 0.05 & -0.00 & 0.05 \\
\hline t-FM & $(1.58)$ & $(0.94)$ & $(3.55)$ & $(3.08)$ & $(3.05)$ & $(2.28)$ & $(-0.06)$ & $(2.40)$ \\
\hline t-GMM & (1.14) & $(0.72)$ & $(2.56)$ & $(2.79)$ & $(2.54)$ & $(2.05)$ & $(-0.02)$ & $(1.04)$ \\
\hline Intercept & -0.01 & 0.00 & 0.00 & 0.00 & 0.02 & 0.01 & 0.01 & -0.04 \\
\hline t-FM & $(-0.82)$ & $(0.25)$ & $(2.50)$ & $(3.46)$ & $(2.47)$ & $(0.86)$ & $(0.67)$ & $(-2.39)$ \\
\hline t-GMM & $(-0.59)$ & $(0.18)$ & $(2.11)$ & $(3.56)$ & $(1.98)$ & $(0.80)$ & $(0.22)$ & $(-1.08)$ \\
\hline$R^{2}$ & 0.70 & 0.72 & 0.86 & 0.83 & 0.71 & 0.54 & 0.99 & 0.98 \\
\hline MAPE, $\%$ & 0.34 & 0.30 & 0.11 & 0.10 & 0.53 & 0.67 & 0.14 & 0.18 \\
\hline RRA & 8.96 & 9.04 & 1.14 & 1.28 & -0.12 & -1.93 & 14.42 & -21.50 \\
\hline Assets & 25 & 25 & 20 & 20 & 6 & 6 & 18 & 18 \\
\hline \multirow[t]{3}{*}{ Quarters } & 148 & 148 & 128 & 128 & 48 & 48 & 83 & 83 \\
\hline & \multicolumn{2}{|c|}{ CDS } & \multicolumn{2}{|c|}{ Commod. } & \multicolumn{2}{|c|}{ FX } & \multicolumn{2}{|c|}{ All Ptfs. } \\
\hline & HKM & AEM & HKM & AEM & HKM & AEM & HKM & AEM \\
\hline Capital & 0.08 & -0.16 & 0.03 & -0.01 & 0.16 & -0.03 & 0.09 & 0.11 \\
\hline t-FM & $(2.62)$ & $(-3.55)$ & $(0.97)$ & $(-0.27)$ & $(4.00)$ & $(-0.57)$ & $(4.93)$ & $(3.52)$ \\
\hline t-GMM & (1.88) & $(-2.50)$ & $(0.91)$ & $(-0.26)$ & $(2.82)$ & $(-0.34)$ & $(3.76)$ & $(2.40)$ \\
\hline Market & 0.07 & 0.06 & 0.02 & 0.03 & 0.10 & 0.11 & 0.02 & 0.02 \\
\hline t-FM & $(3.27)$ & $(2.31)$ & $(0.93)$ & $(1.06)$ & $(3.19)$ & $(5.02)$ & $(1.90)$ & $(2.10)$ \\
\hline t-GMM & $(3.23)$ & $(1.50)$ & $(0.81)$ & $(0.91)$ & (1.98) & $(2.94)$ & $(0.95)$ & $(1.03)$ \\
\hline Intercept & -0.00 & -0.00 & 0.04 & 0.04 & -0.01 & -0.01 & -0.00 & -0.00 \\
\hline t-FM & $(-2.22)$ & $(-1.77)$ & $(3.65)$ & $(3.05)$ & $(-1.08)$ & $(-3.57)$ & $(-0.19)$ & $(-0.35)$ \\
\hline t-GMM & $(-1.55)$ & $(-0.88)$ & $(3.77)$ & $(2.96)$ & $(-0.55)$ & $(-1.78)$ & $(-0.33)$ & $(-0.28)$ \\
\hline$R^{2}$ & 0.84 & 0.95 & 0.13 & 0.12 & 0.55 & 0.52 & 0.06 & 0.06 \\
\hline MAPE, \% & 0.12 & 0.08 & 2.90 & 2.87 & 0.38 & 0.41 & 1.60 & 1.46 \\
\hline $\mathrm{RRA}$ & 5.92 & -10.13 & 2.08 & -0.95 & 11.87 & -1.79 & 6.80 & 6.76 \\
\hline Assets & 20 & 20 & 24 & 24 & 12 & 12 & 125 & 125 \\
\hline Quarters & 23 & 23 & 19 & 19 & 123 & 123 & 148 & 148 \\
\hline
\end{tabular}

Table 11: Cross-sectional Asset Pricing Tests by Asset Class: Pre-crisis Sample

Risk price estimates for shocks to the intermediary capital ratio (HKM) or the Adrian et al. (2014a) leverage factor (AEM), and the excess return on the market. Here we focus on the pre-crisis quarterly sample 1970Q1-2006Q4. Risk prices are the mean slopes of period-by-period cross-sectional regressions of portfolio excess returns on risk exposures (betas). Betas are estimated in a first-stage time-series regression. The intermediary capital ratio is the ratio of total market equity to total market assets (book debt plus market equity) of primary dealer holding companies. Shocks to capital ratio are defined as AR(1) innovations in the capital ratio, scaled by the lagged capital ratio. The AEM leverage factor, defined as the seasonally adjusted growth rate in broker-dealer book leverage level from Flow of Funds, is from its authors. Mean absolute pricing error (MAPE) is in percentage terms. Relative risk aversion (RRA) is the price of intermediary capital risk factor, scaled by its variance. Fama-MacBeth t-statistics (t-FM) adjust for cross-asset correlation in the residuals. The more robust GMM t-statistics (t-GMM) additionally correct for estimation error of the time-series betas. 


\begin{tabular}{|c|c|c|c|c|c|c|c|c|}
\hline & \multicolumn{2}{|c|}{ FF25 } & \multicolumn{2}{|c|}{ US bonds } & \multicolumn{2}{|c|}{ Sov. bonds } & \multicolumn{2}{|c|}{ Options } \\
\hline & HKM & AEM & HKM & AEM & HKM & AEM & HKM & AEM \\
\hline Capital & 0.02 & 0.09 & 0.04 & 0.00 & 0.07 & 0.08 & 0.36 & -0.52 \\
\hline t-FM & $(0.70)$ & (1.39) & $(1.20)$ & $(0.06)$ & $(2.36)$ & $(0.82)$ & $(5.86)$ & $(-5.65)$ \\
\hline t-GMM & $(0.75)$ & $(1.34)$ & $(1.21)$ & $(0.05)$ & $(1.58)$ & $(0.75)$ & $(1.21)$ & $(-1.95)$ \\
\hline Market & -0.00 & 0.00 & 0.03 & 0.03 & 0.01 & 0.03 & -0.00 & 0.02 \\
\hline t-FM & $(-0.03)$ & $(0.11)$ & $(2.24)$ & $(2.28)$ & $(0.50)$ & $(1.54)$ & $(-0.11)$ & $(1.36)$ \\
\hline t-GMM & $(-0.03)$ & $(0.11)$ & $(2.01)$ & (2.07) & $(0.33)$ & $(1.00)$ & $(-0.03)$ & $(0.35)$ \\
\hline Intercept & 0.02 & 0.02 & 0.01 & 0.01 & 0.00 & 0.01 & 0.01 & -0.02 \\
\hline t-FM & $(1.33)$ & (1.34) & $(4.94)$ & $(4.77)$ & $(0.56)$ & (1.64) & $(0.94)$ & $(-1.78)$ \\
\hline t-GMM & $(1.40)$ & (1.37) & $(4.60)$ & $(4.42)$ & $(0.32)$ & $(1.65)$ & $(0.21)$ & $(-0.34)$ \\
\hline$R^{2}$ & 0.28 & 0.30 & 0.64 & 0.64 & 0.80 & 0.73 & 0.96 & 0.95 \\
\hline MAPE, $\%$ & 0.42 & 0.41 & 0.22 & 0.22 & 0.33 & 0.45 & 0.22 & 0.26 \\
\hline RRA & 1.30 & 2.95 & 2.30 & 0.11 & 4.22 & 2.65 & 21.06 & -17.40 \\
\hline Assets & 25 & 25 & 20 & 20 & 6 & 6 & 18 & 18 \\
\hline \multirow[t]{3}{*}{ Quarters } & 92 & 92 & 88 & 88 & 65 & 65 & 88 & 88 \\
\hline & \multicolumn{2}{|c|}{ CDS } & \multicolumn{2}{|c|}{ Commod. } & \multicolumn{2}{|c|}{$\mathrm{FX}$} & \multicolumn{2}{|c|}{ All Ptfs. } \\
\hline & HKM & AEM & HKM & AEM & HKM & AEM & HKM & AEM \\
\hline Capital & 0.10 & -0.24 & 0.07 & 0.01 & 0.07 & -0.14 & 0.06 & 0.08 \\
\hline t-FM & $(3.62)$ & $(-4.80)$ & $(2.26)$ & $(0.15)$ & $(2.35)$ & $(-2.90)$ & $(3.53)$ & $(1.50)$ \\
\hline t-GMM & $(3.75)$ & $(-2.25)$ & $(2.09)$ & $(0.13)$ & $(2.15)$ & $(-2.24)$ & $(1.96)$ & $(0.49)$ \\
\hline Market & 0.03 & 0.05 & 0.03 & 0.05 & 0.05 & 0.03 & 0.01 & 0.02 \\
\hline t-FM & $(1.51)$ & $(2.52)$ & (1.54) & (2.08) & (1.83) & $(1.35)$ & $(1.50)$ & $(1.96)$ \\
\hline t-GMM & $(1.20)$ & $(2.24)$ & (1.37) & $(1.90)$ & $(1.65)$ & (1.18) & $(0.85)$ & (1.11) \\
\hline Intercept & -0.00 & -0.00 & 0.01 & -0.00 & -0.01 & -0.01 & 0.00 & 0.00 \\
\hline t-FM & $(-5.62)$ & $(-2.48)$ & $(0.71)$ & $(-0.05)$ & $(-1.19)$ & $(-1.43)$ & $(1.55)$ & $(0.96)$ \\
\hline t-GMM & $(-3.14)$ & $(-1.15)$ & $(0.59)$ & $(-0.04)$ & $(-0.91)$ & $(-1.02)$ & $(0.69)$ & $(0.37)$ \\
\hline$R^{2}$ & 0.64 & 0.93 & 0.42 & 0.38 & 0.18 & 0.43 & 0.40 & 0.33 \\
\hline MAPE, \% & 0.19 & 0.11 & 1.86 & 1.93 & 0.48 & 0.39 & 0.94 & 1.00 \\
\hline RRA & 5.87 & -8.00 & 3.90 & 0.43 & 4.18 & -4.59 & 3.69 & 2.52 \\
\hline Assets & 20 & 20 & 24 & 24 & 12 & 12 & 125 & 125 \\
\hline Quarters & 47 & 47 & 42 & 42 & 80 & 80 & 92 & 92 \\
\hline
\end{tabular}

Table 12: Cross-sectional Asset Pricing Tests by Asset Class: Recent Sample

Risk price estimates for shocks to the intermediary capital ratio (HKM) or the Adrian et al. (2014a) leverage factor (AEM), and the excess return on the market. Here we focus on the more recent quarterly sample 1990Q1-2012Q4. Risk prices are the mean slopes of period-by-period cross-sectional regressions of portfolio excess returns on risk exposures (betas). Betas are estimated in a first-stage time-series regression. The intermediary capital ratio is the ratio of total market equity to total market assets (book debt plus market equity) of primary dealer holding companies. Shocks to capital ratio are defined as AR(1) innovations in the capital ratio, scaled by the lagged capital ratio. The AEM leverage factor, defined as the seasonally adjusted growth rate in broker-dealer book leverage level from Flow of Funds, is from its authors. Mean absolute pricing error (MAPE) is in percentage terms. Relative risk aversion (RRA) is the price of intermediary capital risk factor, scaled by its variance. Fama-MacBeth t-statistics (t-FM) adjust for cross-asset correlation in the residuals. The more robust GMM t-statistics (t-GMM) additionally correct for estimation error of the time-series betas. 


\begin{tabular}{ccccccccc}
\hline & FF25 & US bonds & Sov. bonds & Options & CDS & Commod. & FX & All Ptfs. \\
\hline Capital & 0.01 & 0.01 & 0.02 & 0.23 & 0.06 & 0.03 & 0.07 & 0.04 \\
t-FM & $(1.20)$ & $(0.77)$ & $(1.65)$ & $(5.09)$ & $(5.32)$ & $(2.36)$ & $(4.64)$ & $(6.34)$ \\
t-GMM & $(1.16)$ & $(0.71)$ & $(1.35)$ & $(0.80)$ & $(3.09)$ & $(2.25)$ & $(3.51)$ & $(3.32)$ \\
Market & 0.00 & 0.01 & 0.02 & 0.02 & -0.00 & 0.01 & 0.03 & 0.01 \\
t-FM & $(0.17)$ & $(1.90)$ & $(2.72)$ & $(3.70)$ & $(-0.23)$ & $(1.71)$ & $(2.57)$ & $(3.44)$ \\
t-GMM & $(0.17)$ & $(1.71)$ & $(2.16)$ & $(0.74)$ & $(-0.16)$ & $(1.62)$ & $(1.76)$ & $(1.55)$ \\
Intercept & 0.01 & 0.00 & 0.00 & -0.02 & -0.00 & 0.00 & -0.00 & -0.00 \\
t-FM & $(1.71)$ & $(4.73)$ & $(0.09)$ & $(-4.33)$ & $(-6.85)$ & $(0.54)$ & $(-2.21)$ & $(-2.16)$ \\
t-GMM & $(1.68)$ & $(4.39)$ & $(0.06)$ & $(-0.77)$ & $(-3.90)$ & $(0.47)$ & $(-1.30)$ & $(-1.28)$ \\
$R^{2}$ & 0.27 & 0.78 & 0.71 & 0.96 & 0.72 & 0.37 & 0.32 & 0.37 \\
MAPE, $\%$ & 0.16 & 0.05 & 0.17 & 0.07 & 0.07 & 0.60 & 0.16 & 0.34 \\
RRA & 2.89 & 2.72 & 3.76 & 47.49 & 11.54 & 5.59 & 14.34 & 8.21 \\
Assets & 25 & 20 & 6 & 18 & 20 & 24 & 12 & 125 \\
Quarters & 516 & 449 & 196 & 310 & 143 & 128 & 407 & 516 \\
\hline
\end{tabular}

Table 13: Cross-sectional Tests at the Monthly Frequency

Risk price estimates for shocks to the intermediary capital ratio and the excess return on the market. The monthly sample is January 1970 to December 2012. The monthly intermediary capital ratio here is the ratio of total market equity (measured monthly) to total market assets (book debt plus market equity) of primary dealer holding companies, where book debt is the latest quarterly observation. Shocks to capital ratio are defined as $\mathrm{AR}(1)$ innovations in the capital ratio, scaled by the lagged capital ratio. Risk prices are the mean slopes of period-by-period cross-sectional regressions of portfolio excess returns on risk exposures (betas). Betas are estimated in a first-stage time-series regression. The AEM leverage factor, defined as the seasonally adjusted growth rate in broker-dealer book leverage level from Flow of Funds, is from its authors. Mean absolute pricing error (MAPE) is in percentage terms. Relative risk aversion (RRA) is the price of intermediary capital risk factor, scaled by its variance. Fama-MacBeth t-statistics (t-FM) adjust for cross-asset correlation in the residuals. The more robust GMM t-statistics (t-GMM) additionally correct for estimation error of the time-series betas. 


\begin{tabular}{|c|c|c|c|c|c|c|c|c|}
\hline & \multicolumn{2}{|c|}{ FF25 } & \multicolumn{2}{|c|}{ US bonds } & \multicolumn{2}{|c|}{ Sov. bonds } & \multicolumn{2}{|c|}{ Options } \\
\hline & HKM & AEM & HKM & AEM & HKM & AEM & HKM & AEM \\
\hline Leverage & 0.12 & -2.12 & 0.09 & -1.63 & 0.15 & -0.33 & 0.09 & -2.92 \\
\hline t-Hodrick & $(3.19)$ & $(-1.73)$ & $(1.75)$ & $(-1.81)$ & $(4.41)$ & $(-0.15)$ & $(2.05)$ & $(-2.00)$ \\
\hline$R^{2}$ & 0.15 & 0.08 & 0.09 & 0.06 & 0.21 & 0.00 & 0.06 & 0.16 \\
\hline Assets & 25 & 25 & 20 & 20 & 6 & 6 & 18 & 18 \\
\hline \multirow[t]{3}{*}{ Quarters } & 168 & 168 & 145 & 145 & 62 & 62 & 100 & 100 \\
\hline & \multicolumn{2}{|c|}{ CDS } & \multicolumn{2}{|c|}{ Commod. } & \multicolumn{2}{|c|}{ FX } & \multicolumn{2}{|c|}{ All Ptfs. } \\
\hline & HKM & AEM & HKM & AEM & HKM & AEM & HKM & AEM \\
\hline Leverage & 0.14 & -1.30 & -0.01 & -1.97 & -0.10 & 0.65 & 0.09 & -1.93 \\
\hline t-Hodrick & $(3.20)$ & $(-0.49)$ & $(-0.46)$ & $(-1.98)$ & $(-2.15)$ & $(0.70)$ & $(2.89)$ & $(-2.03)$ \\
\hline$R^{2}$ & 0.21 & 0.04 & 0.01 & 0.26 & 0.10 & 0.01 & 0.13 & 0.10 \\
\hline Assets & 20 & 20 & 24 & 24 & 12 & 12 & 125 & 125 \\
\hline Quarters & 44 & 44 & 39 & 39 & 132 & 132 & 169 & 169 \\
\hline
\end{tabular}

Table 14: Predictive Regressions by Asset Class

One-year-ahead predictive regression results for each asset class. The quarterly sample is 1970Q1-2012Q4. We regress the mean return on all assets of an asset class on lagged intermediary leverage, which is either the squared inverse of the intermediary capital ratio (HKM), or the Adrian et al. (2014a) leverage ratio (AEM). Regression coefficients are multiplied by 100. Hodrick (1992) t-statistics are reported in parentheses. 


\begin{tabular}{|c|c|c|c|c|c|c|c|c|}
\hline & \multicolumn{2}{|c|}{ FF 25 } & \multicolumn{2}{|c|}{ US bonds } & \multicolumn{2}{|c|}{ Sov. bonds } & \multicolumn{2}{|c|}{ Options } \\
\hline & HKM & AEM & HKM & AEM & HKM & AEM & HKM & AEM \\
\hline Capital & 0.00 & 0.14 & 0.05 & 0.25 & 0.06 & 0.19 & 0.13 & -1.13 \\
\hline t-FM & $(0.02)$ & $(3.26)$ & $(3.16)$ & $(4.48)$ & $(2.37)$ & $(2.19)$ & $(5.03)$ & $(-5.44)$ \\
\hline t-GMM & $(0.02)$ & $(2.60)$ & $(3.05)$ & $(1.25)$ & $(1.83)$ & $(0.67)$ & $(3.12)$ & $(-0.37)$ \\
\hline Intercept & 0.02 & 0.00 & 0.00 & 0.00 & 0.00 & 0.02 & -0.05 & 0.03 \\
\hline t-FM & (1.63) & $(0.43)$ & $(2.11)$ & $(1.95)$ & $(0.73)$ & $(3.04)$ & $(-4.54)$ & $(2.93)$ \\
\hline t-GMM & $(1.63)$ & $(0.26)$ & $(1.78)$ & $(0.93)$ & $(0.51)$ & (1.08) & $(-2.75)$ & $(0.25)$ \\
\hline$R^{2}$ & 0.00 & 0.69 & 0.83 & 0.21 & 0.77 & 0.57 & 0.95 & 0.91 \\
\hline MAPE, $\%$ & 0.55 & 0.27 & 0.13 & 0.29 & 0.42 & 0.55 & 0.29 & 0.37 \\
\hline $\mathrm{RRA}$ & 0.04 & 6.06 & 3.10 & 10.93 & 3.63 & 8.20 & 8.17 & -48.30 \\
\hline Assets & 25 & 25 & 20 & 20 & 6 & 6 & 18 & 18 \\
\hline \multirow[t]{3}{*}{ Quarters } & 172 & 172 & 148 & 148 & 65 & 65 & 103 & 103 \\
\hline & \multicolumn{2}{|c|}{ CDS } & \multicolumn{2}{|c|}{ Commod. } & \multicolumn{2}{|c|}{ FX } & \multicolumn{2}{|c|}{ All Ptfs. } \\
\hline & HKM & AEM & HKM & AEM & HKM & AEM & HKM & $\mathrm{AEM}$ \\
\hline Capital & 0.08 & -0.26 & 0.07 & 0.11 & 0.19 & -0.26 & 0.04 & 0.16 \\
\hline t-FM & $(3.24)$ & $(-5.14)$ & $(2.28)$ & $(1.42)$ & $(4.55)$ & $(-3.59)$ & $(2.36)$ & $(3.82)$ \\
\hline t-GMM & $(3.25)$ & $(-2.84)$ & $(2.04)$ & $(0.89)$ & $(3.28)$ & $(-2.27)$ & (1.19) & $(0.55)$ \\
\hline Intercept & -0.00 & 0.00 & 0.01 & 0.01 & -0.01 & -0.02 & -0.00 & 0.00 \\
\hline t-FM & $(-5.72)$ & $(2.52)$ & $(0.53)$ & (1.18) & $(-2.70)$ & $(-3.87)$ & $(-0.06)$ & $(0.33)$ \\
\hline t-GMM & $(-3.71)$ & (1.06) & $(0.40)$ & $(0.93)$ & $(-1.15)$ & $(-1.62)$ & $(-0.05)$ & $(0.06)$ \\
\hline$R^{2}$ & 0.64 & 0.35 & 0.43 & 0.11 & 0.53 & 0.37 & 0.40 & 0.25 \\
\hline MAPE, $\%$ & 0.20 & 0.33 & 1.85 & 2.15 & 0.44 & 0.49 & 0.95 & 1.00 \\
\hline RRA & 5.20 & -11.26 & 4.18 & 4.66 & 11.83 & -11.27 & 2.28 & 7.05 \\
\hline Assets & 20 & 20 & 24 & 24 & 12 & 12 & 125 & 125 \\
\hline Quarters & 47 & 47 & 42 & 42 & 135 & 135 & 172 & 172 \\
\hline
\end{tabular}

\section{Table 15: Capital Ratio or AEM Leverage: Single Factor Models}

Risk price estimates for shocks to the intermediary capital ratio (HKM) or the Adrian et al. (2014a) leverage factor (AEM) alone. The quarterly sample is 1970Q1-2012Q4. The intermediary capital ratio is the ratio of total market equity to total market assets (book debt plus market equity) of primary dealer holding companies. Shocks to capital ratio are defined as $\mathrm{AR}(1)$ innovations in the capital ratio, scaled by the lagged capital ratio. The AEM leverage factor, defined as the seasonally adjusted growth rate in broker-dealer book leverage level from Flow of Funds, is from its authors. Mean absolute pricing error (MAPE) is in percentage terms. Relative risk aversion (RRA) is the price of intermediary capital risk factor, scaled by its variance. Fama-MacBeth t-statistics (t-FM) adjust for cross-asset correlation in the residuals. The more robust GMM t-statistics (t-GMM) additionally correct for estimation error of the time-series betas. 


\begin{tabular}{lcccccccc}
\hline & FF25 & US bonds & Sov. bonds & Options & CDS & Commod. & FX & All Ptfs. \\
\hline Capital & -0.00 & 0.05 & 0.06 & 0.14 & 0.09 & 0.07 & 0.19 & 0.04 \\
t-FM & $(-0.14)$ & $(3.17)$ & $(2.32)$ & $(5.01)$ & $(3.24)$ & $(2.22)$ & $(4.66)$ & $(2.32)$ \\
t-GMM & $(-0.14)$ & $(3.10)$ & $(1.77)$ & $(2.99)$ & $(2.91)$ & $(1.95)$ & $(3.44)$ & $(1.15)$ \\
Intercept & 0.02 & 0.00 & 0.00 & -0.05 & -0.00 & 0.00 & -0.01 & -0.00 \\
t-FM & $(1.80)$ & $(1.91)$ & $(0.69)$ & $(-4.64)$ & $(-5.74)$ & $(0.31)$ & $(-3.02)$ & $(-0.08)$ \\
t-GMM & $(1.79)$ & $(1.68)$ & $(0.48)$ & $(-2.67)$ & $(-3.73)$ & $(0.24)$ & $(-1.38)$ & $(-0.08)$ \\
$R^{2}$ & 0.00 & 0.84 & 0.72 & 0.94 & 0.63 & 0.42 & 0.58 & 0.39 \\
MAPE, $\%$ & 0.56 & 0.13 & 0.46 & 0.32 & 0.20 & 1.88 & 0.42 & 0.95 \\
RRA & -0.21 & 2.99 & 3.51 & 7.97 & 5.25 & 3.91 & 10.68 & 2.06 \\
Assets & 25 & 20 & 6 & 18 & 20 & 24 & 12 & 125 \\
Quarters & 172 & 148 & 65 & 103 & 47 & 42 & 135 & 172 \\
\hline
\end{tabular}

(a) Single Factor Model

\begin{tabular}{ccccccccc}
\hline & FF25 & US bonds & Sov. bonds & Options & CDS & Commod. & FX & All Ptfs. \\
\hline Capital & 0.06 & 0.07 & 0.07 & 0.29 & 0.13 & 0.07 & 0.19 & 0.09 \\
t-FM & $(1.89)$ & $(2.67)$ & $(2.17)$ & $(5.99)$ & $(4.10)$ & $(2.21)$ & $(4.77)$ & $(5.36)$ \\
t-GMM & $(1.89)$ & $(2.55)$ & $(1.52)$ & $(1.71)$ & $(3.00)$ & $(1.93)$ & $(3.40)$ & $(2.25)$ \\
Market & 0.01 & 0.02 & 0.02 & 0.03 & 0.02 & 0.03 & 0.09 & 0.02 \\
t-FM & $(0.91)$ & $(1.63)$ & $(0.96)$ & $(1.69)$ & $(0.92)$ & $(1.52)$ & $(2.99)$ & $(2.18)$ \\
t-GMM & $(0.89)$ & $(1.15)$ & $(0.60)$ & $(0.54)$ & $(0.56)$ & $(1.31)$ & $(1.81)$ & $(1.07)$ \\
Intercept & 0.00 & 0.00 & 0.00 & -0.01 & -0.00 & 0.01 & -0.01 & -0.00 \\
t-FM & $(0.24)$ & $(2.47)$ & $(0.37)$ & $(-0.84)$ & $(-5.77)$ & $(0.52)$ & $(-1.51)$ & $(-0.59)$ \\
t-GMM & $(0.24)$ & $(2.23)$ & $(0.22)$ & $(-0.24)$ & $(-2.60)$ & $(0.42)$ & $(-0.68)$ & $(-0.42)$ \\
$R^{2}$ & 0.45 & 0.85 & 0.74 & 0.99 & 0.68 & 0.42 & 0.59 & 0.49 \\
MAPE, $\%$ & 0.39 & 0.12 & 0.43 & 0.16 & 0.19 & 1.86 & 0.44 & 0.81 \\
RRA & 3.36 & 3.73 & 3.91 & 16.05 & 7.30 & 3.87 & 10.85 & 4.80 \\
Assets & 25 & 20 & 6 & 18 & 20 & 24 & 12 & 125 \\
Quarters & 172 & 148 & 65 & 103 & 47 & 42 & 135 & 172 \\
\hline
\end{tabular}

(b) Two Factor Model

Table 16: Intermediary Equity Return

The capital factor considered here is the value-weighted equity return of primary dealers. Panel (a) reports risk price estimates for primary dealers' equity return alone, while Panel (b) also includes the excess return on the market. The quarterly sample is 1970Q1-2012Q4. The intermediary capital ratio is the ratio of total market equity to total market assets (book debt plus market equity) of primary dealer holding companies. Shocks to capital ratio are defined as AR(1) innovations in the capital ratio, scaled by the lagged capital ratio. The AEM leverage factor, defined as the seasonally adjusted growth rate in broker-dealer book leverage level from Flow of Funds, is from its authors. Mean absolute pricing error (MAPE) is in percentage terms. Relative risk aversion (RRA) is the price of intermediary capital risk factor, scaled by its variance. Fama-MacBeth t-statistics (t-FM) adjust for cross-asset correlation in the residuals. The more robust GMM t-statistics (t-GMM) additionally correct for estimation error of the time-series betas. 


\begin{tabular}{|c|c|c|c|c|c|}
\hline Benchmark: & CAPM & FF3F & FF5F & Momentum & PS-liquidity \\
\hline Capital & 0.09 & 0.10 & 0.09 & 0.10 & 0.09 \\
\hline t-FM & $(5.53)$ & $(5.30)$ & $(4.96)$ & $(6.27)$ & $(5.83)$ \\
\hline t-GMM & $(2.56)$ & $(2.94)$ & $(2.89)$ & $(2.68)$ & $(2.72)$ \\
\hline Market & 0.02 & 0.02 & 0.01 & 0.02 & 0.02 \\
\hline t-FM & $(1.98)$ & $(2.51)$ & $(2.00)$ & $(2.19)$ & $(1.99)$ \\
\hline t-GMM & $(0.95)$ & $(0.93)$ & $(0.77)$ & $(1.00)$ & $(0.95)$ \\
\hline $\mathrm{SMB}$ & & 0.00 & 0.01 & & \\
\hline t-FM & & $(0.64)$ & $(1.28)$ & & \\
\hline t-GMM & & $(0.17)$ & $(0.54)$ & & \\
\hline HML & & 0.02 & 0.02 & & \\
\hline t-FM & & $(3.23)$ & $(3.11)$ & & \\
\hline t-GMM & & $(0.90)$ & $(1.04)$ & & \\
\hline CMA & & & 0.01 & & \\
\hline t-FM & & & $(3.07)$ & & \\
\hline t-GMM & & & (1.41) & & \\
\hline RMW & & & -0.01 & & \\
\hline t-FM & & & $(-1.42)$ & & \\
\hline t-GMM & & & $(-0.56)$ & & \\
\hline MOM & & & & 0.01 & \\
\hline t-FM & & & & $(0.59)$ & \\
\hline t-GMM & & & & $(0.15)$ & \\
\hline PS & & & & & -0.01 \\
\hline t-FM & & & & & $(-0.65)$ \\
\hline t-GMM & & & & & $(-0.18)$ \\
\hline$R^{2}$ & 0.45 & 0.50 & 0.55 & 0.46 & 0.62 \\
\hline MAPE, $\%$ & 0.85 & 0.84 & 0.85 & 0.91 & 0.84 \\
\hline RRA & 5.71 & 6.37 & 5.68 & 6.03 & 5.82 \\
\hline Assets & 125 & 125 & 125 & 125 & 125 \\
\hline Quarters & 172 & 172 & 172 & 172 & 172 \\
\hline$R^{2} \mathrm{w} / \mathrm{o}$ Capital & 0.33 & 0.40 & 0.48 & 0.34 & 0.42 \\
\hline MAPE w/o Capital & 1.02 & 1.05 & 1.17 & 1.02 & 1.04 \\
\hline
\end{tabular}

\section{Table 17: Comparison with Commonly-used Pricing Factors}

Risk price estimates for shocks to the intermediary capital ratio and the excess return on the market, controlling for commonly used benchmark pricing factors. All test portfolios are included in all columns. The capital ratio is defined as the ratio of total market equity to total market assets (book debt plus market equity) of primary dealer holding companies. Risk prices are the mean slopes of period-by-period crosssectional regressions of portfolio excess returns on risk exposures (betas). Betas are estimated in a first-stage time-series regression. The quarterly sample is 1970Q1-2012Q4. Mean absolute pricing error (MAPE) is in percentage terms. Relative risk aversion (RRA) is the price of intermediary capital risk factor, scaled by its variance. Fama-MacBeth t-statistics (t-FM) adjust for cross-asset correlation in the residuals. The more robust GMM t-statistics (t-GMM) additionally correct for estimation error of the time-series betas. The bottom two statistics are $R^{2}$ and MAPE for similar specifications but without the intermediary capital risk factor. 


\begin{tabular}{|c|c|c|c|c|c|c|c|c|}
\hline & \multicolumn{2}{|c|}{ FF25 } & \multicolumn{2}{|c|}{ US bonds } & \multicolumn{2}{|c|}{ Sov. bonds } & \multicolumn{2}{|c|}{ Options } \\
\hline & HKM & AEM & HKM & $\mathrm{AEM}$ & HKM & AEM & HKM & AEM \\
\hline Capital & 0.08 & 0.16 & 0.07 & 0.29 & 0.08 & -0.02 & 0.25 & -0.82 \\
\hline t-FM & $(4.38)$ & $(4.13)$ & $(2.90)$ & $(2.82)$ & $(3.41)$ & $(-0.23)$ & $(5.38)$ & $(-5.18)$ \\
\hline t-GMM & $(3.81)$ & $(3.38)$ & $(3.20)$ & $(0.92)$ & $(3.49)$ & $(-0.18)$ & (1.39) & $(-0.58)$ \\
\hline Market & 0.02 & 0.02 & 0.05 & 0.05 & 0.01 & 0.05 & 0.01 & -0.01 \\
\hline t-FM & $(2.18)$ & $(2.14)$ & $(2.50)$ & $(3.56)$ & $(0.55)$ & $(2.98)$ & (1.63) & $(-1.30)$ \\
\hline t-GMM & $(2.09)$ & $(2.09)$ & $(2.16)$ & $(1.96)$ & $(0.33)$ & $(2.47)$ & (1.11) & $(-0.26)$ \\
\hline$R^{2}$ & 0.53 & 0.70 & 0.84 & 0.87 & 0.81 & 0.73 & 0.99 & 0.98 \\
\hline MAPE, $\%$ & 0.34 & 0.27 & 0.25 & 0.15 & 0.34 & 0.51 & 0.16 & 0.20 \\
\hline RRA & 4.79 & 6.66 & 4.27 & 12.32 & 4.98 & -0.76 & 15.12 & -35.19 \\
\hline Assets & 25 & 25 & 20 & 20 & 6 & 6 & 18 & 18 \\
\hline \multirow[t]{3}{*}{ Quarters } & 172 & 172 & 148 & 148 & 65 & 65 & 103 & 103 \\
\hline & \multicolumn{2}{|c|}{ CDS } & \multicolumn{2}{|c|}{ Commod. } & \multicolumn{2}{|c|}{$\mathrm{FX}$} & \multicolumn{2}{|c|}{ All Ptfs. } \\
\hline & HKM & AEM & HKM & $\mathrm{AEM}$ & HKM & AEM & HKM & AEM \\
\hline Capital & 0.07 & -0.26 & 0.07 & 0.01 & 0.24 & 0.02 & 0.09 & 0.13 \\
\hline t-FM & $(2.61)$ & $(-5.29)$ & $(2.47)$ & $(0.13)$ & $(5.15)$ & $(0.43)$ & $(6.16)$ & $(3.87)$ \\
\hline t-GMM & $(2.58)$ & $(-2.54)$ & $(2.19)$ & $(0.11)$ & $(2.57)$ & $(0.37)$ & $(2.70)$ & $(0.65)$ \\
\hline Market & 0.00 & 0.04 & 0.04 & 0.05 & 0.07 & -0.06 & 0.02 & 0.02 \\
\hline t-FM & $(0.19)$ & $(2.11)$ & (1.98) & $(2.27)$ & $(2.59)$ & $(-1.83)$ & $(2.26)$ & $(2.45)$ \\
\hline t-GMM & $(0.15)$ & (1.86) & (1.46) & $(2.06)$ & (1.17) & $(-1.47)$ & $(0.90)$ & $(0.94)$ \\
\hline$R^{2}$ & 0.67 & 0.93 & 0.44 & 0.38 & 0.53 & 0.59 & 0.45 & 0.38 \\
\hline MAPE, \% & 0.26 & 0.12 & 1.92 & 1.92 & 0.50 & 0.99 & 0.85 & 0.94 \\
\hline RRA & 4.03 & -11.15 & 4.47 & 0.51 & 14.55 & 1.01 & 5.60 & 5.68 \\
\hline Assets & 20 & 20 & 24 & 24 & 12 & 12 & 125 & 125 \\
\hline Quarters & 47 & 47 & 42 & 42 & 135 & 135 & 172 & 172 \\
\hline
\end{tabular}

Table 18: Cross-sectional Tests without an Intercept

Risk price estimates for shocks to the intermediary capital ratio (HKM) or the Adrian et al. (2014a) leverage factor (AEM), and the excess return on the market, without an intercept in the cross-sectional regression. Risk prices are the mean slopes of period-by-period cross-sectional regressions of portfolio excess returns on risk exposures (betas). Betas are estimated in a first-stage time-series regression. The quarterly sample is 1970Q1-2012Q4. The intermediary capital ratio is the ratio of total market equity to total market assets (book debt plus market equity) of primary dealer holding companies. Shocks to capital ratio are defined as AR(1) innovations in the capital ratio, scaled by the lagged capital ratio. The AEM leverage factor, defined as the seasonally adjusted growth rate in broker-dealer book leverage level from Flow of Funds, is from its authors. Mean absolute pricing error (MAPE) is in percentage terms. Relative risk aversion (RRA) is the price of intermediary capital risk factor, scaled by its variance. Fama-MacBeth t-statistics (t-FM) adjust for cross-asset correlation in the residuals. The more robust GMM t-statistics (t-GMM) additionally correct for estimation error of the time-series betas. 


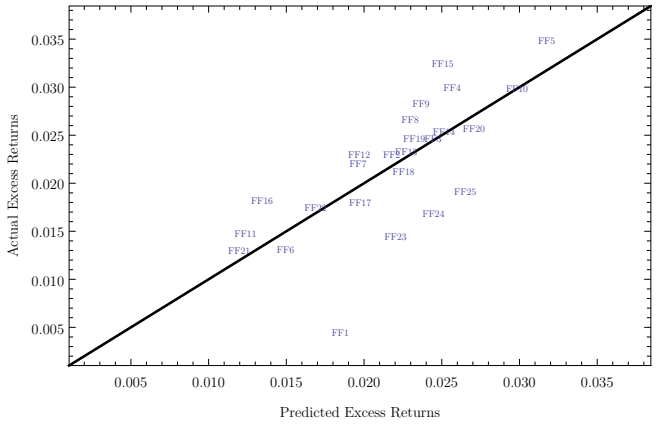

(a) FF25

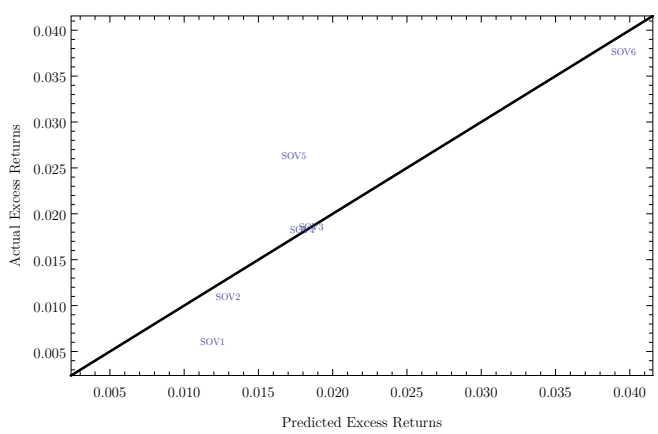

(c) Sovereign bonds

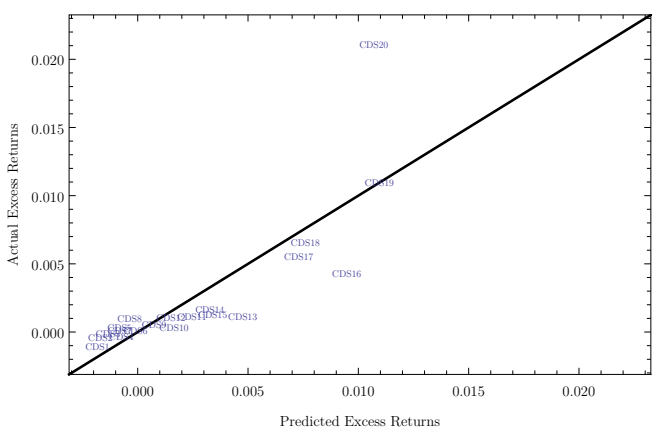

(e) CDS

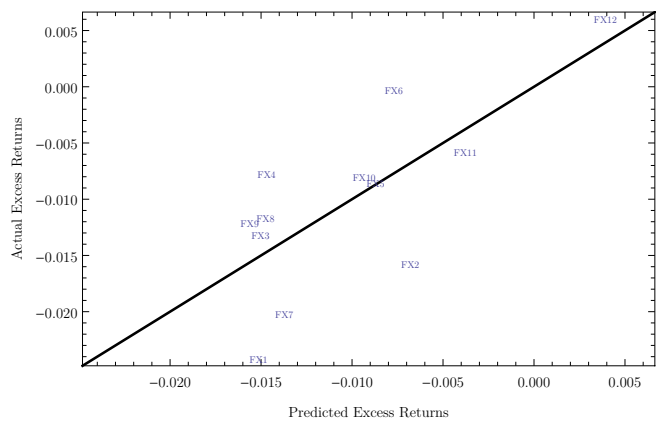

(g) FX

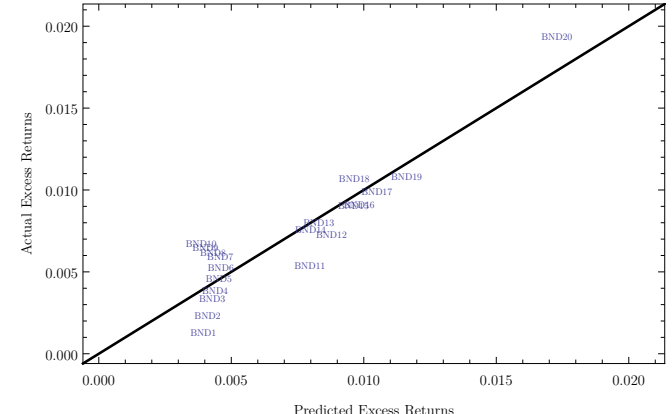

(b) US Bonds

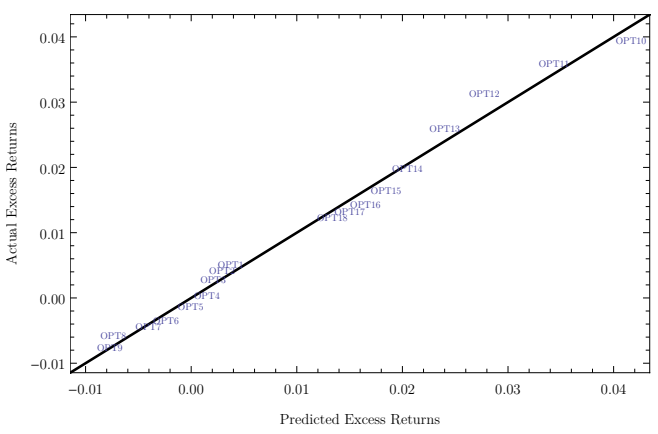

(d) Options

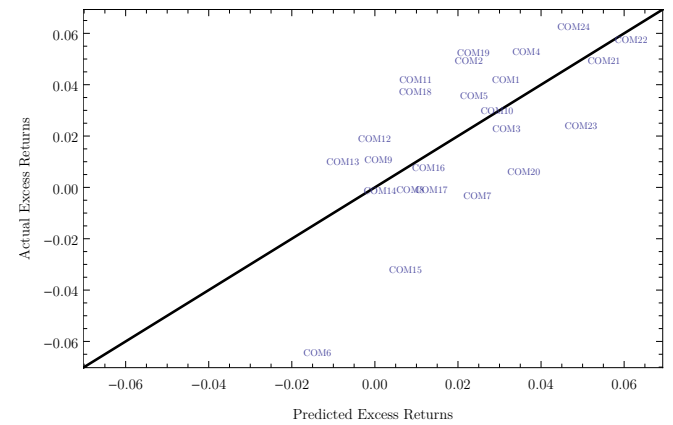

(f) Commodities

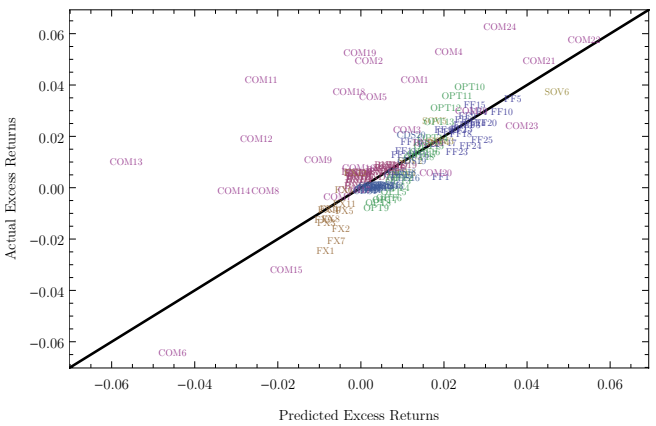

(h) All Portfolios

Figure A.1: Pricing Errors

Actual average excess returns on tested portfolios versus predicted expected returns using their risk exposures (betas) with respect to shocks to the intermediary capital ratio and the excess return on the market. Test portfolios are abbreviated based on their asset class: equities (FF), US bonds (BND), foreign sovereign bonds (SOV), options (OPT), CDS, commodities (COM), and foreign exchange (FX). 


\begin{tabular}{|c|c|c|c|c|c|}
\hline Primary Dealer & Start Date & End Date & Primary Dealer & Start Date & End Date \\
\hline ABN Amro & $9 / 29 / 1998$ & $9 / 15 / 2006$ & HSBC & $5 / 9 / 1994$ & Current \\
\hline Aubrey Lanston & $5 / 19 / 1960$ & $4 / 17 / 2000$ & Hutton & $11 / 2 / 1977$ & $12 / 31 / 1987$ \\
\hline BA Securities & $4 / 18 / 1994$ & $9 / 30 / 1997$ & Irving & $5 / 19 / 1960$ & $7 / 31 / 1989$ \\
\hline Banc One & 4/1/1999 & $8 / 1 / 2004$ & Jefferies & $6 / 18 / 2009$ & Current \\
\hline Bank of America & $5 / 17 / 1999$ & $11 / 1 / 2010$ & JP Morgan & $5 / 19 / 1960$ & Current \\
\hline Bank of America & $11 / 17 / 1971$ & $4 / 15 / 1994$ & Kidder Peabody & $2 / 7 / 1979$ & $12 / 30 / 1994$ \\
\hline Bank of Nova Scotia & $10 / 4 / 2011$ & Current & Kleinwort Benson & $2 / 13 / 1980$ & $12 / 27 / 1989$ \\
\hline Bankers Trust & $5 / 19 / 1960$ & $10 / 22 / 1997$ & Lehman & $11 / 25 / 1976$ & $9 / 22 / 2008$ \\
\hline Barclays & $4 / 1 / 1998$ & Current & Lehman & $2 / 22 / 1973$ & $1 / 29 / 1974$ \\
\hline Barclays De Zoete Wedd & $12 / 7 / 1989$ & $6 / 30 / 1996$ & LF Rothschild & $12 / 11 / 1986$ & $1 / 17 / 1989$ \\
\hline Bartow Leeds & $5 / 19 / 1960$ & $6 / 14 / 1962$ & Lloyds & $12 / 22 / 1987$ & $4 / 28 / 1989$ \\
\hline Bear Stearns & $6 / 10 / 1981$ & $10 / 1 / 2008$ & Malon Andrus & $5 / 19 / 1960$ & $11 / 24 / 1965$ \\
\hline Becker & $11 / 17 / 1971$ & $9 / 10 / 1984$ & Manufac. Hanover & $8 / 31 / 1983$ & $12 / 31 / 1991$ \\
\hline Blyth & $4 / 16 / 1962$ & $1 / 14 / 1970$ & Merrill Lynch & $5 / 19 / 1960$ & $2 / 11 / 2009$ \\
\hline Blyth Eastman Dillon & $12 / 5 / 1974$ & $12 / 31 / 1979$ & Merrill Lynch & $11 / 1 / 2010$ & Current \\
\hline $\mathrm{BMO}$ & $10 / 4 / 2011$ & Current & MF Global & $2 / 2 / 2011$ & $10 / 31 / 2011$ \\
\hline BMO Nesbitt & $2 / 15 / 2000$ & $3 / 31 / 2002$ & Midland-Montagu & $8 / 13 / 1975$ & $7 / 26 / 1990$ \\
\hline BNP Paribas & $9 / 15 / 2000$ & Current & Mizuho & $4 / 1 / 2002$ & Current \\
\hline $\mathrm{BNY}$ & $8 / 1 / 1989$ & $8 / 9 / 1990$ & Morgan Stanley & $2 / 1 / 1978$ & Current \\
\hline Brophy, Gestal, Knight & $5 / 8 / 1987$ & $6 / 19 / 1988$ & NationsBanc & $7 / 6 / 1993$ & $5 / 16 / 1999$ \\
\hline BT Alex Brown & $10 / 23 / 1997$ & $6 / 4 / 1999$ & Nesbitt Burns & $6 / 1 / 1995$ & $2 / 14 / 2000$ \\
\hline BZW & $7 / 1 / 1996$ & $3 / 31 / 1998$ & Nikko & $12 / 22 / 1987$ & 1/3/1999 \\
\hline Cantor Fitzgerald & $8 / 1 / 2006$ & Current & Nomura & $12 / 11 / 1986$ & $11 / 30 / 2007$ \\
\hline Carroll McEntee & $9 / 29 / 1976$ & $5 / 6 / 1994$ & Nomura & $7 / 27 / 2009$ & Current \\
\hline CF Childs & $5 / 19 / 1960$ & $6 / 29 / 1965$ & Northern Trust & $8 / 8 / 1973$ & $5 / 29 / 1986$ \\
\hline Chase & $7 / 15 / 1970$ & $4 / 30 / 2001$ & Nuveen & $11 / 18 / 1971$ & $8 / 27 / 1980$ \\
\hline Chemical & $5 / 19 / 1960$ & $3 / 31 / 1996$ & NY Hanseatic & $2 / 8 / 1984$ & $7 / 26 / 1984$ \\
\hline CIBC & $3 / 27 / 1996$ & $2 / 8 / 2007$ & Paine Webber & $11 / 25 / 1976$ & $12 / 4 / 2000$ \\
\hline Citigroup & $6 / 15 / 1961$ & Current & Paine Webber & $6 / 22 / 1972$ & $6 / 27 / 1973$ \\
\hline Continental & $5 / 19 / 1960$ & $8 / 30 / 1991$ & Paribas & $5 / 1 / 1997$ & $9 / 14 / 2000$ \\
\hline Country Natwest & $9 / 29 / 1988$ & $1 / 13 / 1989$ & Pollock & $5 / 19 / 1960$ & $2 / 3 / 1987$ \\
\hline Countrywide & $1 / 15 / 2004$ & $7 / 15 / 2008$ & Prudential & $10 / 29 / 1975$ & $12 / 1 / 2000$ \\
\hline Credit Suisse & $10 / 12 / 1993$ & Current & $\mathrm{RBC}$ & $7 / 8 / 2009$ & Current \\
\hline CRT & $12 / 22 / 1987$ & $7 / 5 / 1993$ & RBS & $4 / 1 / 2009$ & Current \\
\hline Daiwa & $12 / 11 / 1986$ & Current & REFCO & $11 / 19 / 1980$ & $5 / 7 / 1987$ \\
\hline Dean Witter Reynolds & $11 / 2 / 1977$ & $4 / 30 / 1998$ & Robertson Stephens & $10 / 1 / 1997$ & $9 / 30 / 1998$ \\
\hline Deutshe Bank & $12 / 13 / 1990$ & Current & Salomon Smith Barney & $5 / 19 / 1960$ & $4 / 6 / 2003$ \\
\hline Dillon Read & $6 / 24 / 1988$ & 9/2/1997 & Sanwa & $6 / 20 / 1988$ & $7 / 20 / 1998$ \\
\hline Discount Corp. & $5 / 19 / 1960$ & $8 / 10 / 1993$ & SBC & $3 / 29 / 1990$ & $6 / 28 / 1998$ \\
\hline DLJ & $3 / 6 / 1974$ & $1 / 16 / 1985$ & Second District & $6 / 15 / 1961$ & $8 / 27 / 1980$ \\
\hline DLJ & $10 / 25 / 1995$ & $12 / 31 / 2000$ & Securities Groups & $5 / 19 / 1960$ & $6 / 5 / 1983$ \\
\hline Dresdner Kleinwort & $5 / 8 / 1997$ & 6/26/2009 & Security Pacific & $12 / 11 / 1986$ & $1 / 17 / 1991$ \\
\hline Drexel Burnham & $5 / 19 / 1960$ & $3 / 28 / 1990$ & SG Americas & $2 / 2 / 2011$ & Current \\
\hline DW Rich & $5 / 19 / 1960$ & $12 / 31 / 1969$ & SG Cowen & 7/1/1999 & $10 / 31 / 2001$ \\
\hline Eastbridge & $6 / 18 / 1992$ & $5 / 29 / 1998$ & SG Warburg & $6 / 24 / 1988$ & $7 / 26 / 1995$ \\
\hline FI Dupont & $12 / 12 / 1968$ & $7 / 18 / 1973$ & Smith Barney & $8 / 22 / 1979$ & $8 / 31 / 1998$ \\
\hline First Boston & $5 / 19 / 1960$ & $10 / 11 / 1993$ & Souther Cal. S\&L & $6 / 7 / 1983$ & $8 / 5 / 1983$ \\
\hline First Chicago & $5 / 19 / 1960$ & 3/31/1999 & $\mathrm{TD}$ & $2 / 11 / 2014$ & Current \\
\hline First Interstate & $7 / 31 / 1964$ & $6 / 17 / 1988$ & Thomson McKinnon & $12 / 11 / 1986$ & $7 / 7 / 1989$ \\
\hline First N.B. of Boston & $3 / 21 / 1983$ & $11 / 17 / 1985$ & UBS & $12 / 7 / 1989$ & Current \\
\hline First Pennco & $3 / 7 / 1974$ & $8 / 27 / 1980$ & Weeden & $6 / 17 / 1976$ & $5 / 15 / 1978$ \\
\hline Fuji & $12 / 28 / 1989$ & $3 / 31 / 2002$ & Wertheim Schroder & $6 / 24 / 1988$ & $11 / 8 / 1990$ \\
\hline Goldman Sachs & $12 / 4 / 1974$ & Current & Westpac Pollock & $2 / 4 / 1987$ & $6 / 27 / 1990$ \\
\hline Greenwich & $7 / 31 / 1984$ & $4 / 1 / 2009$ & White Weld & $2 / 26 / 1976$ & $4 / 18 / 1978$ \\
\hline \multirow[t]{2}{*}{ Harris } & $7 / 15 / 1965$ & $5 / 31 / 1995$ & Yamaichi & $9 / 29 / 1988$ & $12 / 4 / 1997$ \\
\hline & & & Zions & $8 / 11 / 1993$ & $3 / 31 / 2002$ \\
\hline
\end{tabular}

\section{Table A.1: Primary Dealers, 1960-2014}

The New York Federal Reserve Bank's list of primary dealers. We have condensed the list slightly by combining entries that differ due to name changes but maintain continuity in primary dealer role, most commonly due to the dealer acquiring another firm. However, we continue to list acquisition targets or merged entities separately for the period that they appear on the dealer list prior to acquisition. 


\begin{tabular}{ccccccccc}
\hline & FF25 & US bonds & Sov. bonds & Options & CDS & Commod. & FX & All Ptfs. \\
\hline Capital & 0.02 & -0.02 & 0.07 & 0.10 & 0.08 & 0.03 & -0.09 & 0.03 \\
t-FM & $(1.58)$ & $(-0.43)$ & $(2.23)$ & $(4.94)$ & $(4.07)$ & $(1.88)$ & $(-3.99)$ & $(2.31)$ \\
t-GMM & $(1.53)$ & $(-0.33)$ & $(2.07)$ & $(2.18)$ & $(2.59)$ & $(1.75)$ & $(-1.06)$ & $(1.37)$ \\
Market & -0.02 & 0.05 & -0.01 & 0.02 & 0.01 & 0.04 & 0.13 & 0.02 \\
t-FM & $(-1.45)$ & $(1.44)$ & $(-0.37)$ & $(1.36)$ & $(0.28)$ & $(1.69)$ & $(4.68)$ & $(2.16)$ \\
t-GMM & $(-1.33)$ & $(1.19)$ & $(-0.34)$ & $(0.91)$ & $(0.19)$ & $(1.41)$ & $(2.08)$ & $(1.04)$ \\
Intercept & 0.04 & 0.00 & 0.01 & -0.00 & -0.00 & 0.01 & -0.03 & 0.00 \\
t-FM & $(3.72)$ & $(5.27)$ & $(2.50)$ & $(-0.34)$ & $(-5.76)$ & $(0.50)$ & $(-6.83)$ & $(0.44)$ \\
t-GMM & $(3.39)$ & $(4.36)$ & $(2.15)$ & $(-0.21)$ & $(-3.46)$ & $(0.37)$ & $(-1.90)$ & $(0.27)$ \\
$R^{2}$ & 0.10 & 0.82 & 0.95 & 0.97 & 0.69 & 0.48 & 0.72 & 0.43 \\
MAPE, $\%$ & 0.52 & 0.13 & 0.17 & 0.18 & 0.18 & 1.78 & 0.37 & 0.94 \\
RRA & 10.33 & -7.53 & 32.08 & 49.49 & 37.44 & 15.36 & -44.78 & 12.53 \\
Assets & 25 & 20 & 6 & 18 & 20 & 24 & 12 & 125 \\
Quarters & 172 & 148 & 65 & 103 & 47 & 42 & 135 & 172 \\
\hline
\end{tabular}

Table A.2: Book Equity instead of Market Equity

Risk price estimates for shocks to the intermediary capital ratio and the excess return on the market. Here, the capital ratio is defined as the ratio of total book equity to total book assets of primary dealer holding companies. Risk prices are the mean slopes of period-by-period cross-sectional regressions of portfolio excess returns on risk exposures (betas). Betas are estimated in a first-stage time-series regression. The quarterly sample is 1970Q1-2012Q4. Mean absolute pricing error (MAPE) is in percentage terms. Relative risk aversion (RRA) is the price of intermediary capital risk factor, scaled by its variance. Fama-MacBeth t-statistics (t-FM) adjust for cross-asset correlation in the residuals. The more robust GMM t-statistics (t-GMM) additionally correct for estimation error of the time-series betas. 